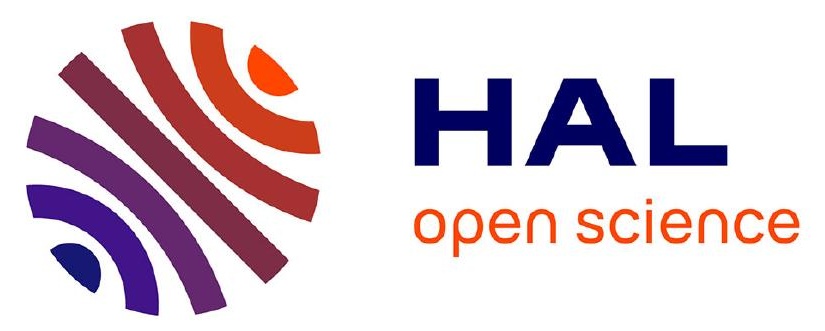

\title{
Hypomethylated poplars show higher tolerance to water deficit and highlight a dual role for DNA methylation in shoot meristem: regulation of stress response and genome integrity
}

\author{
M.D. D Sow, A-L Le Gac, R. Fichot, S. Lanciano, A. Delaunay, I. Le Jan,
} M-C Lesage-Descauses, S. Citerne, J. Caius, V. Brunaud, et al.

\section{To cite this version:}

M.D. D Sow, A-L Le Gac, R. Fichot, S. Lanciano, A. Delaunay, et al.. Hypomethylated poplars show higher tolerance to water deficit and highlight a dual role for DNA methylation in shoot meristem: regulation of stress response and genome integrity. 2021. hal-03239719

\author{
HAL Id: hal-03239719 \\ https://hal.science/hal-03239719 \\ Preprint submitted on 27 May 2021
}

HAL is a multi-disciplinary open access archive for the deposit and dissemination of scientific research documents, whether they are published or not. The documents may come from teaching and research institutions in France or abroad, or from public or private research centers.
L'archive ouverte pluridisciplinaire HAL, est destinée au dépôt et à la diffusion de documents scientifiques de niveau recherche, publiés ou non, émanant des établissements d'enseignement et de recherche français ou étrangers, des laboratoires publics ou privés. 
1

2 Hypomethylated poplars show higher tolerance to water deficit and highlight 3 a dual role for DNA methylation in shoot meristem: regulation of stress 4 response and genome integrity

Title:
6

7

(n)

Short title:

DDM1-dependant DNA methylation in meristem

M.D. Sow ${ }^{\star 1}$, A-L. Le Gac ${ }^{\star 1}$, R. Fichot ${ }^{1}$, S. Lanciano ${ }^{2,3}$, A. Delaunay ${ }^{1}$, I. Le Jan ${ }^{1}$, M-C. LesageDescauses $^{4}$, S. Citerne ${ }^{5}$, J. Caius ${ }^{6}$, V. Brunaud ${ }^{6}$, L. Soubigou-Taconnat ${ }^{6}$, H. Cochard ${ }^{7}$, V. Segura $^{4 \dagger}$, C. Chaparro ${ }^{8}$, C. Grunau ${ }^{8}$, C. Daviaud ${ }^{9}$, J. Tost $^{9}$, F. Brignolas ${ }^{1}$, S.H. Strauss ${ }^{10}$, M. Mirouze $^{2,3}$ and S. Maury $\$ 1$

${ }^{1}$ LBLGC, INRAE, Université d'Orléans, EA 1207 USC 1328, 45067 Orléans, France. ${ }^{2}$ IRD, UMR 232 DIADE, University of Montpellier, France. ${ }^{3}$ Université de Perpignan, Laboratory of Plant Genome and Development, France. ${ }^{4}$ BioForA, INRAE, ONF, UMR 0588, 45075 Orléans, France. ${ }^{5}$ Institut Jean-Pierre Bourgin, INRAE, AgroParisTech, Université Paris-Saclay, 78000, Versailles, France. ${ }^{6}$ Université ParisSaclay, CNRS, INRAE, Université Evry, Institute of Plant Sciences Paris-Saclay (IPS2), 91405, Orsay, France. Université de Paris, CNRS, INRAE, Institute of Plant Sciences Paris-Saclay (IPS2), 91405, Orsay, France. ${ }^{7}$ Université Clermont Auvergne, INRAE, PIAF, 63000 Clermont-Ferrand, France. ${ }^{8}$ IHPE, Université de Perpignan, UMR 5244, 66100, Perpignan, France. ${ }^{9}$ Laboratoire Epigénétique et Environnement, LEE, CNRGH CEA, Evry, France. ${ }^{10}$ Department of Forest Ecosystems and Society, Oregon State University, Corvallis, OR 97331-5752, USA. ${ }^{¥}$ Present address: Institute for Biology III, University of Freiburg, 79104 Freiburg, Germany. ${ }^{\dagger}$ Present address: AGAP, Université Montpellier, CIRAD, INRA, Montpellier SupAgro, UMR 1334, 34060 Montpellier, France.

*: First co-authors with equal contribution.

\$: Corresponding author, stephane.maury@univ-orleans.fr

The author responsible for distribution of materials integral to the findings presented in this article in accordance with the policy described in the Instructions for Authors (www.plantcell.org) is: Stéphane Maury (stephane.maury@univ-orleans.fr). 


\section{Abstract}

As fixed and long living organisms subjected to repeated environmental stresses, trees have developed mechanisms such as phenotypic plasticity that help them to cope with fluctuating environmental conditions. Here, we tested the role DNA methylation as a hub of integration, linking plasticity and physiological response to water deficit in the shoot apical meristem of the model tree poplar (Populus). Using a reverse genetic approach, we compared hypomethylated RNAi-ddm1 lines to wild-type trees for drought tolerance. An integrative analysis was realized with phytohormone balance, methylomes, transcriptomes and mobilomes.

Hypomethylated lines were more tolerant when subjected to moderate water deficit and were intrinsically more tolerant to drought-induced cavitation. The alteration of the DDM1 machinery induced variation in DNA methylation in a cytosine context dependent manner, both in genes and transposable elements. Hypomethylated lines subjected to water deficit showed altered expression of genes involved in phytohormone pathways, such as salicylic acid and modified hormonal balance. Several transposable elements showed stress- and/or line-specific patterns of reactivation, and we could detect copy number variations for two of them in stressed $d d m 1$ lines.

Overall, our data highlight two major roles for DNA methylation in the shoot apical meristem: control of stress response and plasticity through transduction of hormone signaling and maintenance of genome integrity through the control of transposable elements.

5 Keywords: Epigenetics; meristem; drought; transposable element; DNA methylation; 56 phytohormone 


\section{INTRODUCTION}

As long living organisms, trees are subjected to repeated environmental challenges over their lifetime. In recent decades, forest stresses have grown; forest decline has been reported around the world due to heat and drought stress episodes (Allen et al., 2010; Anderegg et al., 2016). In order to survive, they can adjust rapidly using epigenetic as well as physiological levels of regulation (Nicotra et al., 2015). Epigenetics is defined as the study of heritable changes that affect gene expression without changing the DNA sequence (Russo et al., 1996). Efforts have been made, primarily in annuals, to unravel the role of epigenetic mechanisms (in particular DNA methylation) in plant developmental processes, stress response, plasticity, and adaptation (Slotkin and Martienssen, 2007; Colomé-Tatché et al., 2012; Cortijo et al., 2014; Kooke et al., 2015; Raju et al., 2018; Schmid et al., 2018).

Although epigenetic processes are commonly regarded as a source of flexibility in perennials like trees (Bräutigam et al., 2013; Zhu et al., 2013; Yakovlev et al., 2012, 2016; Carneros et al., 2017; Plomion et al., 2016; Lafon-Placette et al., 2018; Sow et al., $2018 \mathrm{~b}$ ), the functional role of DNA methylation in forest trees under environmental changes is still unclear. As a model tree with important genomic resources (Tuskan et al., 2006; Jansson and Douglas, 2007), poplar (Populus spp.) has been a prime system for the study of the ecophysiological and molecular basis of drought response (Monclus et al., 2006; Street et al., 2006; Bogeat Triboulot et al., 2007; Cohen et al., 2010; Hamanishi et al., 2012; Fichot et al., 2015). For example, differences in global DNA methylation levels among poplar hybrid genotypes have been shown to correlate with biomass production under water deficit (Gourcilleau et al., 2010; Raj et al., 2011; Le Gac et al., 2019). Recently, DNA methylation-based models have been proposed as a strategy to validate the identity, provenance or quality of agro-forestry products (Champigny et al., 2019). Lafon-Placette et al. (2018) established that drought preferentially induced changes in the DNA methylation of phytohormone-related genes, apparently elevating phenotypic plasticity (Lafon-Placette et al., 2018). This has raised the question of a possible link between epigenetics and phytohormone signaling / synthesis in order to explain plasticity in plants, in particular in meristematic tissues where development takes place (Maury et al., 2019). Phytohormones are key regulatory 
90

91

92

93

94

95

elements in plant development and stress response, and their action is often fast and transient. Epigenetic regulations could play a role by modifying the expression of genes in the phytohormone pathways, notably by maintaining them after a hormonal peak, or priming their expression through time to remember the stress episode (i.e., epigenetic memory). In line with this, it has been shown that winter-dormant shoot apical meristems of poplar genotypes grown in field conditions can keep an epigenetic memory of a summer drought episode experienced during the growing season through modifications in DNA methylation (Le Gac et al., 2018; Sow et al., 2018a). The role of epigenetic memory in trees besides poplar, in response to biotic and abiotic stresses, is becoming increasingly documented (Yakovlev et al., 2014; Carneros et al., 2017; Gömöry et al., 2017; Yakovlev and Fosdal, 2017).

In plants, DNA methylation occurs in three different contexts $(\mathrm{CHH}, \mathrm{CHG}$ and $\mathrm{CpG}$, with $\mathrm{H}=\mathrm{A}, \mathrm{C}$ or $\mathrm{T}$ ), and the methylation or demethylation of cytosines (de novo or maintenance during replication) is ensured by different DNA methyltransferases or DNA glycosylases/lyases, respectively (Zemach et al., 2010; Zhang et al., 2018). DNA methylation affects gene expression (Niederhuth and Schmitz, 2017; Bewick and Schmitz, 2017). While methylation in promoters is usually associated with gene silencing, gene-body methylation is more complex, and is often linked to tissue-specific expression or alternative splicing (Vining et al., 2012; Lafon-Placette et al., 2013; Maor et al., 2015; Zhu et al., 2016; Zhu et al., 2018).

So far, most of the studies conducted on trees and focusing on DNA methylation and gene expression have used a correlative approach. In poplar, extensive gene-body methylation is found in the open chromatin state, and is linked to structural gene characteristics, and correlated with tissue-specific gene expression or stress (Vining et al., 2012; Bräutigam et al., 2013; Lafon-Placette et al., 2013; Liang et al., 2014; LafonPlacette et al., 2018). In addition to controlling gene expression, it is clear that methylation also helps to maintain genome integrity by silencing the relics of viral genomes (i.e., transposable elements, TEs), stopping them from spreading within the host genome (Ikeda and Nishimura, 2015; Fultz et al., 2015). For a long time considered as 'junk DNA,' the evolutionary impact of TEs is now well established, and TEs 
120

121

122

123

124

125

126

127

128

129

130

131

132

133

134

135

136

137

138

139

140

141

142

143

144

145

146

147

148

149

contribute strongly to genome plasticity in eukaryotes (Lisch, 2012; Ayarpadikannan and Kim, 2014; Hirsch and Springer, 2017). In plants, most TEs can be activated, and their contribution to genome size is not negligible, especially for trees with large genomes (Kejnovsky et al., 2012; Lee and Kim, 2014). DNA methylation is required to silence these TEs located in the heterochromatin, and a decrease in DNA methylation level could result in their reactivation (Lippman et al., 2004; Mirouze et al., 2009; Mirouze and Paszkowski, 2011). The overall functional role of DNA methylation, both for control of gene expression and TE dynamics in a developmental and ecological context, is poorly understood.

DDM1 belongs to the SWI/SNF chromatin remodeling complex, and encodes a chromatin remodeling factor required for the maintenance of DNA methylation. Its depletion affects the distribution of methylation in all sequence contexts (Vongs et al., 1993; Jeddeloh et al., 1998; Gendrel et al., 2002; Zhu et al., 2013; Zemach et al., 2013).

DDM1 was first identified in Arabidopsis through EMS (ethyl methane sulfonate) treatment, which caused a "decrease in DNA methylation" (Vongs et al., 1993). Vongs et al., showed that Arabidopsis $d d m 1$ mutants displayed a 70 to $75 \%$ reduction in cytosine methylation compared to the wild-type (WT). Nonetheless phenotypic variations only appeared several generations after the initial loss of DDM1 activity, notably through reactivation of TEs (Miura et al., 2001). Several studies further characterized ddm1 mutants in Arabidopsis (Saze and Kakutani, 2007; Yao et al., 2012; Zemach et al., 2013; Cortijo et al., 2014; Ito et al., 2015; Kawanabe et al., 2016), turnip (Fujimoto et al., 2008; Sassaki et al., 2011), maize (Li et al., 2014), and rice (Higo et al., 2012; Tan et al., 2016). In poplar, RNAi $d d m 1$ lines have been obtained by targeting the transcripts of the two orthologous DDM1 paralogs in Populus tremula $\times$ Populus alba cv. INRA 717-1B4 (Zhu et al., 2013). Under standard greenhouse conditions, the regenerated lines did not show developmental defects, but newly formed leaves displayed a mottled phenotype after a cycle of dormancy (Zhu et al., 2013). These RNAi ddm1 lines have never been studied under stressed conditions.

To investigate whether variation in DNA methylation has the potential to facilitate tree plasticity under stress, we studied these $d d m 1$ RNAi lines during a water stress 
150

151

152

153

154

155

156

157

158

159

160

161

162

163

164

165

166

167

168

169

170

171

172

173

174

175

176

177

178

experiment. Here, plasticity is defined as modifications in phenotype (growth, morphology, anatomy, or gene expression) under a drought - re-watering regime for a given genotype (Bradshaw, 2006; Nicotra et al., 2010, 2015). To address this question in a developmental context, we focused our analysis on the shoot apical meristem (SAM, center of plant morphogenesis) one week after re-watering in order to focus on 'stable' post-stress epigenetic events (Lafon-Placette et al., 2018). Previous studies have shown that SAM is a critical organ where epigenetic modifications can affect plant development (Gourcilleau et al., 2010; Lafon-Placette et al., 2013; Conde et al., 2017; Lafon-Placette et al., 2018; Le Gac et al., 2018, Sow et al., 2018; Maury et al., 2019). To examine whether plasticity was associated with epigenetic variation within wild type or RNAi lines, we combined a fine scale ecophysiological characterization of growth dynamics and water relations with genomics (identification of differentially methylated regions (DMR) using whole genome bisulfite sequencing, differentially expressed genes (DEG) using RNA-seq, and active transposable elements using mobilome-seq). We report a comprehensive analysis of the functional role of DNA methylation in the poplar SAM in terms of gene expression, reactivation of TEs, and hormonal balance in response to variations in water availability.

\section{RESULTS}

\section{Phenotypic and physiological differences among lines under well-watered conditions}

Plants from the WW treatment remained close to field capacity during the whole experiment, with relative extractable water (REW) never dropping below 70\% (Fig. 1) and $\Psi_{\mathrm{pd}}$ values remaining above $-0.5 \mathrm{MPa}$ (Sup. Fig. 2A). There was no significant difference in either REW or $\Psi_{\mathrm{pd}}$ among lines (Fig. 1 and Sup. Fig. 2A). The WT and $d d m 1$ lines all showed linear growth, and exhibited a similar height growth rate during

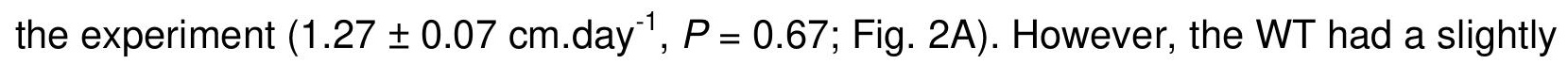
higher diameter growth rate than the $d d m 1$ lines $\left(0.11 \pm 0.02\right.$ vs. $0.08 \pm 0.01 \mathrm{~mm}$ day $^{-1}$, $P=0.036$; Fig. 2A). Differences among lines were much stronger for total leaf area, with 
179

180

181

182

183 $d d m 1$ lines exhibiting significantly lower values ( $28 \%$ reduction on average, $P=0.021$ ) compared to the WT (Sup. Fig. 3). This was explained by a particular vertical profile of individual leaf area in the middle canopy (Sup. Fig. 3).

All lines showed comparable leaf $\Psi_{\min }$, leaf $\delta^{13} \mathrm{C}$ and stomatal density (Sup. Fig. 2B), but significant differences were observed for xylem vulnerability to cavitation $(P<$ 0.001 , Fig. 2B). The WT was the most vulnerable $\left(P_{50}=-2.16 \pm 0.05 \mathrm{MPa}\right)$, while ddm123 was the most resistant $\left(P_{50}=-2.45 \pm 0.04 \mathrm{MPa}\right)$, and ddm1-15 was intermediate $\left(\mathrm{P}_{50}\right.$ $=-2.28 \pm 0.04 \mathrm{MPa}$ ) (Table 1). Differences among lines were not found in other xylem structural or biochemical traits (Table 1).

The proportion of "mottled leaves" reached $40 \%$ for ddm1-23, and more than $60 \%$ for ddm1-15 at the end of the experiment, while it remained close to zero for the WT (Sup. Fig. 4). Symptom occurrence was not linear but tended to increase at a specific physiological stage (Sup. Fig. 4). In addition, the line ddm1-23 exhibited several leaves that tended to fold around the midvein, a physical defect that was not found in the WT, and only rarely in $d d m 1-15$ (Sup. Fig. 4).

Table 1: Xylem structural, functional and biochemical traits measured for the wild type and the two RNAi-ddm1 (ddm1-15, ddm1-23) poplar lines in control (well-watered, WW) and stress (moderate water deficit followed by rewatering, WD-RW) treatments. Values are genotypic means \pm SE ( $n=6$ per line per treatment). The P50 is the xylem tension inducing $50 \%$ loss of hydraulic conductance estimated from vulnerability curves (see Materials and Methods for additional information). S/G corresponds to the ratio between syringyl-like (S) and guaiacyl-like lignin monomeric units $(\mathrm{G})$. Treatment effects were evaluated within each line by using a t-test. Different letters indicate significant differences between genotypes within treatments following Tukey's post hoc test. Levels of significance are ${ }^{*}, 0.01<\mathrm{P}<0.05 ;{ }^{* *}, 0.001<\mathrm{P}<0.01$; ${ }^{* *}, \mathrm{P}<0.001$; ns, nonsignificant; na, not available. 


\begin{tabular}{|c|c|c|c|}
\hline Phenotypic traits & WT & ddm1_15 & ddm1_23 \\
\hline Wood density (g.cm-3) - WW & $0.31 \pm 0.01$ & $0.31 \pm 0.004$ & $0.32 \pm 0.007$ \\
\hline Wood density (g.cm-3) - WD-RW & $0.40 \pm 0.02^{* \star *}$ & $0.42 \pm 0.01^{* * *}$ & $0.43 \pm 0.02^{\star * \star}$ \\
\hline Xylem vessel diameter $(\mu \mathrm{m})$ - WW & $44.28 \pm 1.37$ & $44.01 \pm 0.97$ & $41.08 \pm 2.39$ \\
\hline Xylem vessel diameter $(\mu \mathrm{m})$ - WD-RW & $42.00 \pm 1,48$ & $43.18 \pm 0.56$ & $40.36 \pm 0.89$ \\
\hline Xylem vessel density (nb. $\left.\mathrm{mm}^{2}\right)-\mathrm{WW}$ & $100.61 \pm 10.85$ & $100.09 \pm 5.10$ & $112.13 \pm 16.67$ \\
\hline Xylem vessel density (nb. $\mathrm{mm}^{2}$ ) - WD-RW & $111.24 \pm 9.61$ & $105.23 \pm 5.06$ & $123.66 \pm 4.37$ \\
\hline $\begin{array}{l}\text { Theoretical specific hydraulic conductivity } \\
\text { (kg.m.s-1.Mp-1) - WW }\end{array}$ & $11.81 \pm 0.90$ & $11.31 \pm 0.67$ & $9.82 \pm 1.08$ \\
\hline $\begin{array}{l}\text { Theoretical specific hydraulic conductivity } \\
\text { (kg.m.s-1.Mp-1) - WD-RW }\end{array}$ & $10.15 \pm 0.67$ & $11.24 \pm 0.52$ & $10.69 \pm 0.86$ \\
\hline |P50| values (Mpa) - WW & $2.12 \pm 0.06 a$ & $2.25 \pm 0.05 a b$ & $2.39 \pm 0.05 b$ \\
\hline Lignin klason prediction by MIRS (\%) -WW & $21.24 \pm 0.42$ & $20.90 \pm 0.34$ & $20.26 \pm 0.44$ \\
\hline $\begin{array}{l}\text { Lignin klason prediction by MIRS (\%) - WD- } \\
\text { RW }\end{array}$ & $20.56 \pm 0.26$ & $20.73 \pm 0.46$ & $19.99 \pm 0.27$ \\
\hline $\begin{array}{l}\text { Tension wood prediction by MIRS (\%) - } \\
\text { WW }\end{array}$ & $11.05 \pm 3.22$ & $13.58 \pm 2.89$ & $14.59 \pm 3.68$ \\
\hline $\begin{array}{l}\text { Tension wood prediction by MIRS (\%) - } \\
\text { WD-RW }\end{array}$ & $18.24 \pm 1.87^{*}$ & $16.39 \pm 2.20 \mathrm{~ns}$ & $22.39 \pm 2.42 \mathrm{~ns}$ \\
\hline S/G prediction by MIRS (\%) - WW & $1.15 \pm 0.03$ & $1.18 \pm 0.03$ & $1.22 \pm 0.30$ \\
\hline S/G prediction by MIRS (\%) - WD-RW & $1.20 \pm 0.02$ & $1.20 \pm 0.03$ & $1.16 \pm 0.01$ \\
\hline
\end{tabular}

209 Soil water content of plants in drought conditions started to be significantly lower four 210 days after the initiation of water deficit. Values of REW were maintained around 35\% 211 until $t_{1}$; re-watering at $t_{1}$ increased REW back to control values (Fig. 1). Predawn leaf 
water potential $\left(\Psi_{\mathrm{pd}}\right)$ at $\mathrm{t}_{1}$ was significantly lower than in well-watered plants $(P<0.001)$, and reached approximately -0.8 MPa, with no difference among lines (Sup. Fig. 2A); in contrast, $\Psi_{\min }$ values were not significantly affected by drought (Sup. Fig. 2 A). Height and diameter growth rates during drought were significantly lower in the WT only (Fig. 2A, $P<0.001$ and $P=0.026$, respectively). The effect persisted after re-watering until $t_{2}$ for diameter $(P<0.001)$ while height growth recovered to control values.

In response to water deficit, $\mathrm{g}_{\mathrm{s}}$ started to decrease significantly 10 days after drought initiation, i.e. once REW had dropped below $40 \%$ ( $P=0.027$ for WT, $P=0,171$ for ddm1_15 and $P=0.021$ for ddm1_23 Fig. 1, 2C). The WT and ddm1-23 showed relatively comparable dynamics, and reached almost an $80 \%$ decrease relative to controls, while stomatal closure was less pronounced in ddm1-15 (Fig. 2C). $A_{\text {net }}$ was less impacted than $\mathrm{g}_{\mathrm{s}}$, especially in $d d m 1-15$, in agreement with the moderate intensity of water deficit (Fig. $2 \mathrm{C}$ ). Therefore, the increase in intrinsic water-use efficiency (i.e. the ratio $A_{\text {net }} / g_{s}$ ) was more pronounced in the WT and ddm1-23 (Fig. 2C), which was confirmed by a greater $\delta^{13} \mathrm{C}$ increase in these same lines (Sup. Fig. 2B). Total stomatal density was not impacted by water deficit in $d d m 1$ lines, while it was significantly increased in the WT ( $P=0.030$, Sup. Fig. $2 C)$. Xylem traits were only seldom affected by water deficit (Table 1). Xylem density was significantly increased in all lines $(P<$ 0.001 ), while the proportion of tension wood increased in the WT only (Table 1). Water deficit had no significant effect on the occurrence of mottled or folded leaves (Sup. Fig. $4)$.

\section{Phytohormone concentration in SAMs}

There was no significant change among lines in terms of salicylic acid (SA) or the different types of cytokinin in the WW treatment (Fig. 3). In response to water deficitrewatering, SA increased while zeatin riboside and zeatin -O- glucoside riboside decreased in RNAi lines compared to the WT (Fig. 3). The other type of cytokinin, the isopentenyladenosine, showed a more complex pattern in RNAi lines. In addition, the ddm1-23 line showed a significant response for SA and for two cytokinins, with a similar trend to WT (Fig. 3). The ddm1-15 line showed a significant response for one cytokinin only (Fig. 3). ABA and free auxin remained unaffected in all treatments. 


\section{Methylome analysis and identification of line- and stress-specific DMRs}

243 Global DNA methylation content (HPLC analysis) ranged from 17.5 to $21.3 \%$ between 244 lines and treatments (Sup. Fig. 5A). There was no significant line $\times$ treatment interaction 245 effect. Global DNA methylation was significantly lower in RNAi lines than in the WT 246 under water deficit only, although there was no significant effect of water deficit (Sup. 247 Fig. 5A). Cytosine methylation percentages (WGBS analysis) for the three contexts 248 ranged from 18.6 to $19.6 \%$ in $\mathrm{CpG}, 4.4$ to 6.0 in $\mathrm{CHG}$ and 1.6 to 2.0 in $\mathrm{CHH}$ contexts, 249 with the ddm1-15 lines displaying the lowest values in all contexts (Sup. Table 1, Sup. 250 Fig. 1D).

Only a few stress-specific DMRs were identified. In contrast, thousands of linespecific DMRs were identified, especially for ddm1-15 (Sup. Fig. 5B). The two RNAi lines displayed a different number of DMRs (29785 vs. 30925 for ddm1-15 in WW and WD-RW treatments, respectively, and 11409 vs. 11104 for ddm1-23 in WW and WD-RW treatments, respectively). Most of these DMRs were hypomethylated and contextdependent with higher values found in CHG context, especially in ddm1-15 (20310 vs. 20847 DMRs in WW and WD-RW treatments, respectively) (Sup. Fig. 5C \& 5D). Linespecific DMRs were unequally distributed in the three different contexts. In the CpG context, DMRs presented a bimodal distribution with both hypo and hypermethylated DMRs (Sup. Fig. 5E). In the CHG context, most DMRs were hypomethylated, while in the $\mathrm{CHH}$ context DMRs were mostly slightly hypomethylated (Sup. Fig. 5E). The number of stress-specific DMRs was similar between the WT and ddm1 lines, and between the hypo and hypermethylated states (Fig. 4A). These DMRs were mainly found in CG and CHG contexts (Fig. 4A).

In order to focus on DMRs systematically associated with DDM1 defects, we identified DMRs commonly shared between ddm1-23 and ddm1-15 RNAi lines in either WW or WD-RW treatments (Fig. 4B). Regardless of the treatment, common DMRs were systematically over-represented in the CHG context (3463 vs. 3378 DMRs in WW and WD-RW treatments, respectively) and were mostly hypomethylated (Fig. 4B). Among common DMRs, 19 and 21\% were localized in genes, 7 and $8 \%$ in promoters (+/-2kb from the TSS) and 1\% in transposable elements (TEs), for WW and WD-RW treatments, 
272 respectively (Sup. Fig. 6A). The majority of DMRs (73 and 71\% in WW and WD-RW 273 treatments, respectively) were therefore localized in intergenic regions (Sup. Fig. 6A). In

274 the WW treatment, 879 genes were found to be strictly included within the common 275 DMRs (hereafter called DMGs for Differentially Methylated Genes), while 910 DMGs 276 were found in the WD-RW treatment. These numbers increased considerably (up to 277 more than 13,000 genes) when enlarging the windows for DMR identification from $2 \mathrm{~kb}$ 278 to $25 \mathrm{~kb}$ (Sup. Fig. 6B). In both treatments, a similar number of hypo and 279 hypermethylated DMGs was found in the CG context, while in the $\mathrm{CHG}$ and $\mathrm{CHH}$ 280 contexts, DMGs were mostly hypomethylated (Fig. 4C). In the CHH context, DMGs were 281 slightly methylated (between 25 to $50 \%$ of difference), compared to the CG and CHG 282 contexts (Fig. 4C). Gene Ontology annotation of DMGs revealed significant enrichment 283 in biological functions such as multicellular organism development (including shoot 284 system development), negative regulation of biological processes, and response to 285 abiotic stress (including response to hormones) (Sup. Fig. 6C).

\section{Transcriptome analysis for the water deficit - rewatering condition}

287 The identification of DEGs focused on the WD-RW treatment, but revealed clear 288 differences between the WT and the ddm1-23 lines. An average of $96 \%$ mapping 289 efficiency was found for the $P$. tremula $\times$ alba reference genome (v1). A total of 32048 290 genes were analyzed, but only 136 genes were significantly differentially expressed $(P<$ 291 0.05). Gene ontology annotation revealed significant enrichment in functions such as 292 defense response, including immune response, response to hormones (SA, Ethylene), 293 response to chitin, and regulation of RNA metabolism (Fig. 5A). The 136 DEGs (76 up294 regulated and 60 down-regulated) were grouped according to Arabidopsis thaliana gene 295 annotation homology into seven main classes: cell death, defense response and cell 296 wall, immune response, metabolism, signalization, transcription factors, and unknown 297 function (Fig. 5B). Genes related to immune response were systematically up-regulated 298 (RBOHD, CYP94B1, RLP1, RLP56, RPM1, PLDGAMMA1, PDF1). Most genes related 299 to transcription factors (15/17) were also up-regulated (WRKY, MYB106, ERF, SZF2, 300 PDF2, SVP/AGL22), with only two genes down-regulated (MYB48 and DTA2). Defense 301 and cell wall related genes were both up- (18, including CHITIV, KTI1, PR4, etc. 
302

303

304

305

306

307

308

309

310

311

312

313

314

315

316

317

318

319

320

321

322

323

324

325

326

327

328

329

330

331

involved in plant pathogen-interaction) and down-regulated (13). Phytohormone pathways were also over-represented in distinct classes with 13 DEGs (8 up- and 5 down-regulated) directly involved in defense responsive hormone biosynthetic pathways, such as SA pathways (SAMTs), the jasmonic acid (JA) pathway (OPR2, CYP94B1), the ethylene (ET) pathway (ERF1, ERF12), or auxin responsive genes (SAUR29, GH3.1, IBR3, BG1, ABCG36), gibberellic acid (GA) synthesis (GA3OX1) and cytokines (CK) pathways (AHP1) (Fig. 5B).

In order to test the link between gene expression and DNA methylation, DEGs were co-localized with common DMRs among ddm1 lines. Although only seven DEGs (Potri.001G048700, Potri.001G065300, Potri.002G192400, Potri.009G051300, Potri.016G130900, Potri.T041700, Potri.T085000) overlapped with the DMR genomic locations, 53 were located in the direct vicinity of a DMR $(+/-10 \mathrm{~kb})$ and $98 \mathrm{at}+/-25 \mathrm{~kb}$ (Sup. Fig. 7A). A significant and negative rank correlation (Spearman's $r h o=-0.32, P<$ 0.001 ) was observed between methylation in the three contexts and expression values when considering at least $\mathrm{a}+/-10 \mathrm{~kb}$ window for DMRs to reach statistical significance (Sup. Fig. 7B).

\section{Mobilome analysis and identification of line- and/or stress-specific active TEs}

We identified between 44 (ddm1-23 in WW) and 169 (ddm1-15 in WD-RW) TE families producing extrachromosomal circular DNAs (eccDNAs), depending on lines and treatments (Sup. Fig. 8A). In each line, the number of identified TE families was always higher in the WD-RW treatment (Sup. Fig. 8A). Overall, the two different classes of TEs (DNA transposons and retrotransposons) were detected in our mobilome-seq data (Fig. $6 \mathrm{~A})$. Most of the eccDNAs identified belonged to the annotated Gypsy, Copia, ENSPM, L1, Ogre, POPGY and SAT superfamilies of TEs and repeats. TEs Depth depth oOf cCoverage $(\mathrm{DOC})$ ranged from $4 \mathrm{X}$ to $51000 \mathrm{X}$ for the most active TEs, whereas Split Reads (SRs) coverage ranged from $3 X$ to $4600 X$ (Fig. 6A). Reads spanning the two TE extremities constitute an evidence of a circular TE and were detected using a split reads (SRs) mapping strategy. We detected a high number of SRs with a coverage ranged from $3 \mathrm{X}$ to $4600 \mathrm{X}$ confirming the presence of eccDNAs from TEs (Fig. 6A). The detection of SRs suggested the presence of reads spanning the junction of eccDNAs. 
332

333

334

335

336

337

338

339

340

341

342

343

344

Given the range of variation of the DOC coverage, we assigned TE families to four groups following Lanciano et al., (2017). TEs identified in the WT and RNAi lines belonged to the four groups in both WW and WD-RW treatments (Fig. 6A). The "TE"++"group was exclusively represented by the Gypsy superfamily, while the

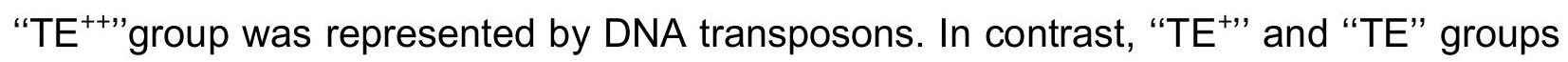
were represented by different superfamilies (Fig. 6A).

The most active TE (Gypsy23, with a DOC ranging from 36000X to 52000X) was present in all lines, but only in the WD-RW treatment (Fig. 6A). The second most active TE also belonged to the Gypsy superfamily (Gypsy27, DOC ranging from 14000X to 25000X), and was detected in the three lines in the WW treatment but only in the WT line in the WD-RW treatment. We also identified eccDNAs that were line- and/or stressspecific, such as those originating from the satellite SAT-1 specifically activated in $d d m 1-15$, in both WW and WD-RW treatments (9000X and 5200X, respectively), and in the WT line only in the WD-RW condition. Two DNA-3-3 TEs with the same name, but different in terms of sequence were also detected in the WW treatment only. The first one (named DNA-3-3_1) was activated in the two RNAi lines (6000X in ddm1-15 and $1500 \mathrm{X}$ in $d d m 1-23$ ), while the second one (named DNA-3-3_2) was specific to ddm1-15 (5200X) (Fig. 6A). We were also able to detect TEs that belonged to the "TE" group that were line- or stress-specific (Fig. 6A). GO annotation of the genes co-localizing with TEs (+/- $10 \mathrm{~kb}$ of genes) revealed enrichment in functions such as response to stress, including hormone response, multicellular organism development, and negative regulation of cellular processes (Sup. Fig. 8B). The number of genes identified in the vicinity of TEs varied between 45 (TEs inside genes) and 1788 (when considering TEs at $+/-25 \mathrm{~kb}$ of genes) (Sup. Fig. $8 \mathrm{C}$ ). However, only a few of these genes showed changes in their expression level (seven DEGs when considering the vicinity of $+/-25 \mathrm{~kb}$; Potri.005G223200, Potri.006G062100, Potri.013G100800, Potri.013G101000, Potri.013G103000, Potri.013G120800, Potri.016G070100).

Methylation of active TEs and estimation of copy number variations for highly active TEs 
About $21 \%$ of the mobilome-seq TE families strictly co-localized within common DMRs. This percentage raised to more than $50 \%$ when considering the presence of $+/-25 \mathrm{~kb}$ of a DMR in the vicinity (Sup. Fig. $8 \mathrm{C}$ ). These methylated active TE families were in majority hypomethylated (ca. $92 \%$ of the TE families) in $d d m 1$ lines (Fig. 6B). In the WW treatment, active TEs were hypomethylated mostly in CG and CHG contexts, while in the WD-RW treatment, active TEs were hypomethylated in CG and CHG contexts but mostly hypermethylated in the $\mathrm{CHH}$ context (Fig. 6B). The most active TEs were methylated in $\mathrm{CHG}$ context.

To investigate whether TE activity (as detected by eccDNA presence) had led to new integrations in the genome, copy number variation was assessed for three active TEs (DNA-3-3_1, Gypsy23 and SAT-1) localized in or near DMRs by qPCR analysis (Fig. 6C). For DNA-3-3_1, there was no significant variation in the copy number regardless of the lines and treatments (Fig. $6 \mathrm{C}$ ). In contrast, an increase in copy number was detected in the WD-RW treatment for Gypsy23 in ddm1-23 (15 copies), and for SAT-1 in ddm1-15 (18 copies) (Fig. 6C). Gypsy23 was hypomethylated in the CHG context, while $S A T-1$ was found in $+/-2 \mathrm{~kb}$ of DMRs that were CG and CHG hypomethylated.

\section{DISCUSSION}

DDM1-dependent DNA methylation plays a role in tree phenotypic plasticity in response to water deficit

\section{Hypomethylated poplar RNAi-ddm1 lines are more tolerant to water deficit}

Tolerance to water deficit is a complex trait encompassing multiple physiological determinants that can relate to processes as diverse as growth maintenance, survival, or recovery, depending on the context \{intensity $\times$ duration\} considered (McDowell et al., 2008; Volaire et al., 2018). Poplars are among the most sensitive temperate trees to water deficit although significant variation naturally occurs between and within species (Monclus et al., 2006; Street et al., 2006; Fichot et al., 2015). The water deficit imposed in our experiment was deliberately controlled and moderate, as attested by the relatively 
high $\Psi_{\text {pd }}$ (ca. - $0.8 \mathrm{MPa}$ ) and the small effects on net $\mathrm{CO}_{2}$ assimilation rates. This avoided rapid growth cessation and instead promoted steady-state acclimation. However, this was sufficient to reveal clear differences in drought responses between the wild type and hypomethylated $\mathrm{RNA}_{\mathrm{i}}-d d m 1$ lines. While growth was progressively slowed down in the wild type as REW dropped below 40\% (Bogeat-Triboulot et al., 2007), both RNAi-ddm1 lines remained unaffected, suggesting improved tolerance to moderate water deficit. RNA-ddm1 lines showed a limited increase in time-integrated WUE in response to water deficit as compared to the wild type, which was partly attributable to a less important stomatal closure, at least in $d d m 1-15$. The slightly more negative leaf $\Psi_{\min }$ observed in $\mathrm{RNA}_{\mathrm{i}}-d d m 1$ lines tended to confirm the idea that improved tolerance might have been linked partly to a better ability for leaf gas exchange maintenance. In addition, while stomatal density was comparable between the wild type and $\mathrm{RNA}_{\mathrm{i}}$-ddm1 lines under standard conditions, stomatal density increased in response to water deficit in the wild type only. $d d m 1$ mutants in Arabidopsis were reported to have more stomata with modified organization (grouped clusters of two or more stomata) (Vassileva et al., 2016), suggesting that DDM1 modifications have the potential to modify stomatal patterning and therefore leaf physiology. Our findings go further and suggest that these effects may also depend on the environmental context. Interestingly, stomatal density seems to be tightly linked to the dynamics of VPD- and irradiance-induced stomatal closure/opening under water deficit in poplar, with higher densities being correlated with faster stomatal dynamics (Durand et al., 2019). It is therefore possible that the increased stomatal density observed in the wild type under water deficit contributed to a higher stomatal sensitivity, providing one possible explanation for constrained leaf gas exchange and growth reduction as compared to $\mathrm{RNA}_{\mathrm{i}}-d d m 1$ lines.

Besides differences in dynamic drought responses, our results also suggest that $\mathrm{RNA}_{\mathrm{i}}-d d m 1$ lines were intrinsically more tolerant to severe water deficit because of 416 higher xylem resistance to drought-induced cavitation. Xylem resistance to droughtinduced cavitation is a key trait for plant water relations in a context of survival, as it 418 partly sets operational limits for water transport under tension (Brodribb \& Cochard, 419 2009; Barigah et al., 2013). How modifications of the DDM1 machinery can affect xylem resistance to cavitation remains unknown at this stage. Interestingly, basic xylem 
421 properties such as vessel diameter and density, xylem density, or even xylem

422 biochemical composition were not significantly different from the wild type. However,

423 given the mechanistic understanding of drought-induced cavitation in angiosperms

424 (Choat et al., 2018), it is likely that the increased resistance observed in the RNA $\mathrm{A}_{\mathrm{i}}-d d m 1$

425 lines was primarily linked to modifications of the ultrastructure of vessel-vessel bordered

426 pits (Plavcová Hacke, 2011; Awad et al., 2012; Dusotoit-Coucaud et al., 2014; Herbette

427 et al., 2014). Whether the slight gain in intrinsic cavitation resistance (i.e. a few tenth of

428 an $\mathrm{MPa}$ ) does promote increased survival rates under severe water deficit, and whether

429 epigenetics might be exploited as such for increasing drought tolerance, remains to be

430 purposely tested.

431 Several DEGs identified in the SAM of RNAi-ddm1 lines could explain at least in 432 part the improved tolerance to moderate water deficit. Indeed, genes involved in the 433 cuticle and waxes (CER8, FLA12) that provide protection from abiotic and biotic stresses 434 were upregulated in RNAi-ddm1 lines. Increased levels of cuticular waxes have been 435 associated with enhanced drought tolerance by preventing uncontrolled water loss 436 (Chen et al., 2011; Wettstein-Knowles, 2016). Similarly, the MYB106 TF, a major 437 regulator of cuticle formation was upregulated in the $d d m 1$ line (Oshima and Misuda, 438 2013, 2016). Other transcription factors (TFs) (SVP, MYB48, MYB106, WRKY36, 439 WRKY33, WRKY53) associated with drought tolerance in plants were also upregulated 440 in the ddm1 lines (Bechtold et al., 2016; Sun \& Yu, 2015; He et al., 2016; Guo et al., 441 2019). Finally, previous studies in Arabidopsis ddm1 mutants and derived epiRILs 442 subjected to drought, or more broadly to increased nutrients or salt stress, have 443 provided evidence that variation in DDM1-derived DNA methylation can cause 444 substantial heritable variation in ecologically important plant traits and their plasticity 445 (Reinders et al., 2009; Johannes et al., 2009; Latzel et al., 2013; Cortijo et al., 2014; 446 Zhang et al., 2013, Kooke et al., 2015; Cho et al., 2016; Zhang et al., 2018; Furci et al., 447 2019). 
450 First characterized by Zhu et al., 2013, poplar RNAi-ddm1 lines did not show any growth

451 or developmental defects when grown under standard greenhouse conditions, but some 452 newly formed leaves displayed a mottled phenotype after a dormancy cycle. This is 453 similar to other reports in Arabidopsis and other species, where developmental 454 abnormalities usually appear in later generations (Kakutani, 1997; Tan et al., 2016; 455 Corem et al., 2018; Long et al., 2019). In our RNAi-ddm1 lines we found two distinct leaf 456 phenotypes: "mottled leaves" and "folded leaves." However, the two RNAi lines differed 457 in terms of the quantities of symptomatic leaves, with higher values in $d d m 1-15$ for 458 mottled leaves. This was observed even though our stress treatments had no effect on 459 leaf symptom numbers for either line. The alteration of leaf phenotype has already been 460 attributed to DDM1 mutation in Arabidopsis, where mutants showed altered leaf shape 461 (Kakutani et al., 1995; Qüesta et al., 2013; Kooke et al., 2015), and curled or folded 462 leaves were also observed in hypomethylated ddc (drm1 drm2 cmt3) mutants (Forgione 463 et al., 2019). However, here we report that stressed conditions do not have an effect on 464 this phenotype.

The presence of mottled leaves could be suggestive of a hypersensitive response (HR) which could result in the hyperactivation of disease resistance genes (Zhu et al., 2013) due to the constitutive hypomethylation in RNAi-ddm1 lines. This is in agreement with the recent report of Furci et al., (2019) showing that hypomethylation in Arabidopsis $d d m 1$-epiRILs at selected pericentromeric regions controls quantitative disease resistance against Hyaloperonospora arabidopsidis, which is associated with genome471 wide priming of defense-related genes. Lesion mimic mutants, characterized by the 472 formation of necrotic leaves (hereafter called mottled leaves) in the absence of 473 pathogens have been identified, and most importantly, these mutants show enhanced 474 resistance to pathogen infection. This is probably due to mis-regulation of defense responsive genes (Lorrain et al., 2003; Wu et al., 2008). In poplar RNAi-ddm1 lines, we found an important set of genes involved in defense and immune response that were 477 significantly and differentially expressed in RNAi lines compared to the WT. Immune responsive genes were upregulated in RNAi-ddm1 lines, while defense related genes were in majority downregulated. Consequently, genes involved in cell death and leaf senescence (MLO12 and NHL10) were upregulated. The activation of immune response 
481

482

483

484

485

486

487

488

489

490

491

492

493

494

495

496

497

498

499

500

501

502

503

504

505

506

507

508

509

510

511

genes in RNAi-ddm1 lines suggests that trees react as if they were attacked by pathogens. This could be particularly important as it could prime $d d m 1$ lines against future pathogen infections (Lopez Sanchez et al., 2016; Furci et al., 2019). Indeed, different TFs (WRKY18, WRKY33, WRKY70, WRKY53 and ERF1) known to be activated during pathogen attack were overexpressed in $d d m 1$ lines. The WRKY TFs are known to play important roles in plant defense responses that are related to attacks by several pathogens. Accordingly, overexpression of one of these WRKY TFs in $A$. thaliana, Brassica napus or Oryza sativa resulted in enhanced disease resistance (Li et al., 2004; Wang et al., 2014; Wang et al., 2017; Chujo et al., 2007; Marcel et al., 2010; Chen and Chen, 2002; Abeysinghe et al., 2018). In poplar, overexpression of WRKY18 (with WRKY35) also activates pathogenesis-related genes, and increases resistance to the biotrophic pathogen Melampsora (Jiang et al., 2017).

The RNAi-ddm1 lines also had altered expression of a cluster of disease resistance genes, as was already reported in $A$. thaliana (Saze and Kakutani, 2007; Stokes et al., 2002; Lopez Sanchez et al., 2016; Furci et al., 2019). There are multiple mechanisms by which DNA hypomethylation could regulate defense gene induction in cis (promoter or nearby TEs) or trans contexts. A few cis-regulated genes can control the induction of several groups of defense genes by DNA (de)methylation, and hypomethylation can influence chromatin structure at distant genome loci such as TEs activating the RdDM pathway (Grandbastien, 1998; Makarevitch et al., 2015; Quadrana et al., 2019). This recent data in Arabidopsis have shown that methylation controls global defense gene responsiveness via trans-acting mechanisms (Lopez Sanchez et al., 2016; Cambiagno et al., 2018; Furci et al., 2019). Accordingly, we found, by overlapping DMRs and DEGs, that only seven DEGs co-localized with DMRs. Expression and methylation values (DEGs at +/-10 kb of DMRs) showed a significant correlation. This suggests that these genes may not be the primary target of DDM1.

Active extrachromosomal forms of TEs from several families were identified in water deficit conditions or in DDM1 lines (mostly hypomethylated). Some of these endogenous TE insertions are located in the vicinity of stress responsive genes (45) and of DEGs (3, at +/-10 kb of TEs). Furci et al., (2019) reported that DNA hypomethylation at TE-rich epiQTLs in Arabidopsis thaliana could mediate the induction of defense- 
512

513

514

515

516

517

518

519

520

521

522

523

524

525

526

527

528

529

530

531

532

533

534

535

536

537

538

539

540

541

542

related genes across the genome via a trans-acting mechanism. Quadrana et al., (2019) further showed that in Arabidopsis epiRILs, the insertion of Copia elements preferentially targets environmentally responsive genes such as cell death, defense response and immune response, potentially facilitating rapid adaptation. Here, we could detect increased copy numbers for two TE families in the hypomethylated $d d m 1$ stressed lines. The potential impact of these new insertions on adaptation is unclear. Finally the fact that only two TE families showed increased copy number suggests that additional mechanisms prevent genomic insertions of reactivated TEs.

\section{Hypomethylated poplar lines exhibit an altered phytohormonal balance in the} shoot apical meristem

Phytohormones are key regulators of plant development and response to stress (Gaillochet \& Lohmann, 2015), and have been linked to epigenetic control (Latzel et al., 2012; Yamamuro et al., 2016; Ojolo et al., 2018; Raju et al., 2018), where this interplay could have a major role in meristems for developmental plasticity (Maury et al., 2019). Here, we report that $d d m 1$ lines exhibited modified shoot apex hormonal balance immediately post-rewatering. Although abscisic acid (ABA) (Zhang et al., 2006; Fernando \& Schroeder, 2015) and free auxins (Shi et al., 2014; Basu et al., 2016) are known to mediate physiological responses to water deficit, we found no treatmentinduced difference in the SAMs of ddm1-lines. In contrast, salicylic acid (SA) and cytokinins $(\mathrm{CK})$ showed significant variations among our $d d m 1$ lines compared to the WT after drought treatment. Increased SA level was accompanied by a decrease in CK content (especially for zeatine riboside and zeatine-O-glucoside riboside) in post-stress $d d m 1$ lines. This is in agreement with several reports, which found that drought-stressed plants tend to increase the endogenous level of SA promoting tolerance to several stresses including drought (Munne-Bosch and Penuelas, 2003; Bandurska \& Stroi ski, 2005; Azooz \& Youssef 2010; Pandey \& Chakraborty, 2015; Sedaghat et al., 2017), and decreasing CK levels (Havlovà et al., 2008; Nishiyama et al., 2011; Ha et al., 2012). Altogether our data show that the shoot apex of hypomethylated, stressed lines displayed specific hormonal changes for SA and CK. Shoot apices were collected after three weeks of stress (the day of rewatering) to measure the hormonal balance at the 
543 end of the treatment. This timing of sampling could explain why drought-related 544 modifications in ABA or auxin contents were not observed. Correia et al., (2014) have 545 shown in Eucalyptus globulus that while drought causes an increase in ABA levels in 546 leaves, rewatering was accompanied by a gradual decrease and stressed and non547 stressed plants reached the same amount of ABA seven days post-drought. This also in 548 agreement with Cotrozzi et al., (2017) who showed a very transient peak of ABA 549 following drought conditions in Quercus ilex. However, this timing of sampling for 550 hormonal content enabled us to compare it with the presumably (meta)stable epigenetic 551 condition (memory) one week post-rewatering.

552 DMGs and DEGs nearby active TEs identified in the SAM of ddm1 stressed lines 553 were mainly involved in development, stress response and phytohormone pathways 554 (such as JA, SA and ethylene). When comparing the genome-wide distribution of DMRs 555 to DEGs in poplar, Lafon-Placette et al., (2018) showed that variations in soil water 556 availability induced changes in DNA methylation preferentially in genes involved in 557 phytohormone metabolism and signaling, potentially promoting phenotypic plasticity. 558 Accordingly, poplar SAMs may also retain an environmental epigenetic memory by 559 targeting hormone-responsive genes (Le Gac et al., 2019). SAMT1, a salicylic acid 560 methyltransferase gene was still up-regulated one week post-stress in RNAi-ddm1 lines 561 compared to the WT, supporting the increase in SA content at the end of the stress. 562 When screening for candidate genes for drought tolerance in Coffea arabica cultivars, 563 Mofatto et al., (2016) found that SAMT1 was upregulated under drought conditions. 564 Zhang et al., (2016) have also shown that DDM1 affects early seedling growth heterosis 565 in Col/C24 hybrids. Indeed, ddm1 mutants showed impaired heterosis (Kawanabe et al., 566 2016) and increased expression of non-additively expressed genes related to salicylic 567 acid metabolism. They proposed that DDM1 acts as an epigenetic link between salicylic 568 acid metabolism and heterosis, also protecting plants from pathogens and abiotic stress. 569 SA accumulation has also been widely used as a reliable marker of elevated defense 570 responses under pathogen infection, and has been associated with HR cell death or 571 systemic acquired resistance, as well as with DDM1 mutation (Dong, 2004; Song et al., 572 2004; Liu et al., 2010; Zhang et al., 2016; Badmi et al., 2019). 
The elevated amount of SA levels in RNAi-ddm1 lines could be suggestive of acquired disease resistance in $d d m 1$ mutants. Similarly, two genes (CYP94B1 and OPR2) involved in JA metabolism were upregulated in the RNAi-ddm1 lines. CYP94B1 and OPR2 have been shown to contribute to the attenuation of the JA-dependent wound responses in response to pathogen attack (Koo et al., 2014; Pandey et al., 2017; Wasternack \& Hausse, 2018). Moreover, Latzel et al., (2012) have established a positive correlation between DNA methylation variations (epiRILs) and JA and SA responses, and proposed that part of the variation of plant defenses observed in natural populations may be due to underlying epigenetic, rather than entirely genetic, variation. Several TFs involved in abiotic (drought) or biotic stress, and acting in phytohormone pathways, were upregulated in stressed $d d m 1$ lines in comparison to WT; this includes genes such as SVP (SHORT VEGETATIVE PHASE) that can confer drought resistance by regulating ABA catabolism (Wang et al., 2018), MYB48 that can improve tolerance to drought when overexpressed (Wang et al., 2017) and ERF1, which can activate a subset of ethyleneinducible genes as the immune responsive gene PDF1 (Solano et al., 1998; Fujimoto et al., 2000; Heyman et al., 2018).

Altogether our data suggest a direct connection between epigenetic regulation and phytohormones in the meristem for the control of plasticity as previously proposed (Maury et al., 2019). This interplay could control the expression of cell identity genes, the stable activation of hormone-responsive genes post-stress, or act as an integrative hub for the sensing of hormonal balance to ensure plasticity, and potentially environmental 594 memory (Maury et al., 2019).

595 DDM1-dependent DNA methylation in poplar shoot apical meristem is context dependent and affects both genes and TE activity

Poplar ddm1 RNAi knock down lines were hypomethylated in SAMs according to global 599 DNA methylation levels (7 to 17\% reduction compared to WT). This is in agreement with both the WGBS analysis, which showed DMRs mostly hypomethylated, and with the report of Zhu et al., (2013), who found comparable reductions in leaves. While poplar 602 DDM1-dependent DNA methylation was affected in the three contexts (CpG, CHG \& 
$603 \mathrm{CHH}$ ), strong differences were observed among the contexts. The methylation level in $604 \mathrm{CHG}$ was drastically reduced compared to $\mathrm{CpG}$ or $\mathrm{CHH}$ contexts, suggesting that in 605 poplar, DDM1 preferentially targets methylation in the CHG context. This is in 606 accordance with rice (Tan et al., 2016), and maize (Li et al., 2014; Long et al., 2019), but 607 contrasts with Arabidopsis and tomato, where the disruption of DDM1 led to a drastic 608 hypomethylation of the genome, mainly in CpG and CHG contexts (Vongs et al., 1993; 609 Kakutani et al., 1995, 1997; Lippman et al., 2004; Zemach et al., 2013; Corem et al., 610 2018). These observations suggest that DDM1 has differential effect on DNA 611 methylation patterns in diverse species (Tan et al., 2016; Long et al., 2019).

We also found that $D D M 1$ reduction caused extensive $\mathrm{CpG}$, and to a lower extent $\mathrm{CHG}$, hypermethylation of intergenic regions and genes, and that $\mathrm{CHH}$ hypermethylation of TEs only occurred in stressed conditions. The loss of DDM1 has already been associated with hypermethylation in CHG contexts in genes of Arabidopsis and rice, as well as more limited hypermethylation in both $\mathrm{CpG}$ and $\mathrm{CHG}$ contexts for euchromatic regions in tomato and maize (Lippman et al., 2004; Mathieu et al., 2006; Saze \& Kakutani, 2007; Zemach et al., 2013; Tan et al., 2016; Corem et al., 2018; Long et al., 2019). $\mathrm{CHH}$ hypermethylation has also been reported for heterochromatic TEs in rice and tomato (Tan et al., 2016; Corem et al., 2018). Here, we found that extensive CpG hypermethylation, notably in genes, was not associated with differential expression level, and overlapped with only a few active TEs, while hypermethylated $\mathrm{CHH}$ TEs showed 623 reduced activity in comparison to hypomethylated CG and CHG TEs. It has been 624 proposed that these hypermethylation events are likely to be mediated by different, 625 potentially overlapping mechanisms that act as an internal balancing mechanism to 626 compensate for the extensive loss of methylation in other contexts (Zemach et al., 2013; 627 Tan et al., 2016; Corem et al., 2018).

Altogether, we propose that hypermethylation events, being species-dependent, 629 may participate in pleiotropic effects. This could be related to variations in the functional 630 role of $D D M 1$ in the different species, and/or in relation to their epigenetic machinery and 631 genome complexity. We provide evidence that this phenomenon is also stress- 
632 dependent, and occurs in the shoot apical meristem with possible implications for mitotic 633 and meiotic transmission.

\section{DDM1 impairment of gene methylation has limited effects on gene expression}

635 DDM1 decrease in poplar affected the methylation of 879 and 910 genes in WW and 636 WD-RW treatments, respectively. In poplar, gene methylation typically occurs in CpG 637 and CHG contexts, and to a lower extent in the $\mathrm{CHH}$ context (Feng et al., 2010; Vining 638 et al., 2012; Lafon-Placette et al., 2013). Despite a strong reduction in genome-wide $639 \mathrm{CHG}$ methylation, the numbers of DMGs found in $\mathrm{CpG}$ and $\mathrm{CHG}$ were of similar order. 640 However, in $\mathrm{CHG}$ and $\mathrm{CHH}$ contexts genes found were in majority hypomethylated 641 (>90\%), whereas in the CpG context an equal number of genes were hypo- or 642 hypermethylated. between the WT and ddm1-23 in response to water deficit, with 76 upregulated and 60 downregulated genes. Previous data on Arabidopsis and tomato $d d m 1$ mutants were of similar magnitude (Zemach et al., 2013; Corem et al., 2018), while more DEGs were reported in rice (Tan et al., 2016) or in infected Arabidopsis EpiRILs (Furci et al., 2019). Among DEGs, only seven strictly overlapped with DMRs (up to 39\% for genes at +/-10 $\mathrm{kb}$ of DMRs); in agreement with tomato ddm1 mutants (Corem et al., 2018). This 650 suggests that not all of these DEGs are primary targets of DDM1. A significant negative rank correlation was detected, however, between gene expression and methylation for 652 the 53 DEGs located at less than $+/-10 \mathrm{~kb}$ of DMRs. Although changes in 5' DNA 653 methylation may influence gene expression (Seymour \& Becker, 2017), the role of genebody methylation still remains disputed (Bewick \& Schmitz, 2017), and to date it has been difficult to differentiate between direct changes mediated by DNA methylation and secondary effects (Meyer, 2015). In most available studies, no correlation could be detected between DNA methylation and expression changes at the genomic level. However, in agreement with other studies, our data show that the transcriptional activity of a subset of genes might be regulated by DNA methylation in response to abiotic 660 stress (Karan et al., 2012; Garg et al., 2015; Chwialkowska et al., 2016, Lafon-Placette 661 et al., 2018). These genes, including TFs and hormones-related pathways, are likely to 
662

663

664

665

666

667

668

explain, at least in part, the developmental plasticity of poplar ddm1 lines (Maury et al., 2019).

\section{DDM1-dependent DNA methylation favors TEs reactivation and insertion during} stress

The role of DNA methylation and DDM1 on TE proliferation is well-established in plants (Miura et al., 2001; Mirouze et al., 2009; Tsukahara et al., 2009). TE proliferation has also been investigated in DDM1-epiRILs in Arabidopsis and tomato (Reinders et al., 2009; Johannes et al., 2009; Corem et al., 2018; Quadrana et al., 2019). Here, we reported TE activity in the SAM of WT and RNAi-ddm1 lines using the mobilome-seq workflow (Lanciano et al., 2017). TEs, which represent $\sim 42 \%$ of the genome of poplar (Kejnovski et al., 2012), were evaluated both under control and post water deficit conditions. The pattern of TE methylation varied widely between the different contexts. While most TEs were hypomethylated in CG and CHG contexts, we could not detect any TEs overlapping with the common DMRs, suggesting a limited effect in the $\mathrm{CHH}$ context (Corem et al., 2018). This could be related also to the threshold that we applied during DMR identification, which considered only DMRs with at least $10 \%$ of difference and $10 \mathrm{X}$ of coverage. This is very stringent since $\mathrm{CHH}$ methylation level in poplar is very low compared to $\mathrm{CG}$ and $\mathrm{CHH}$ contexts ( 3,25\%; Feng et al., 2010). This result also supports a redundant function of $\mathrm{CG}$ and non-CG methylation in the transcriptional silencing of the TEs (Ikeda \& Nishimura, 2015). The burst of TEs in $d d m 1$ lines were recorded for the two different classes (DNA transposons and retrotransposons), with a notable enrichment for the retrotransposons of the Gypsy family. Interestingly, when assessing the copy number variation of the most active TEs, we could detect only increased copy number for Gypsy retrotransposons (Gypsy-23 and SAT-1/Gypsy78_Ptr-I-int) during the post stress episode, suggesting specific control of Gypsy activity by DDM1 during the stress. Gypsy elements are long terminal repeat (LTR)-flanked retrotransposons that are concentrated in pericentromeric heterochromatin, in comparison to other repeats that are more dispersed e,g,m (Copia, LINE, SINE). Wang et al., (2018) recently reported a constant conflict between Gypsy retrotransposons and $\mathrm{CHH}$ methylation within a stress-adapted mangrove genome, and found differential 
692

693

694

695

696

697

698

699

700

701

702

703

704

705

706

707

708

709

710

711

712

713

714

715

716

717

718

719

720

721

accumulation among classes of LTR TEs mainly due to siRNA-mediated $\mathrm{CHH}$ methylation preferentially targeting Gypsy elements. This is consistent with our data as we observed extensive $\mathrm{CHH}$ methylation of TEs (such as Gypsy elements) during drought in the $d d m 1$ lines associated with enrichment in non-coding RNA (ncRNA) GO labels. This may suggest that $d d m 1$ lines tend to methylate TEs in $\mathrm{CHH}$ contexts in order to repress their activity. Wang et al., (2018) subsequently proposed that the apparent conflict between TEs activity and repression of integration may enable the maintenance of genetic diversity and thus evolutionary potential during stress adaptation. This is particularly interesting as genes found with nearby active TEs in $d d m 1$ lines are mainly involved in stress response and development. Quadrana et al., (2019) recently proposed that TEs are potent and episodic (epi)mutagens that increase the potential for rapid adaptation. They proposed that this is in large part due to epigenetic mechanisms of suppression that limit their activity which might result in purifying selection against them, and also limits their mutation rate due to their presence in highly compact chromatin. Here our data suggest that DDM1 could play a role in these repressive but diversity maintaining mechanisms during drought stress in poplar.

\section{Shoot apical meristem is a central place for epigenetic control of developmental plasticity}

Our study focused on meristems, previously described as "organs with specific epigenetic machinery" (Baubec et al., 2014; Lafon-Placette et al., 2018; Le Gac et al., 2018, 2019) and as controlling centers of development and acclimation. They are also the loci of mitotic and meiotic transmission. Here, we report the detailed characterization from physiological to omics levels of two independent ddm1 poplar RNAi lines. Both lines exhibited higher tolerance to drought, mottled leaves, and modification of hormonal balance. Our study shows that DDM1-dependent DNA methylation in the shoot apical meristem of poplar trees plays two roles: controlling developmental plasticity and enabling stress response through a direct interplay with hormonal pathways (Maury et al., 2019). DDM1-dependent DNA methylation also controls the activation, and probably the integration, of TEs whose movements can induce heritable mutations and affect the 
722

723

724

725

726

727

728

729

730

731

732

733

734

735

736

737

738

739

740

741

742

743

744

745

746

747

748

749

750

potential for rapid adaptation (Kawakatsu \& Ecker, 2019; Quadrana et al., 2019). These results are in agreement with previous studies in poplars (Gourcilleau et al., 2010; Zhu et al., 2013; Conde et al., 2017; Lafon-Placette et al., 2018; Le Gac et al., 2018, 2019; Sow et al., 2018) and recent findings in annuals (Raju et al., 2018; Schmid et al., 2018; Zhang et al., 2018; Furci et al., 2019; Quadrana et al., 2019), both showing that epigenetic variation and TEs have the potential to create phenotypic variation that is substantial, persistent, and stable, thus of adaptive and evolutionary significance.

Our data are consistent with recent models about role of epigenetic variation in plants (Yona et al., 2015; Richards et al., 2017; Kawakatsu \& Ecker, 2019; Maury et al., 2019) that view meristems as an interface between physiological response and genetic adaptation. Further studies are needed to examine the role of stress-induced epigenetic variation and associated mutation that examine a far greater range of stresses, species, and genotypes. This will enable its importance relative to more traditional sources of adaptive and evolutionary variation to be interpreted. Such studies are of particular interest for long-lived organisms in the age of rapid, anthropogenic climate change.

\section{METHODS}

\section{Plant material, experimental design, and control of water deficit}

Experiments were conducted on two PtDDM1 RNAi lines (ddm1-15 and ddm1-23), and a wild type (WT) line of Populus tremula $\times$ Populus alba (clone INRA 717-1B4). These two RNAi lines were chosen among those previously described by Zhu et al., (2013) for consistently lower levels of both cytosine methylation $(17.0$ and $16.7 \%$ reduction compared to WT, respectively) and PtDDM1 residual expression (ca. 62\% reduction). Six week-old in vitro propagated plantlets were first transferred into small sealed chambers for progressive acclimation. Acclimated plantlets were then transferred to $4 \mathrm{~L}$ pots filled with a potting substrate (Klasmann RHP 25-564, $\mathrm{pH}=5.8$ ) complemented with Osmocote PG Mix (1 kg/m³ of N-P-K 80/35/60). The experiment was conducted in a greenhouse located at the research station of INRAE Orléans Centre Val-de-Loire $\left(47^{\circ} 46^{\prime} \mathrm{N}, 1^{\circ} 52^{\prime} \mathrm{E}\right)$, with a photoperiod of $16: 8$, an average temperature of $21^{\circ} \mathrm{C}$, and a 
751 relative humidity of $32 \%$. Right before the water deficit experiment started (2 month-old 752 plants), three plants per line were randomly sampled $\left(t_{0}\right)$. The remaining 81 plants were 753 then randomly distributed into nine blocks ( $n=3$ trees per line per block) and assigned 754 to either a well-watered control treatment (WW, $\mathrm{n}=1$ per line per block) or a water 755 deficit treatment followed by re-watering (WD-RW, $\mathrm{n}=2$ per line per block).

Water deficit was initiated at $t_{0}$ and lasted three weeks until $t_{1}$. Watering was performed every two days and was adjusted for each plant based on volumetric soil 758 water content (SWC) estimated via pot weighing. Values of SWC at time i $\left(S_{W} C_{i}\right)$ were converted to soil relative extractable water $\left(\mathrm{REW}_{\mathrm{i}}, \%\right)$ using the following equation: $R E W_{i}=\left(S W C_{i}-S W C_{w p}\right) /\left(S W C_{f c}-S W C_{w p}\right) \times 100$ where $S W C_{f c}$ and $S W C_{w p}$ correspond to the SWC at field capacity and at the wilting point, respectively. Plants from the WW treatment were always watered to field capacity, while plants from the WDRW treatment were re-watered to a target value of approx. $40 \%$ of REW. At $t_{1}$, plants 764 from the WD-RW treatment were re-watered to field capacity, three blocks were sampled, and the remaining six blocks were maintained watered for one week until $t_{2}$, after which all remaining plants were sampled. The water deficit intensity was evaluated at $t_{1}$ by measuring the predawn leaf water potential $\left(\Psi_{\mathrm{pd}}, \mathrm{MPa}\right)$ during the night preceding the re-watering. Measurements were performed on a subset of five randomly selected blocks using a pressure chamber (PMS instruments, Albany, OR, USA). Minimum leaf water potential $\left(\Psi_{\min }\right)$ was estimated for the same plants at midday on the day preceding re-watering.

\section{Physiological and phenotypic characterization}

\section{Growth and leaf symptoms}

774 Stem height was measured every two days using a telescopic ruler, while stem diameter 775 was measured every four days using a digital caliper. Due to Zhu et al. (2013) reporting 776 the occurrence of spontaneous necrotic spots on the leaves of $d d m 1$ RNAi lines (mottled 777 phenotype), we repeatedly measured the number of leaves showing necrotic symptoms 778 (mottled leaves) during the whole duration of the experiment. We also counted the 
779

780

781

782

783

number of leaves showing a 'folded' morphology (see results section). These measurements were performed on three randomly selected blocks.

\section{Leaf gas exchange, bulk leaf carbon isotope composition $\left(\delta^{13} \mathrm{C}\right)$, and stomatal density}

Leaf gas exchange were measured using a LI-6400 open path photosynthesis system (Li-Cor, Lincoln, NE, USA) equipped with an LED light source (LI-6400-02B). Measurements were systematically performed on fully mature leaves in the top third of the plant in the same five blocks as those used for $\Psi_{p d}$ and $\Psi_{\min }$. From the time of drought initiation onwards, net $\mathrm{CO}_{2}$ assimilation rate $\left(A_{n e t}, \mu \mathrm{mol} \mathrm{m} \mathrm{m}^{-2} \mathrm{~s}^{-1}\right)$, and stomatal conductance to water vapor $\left(g_{s}, \mathrm{~mol} \mathrm{~m}^{-2} \mathrm{~s}^{-1}\right)$ were measured every day between 9 am and $3 \mathrm{pm}$ in order to characterize the dynamic response of the genotypes to water deficit. Measurements were performed at a saturating photosynthetic photon flux density (PPFD) of $2000 \mu \mathrm{mol} \mathrm{m} \mathrm{m}^{-2} \mathrm{~s}^{-1}$, an ambient $\mathrm{CO}_{2}$ concentration of $400 \mathrm{ppm}$, a constant block temperature of $25^{\circ} \mathrm{C}$, and a reference vapor pressure deficit (VPD) maintained close to $1 \mathrm{kPa}$.

Bulk leaf carbon isotope composition $\left(\delta^{13} \mathrm{C}\right)$ was used as a time-integrated surrogate of leaf intrinsic water-use efficiency (Farquhar et al., 1982). Six calibrated discs (3.14 $\mathrm{cm}^{2}$ ) of leaf lamina were punched from a mature leaf at $t_{2}$ on all plants. Leaf disks were oven-dried at $60^{\circ} \mathrm{C}$ for $48 \mathrm{hrs}$ before being ground to a fine powder. One milligram subsamples were then enclosed in tin capsules and combusted at $1200^{\circ} \mathrm{C}$. The $\mathrm{CO}_{2}$ produced by combustion was purified, and its ${ }^{13} \mathrm{CO}_{2} /{ }^{12} \mathrm{CO}_{2}$ ratio was analyzed using isotope ratio mass spectrometry (IRMS, Finnigan MAT Delta S, Bremen, Germany). The $\delta^{13} \mathrm{C}(\%)$ was expressed relative to the Vienna Pee Dee Belemnite standard and calculated as $\delta^{13} \mathrm{C}=\left(\mathrm{R}_{\mathrm{sa}}-\mathrm{R}_{\mathrm{sd}}\right) / \mathrm{R}_{\mathrm{sd}} \times 1000$ where $\mathrm{R}_{\mathrm{sa}}$ and $\mathrm{R}_{\mathrm{sd}}$ are the ${ }^{13} \mathrm{CO}_{2} /{ }^{12} \mathrm{CO}_{2}$ ratios of the sample and the standard, respectively (Farquhar et al., 1989). The accuracy of the $\delta^{13} \mathrm{C}$ measurements done by IRMS during the time samples was assessed using referenced standards of $\pm 0.05 \%$ (SE). All measurements were performed at the INRAE-Nancy technical platform of functional ecology in France. 
Stomatal counts were measured on a subset of three blocks, following the method described by $\mathrm{Xu} \&$ Zhou (2008). Stomatal imprints were taken between the central leaf vein and the leaf edge on both adaxial and abaxial sides, and then fixed on microscopic slides using scotch tape. Slides were observed under a light microscope coupled to a Moticam 580 5.0MP digital camera, and three pictures were taken on each

812 filmstrip side.

\section{Xylem structure, function and biochemical composition}

Xylem vulnerability to drought-induced cavitation was assessed at $t_{2}$ on the well-watered 815 plants of all blocks (INRAE Phenobois Platform, Clermont-Ferrand, France). 816 Vulnerability to cavitation sets the operational limit of xylem under drought, and is a key 817 trait involved in drought tolerance (Brodribb \& Cochard, 2009). We used the Cavitron 818 technique which is well suited to poplars (Cochard et al., 2005, Fichot et al., 2015). In 819 short, the technique uses the centrifugal force to increase xylem tension ( $\left.\Psi_{\mathrm{x}}, \mathrm{MPa}\right)$ in 820 stem segments, while at the same time measuring the percent loss of hydraulic 821 conductance (PLC, \%). The dependence of PLC upon $\Psi_{x}$ was used to generate 822 vulnerability curves for each stem segment. The following sigmoid function was fitted to 823 data (Cochard et al., 2007): PLC $=100 /\left(1+\exp \left((s / 25) \times\left(P-P_{50}\right)\right)\right.$, where $P_{50}$ is the xylem 824 tension causing $50 \%$ loss of hydraulic conductance (MPa) and $\mathrm{s}$ is the slope of the curve 825 at the inflexion point (\%. $\left.\mathrm{MPa}^{-1}\right)$. Values of $\mathrm{P}_{50}$ were used as proxies for vulnerability to xylem drought-induced cavitation.

Xylem histology was performed on stem segments of all plants at $\mathrm{t}_{2}$. Stem crosssections $30 \mu \mathrm{m}$-thick were obtained using a hand microtome (RM 2155, Leica Microsystems, Vienna, Austria), and stained with safranin (1\% in 50\% ethanol), and followed by Astra blue (1\% in $100 \%$ ethanol), before being permanently mounted in

831 Canada Balsam. Stained sections were examined under a light microscope coupled to a 832 Moticam 580 5.0MP digital camera. Pictures covering pith to cambium were taken at a 833 10x magnification on three opposite radial sectors in order to estimate vessel diameter $834(\mu \mathrm{m})$, vessel density $\left(\mathrm{mm}^{-2}\right)$, vessel lumen fraction (\%), and theoretical xylem specific 835 hydraulic conductivity (Fichot et al., 2010). Image analyses were all performed using the 836 ImageJ software (Schneider et al., 2012). Xylem density was assessed on the same 
stem segments using $4 \mathrm{~cm}$-long samples. Measurements were realized using the Archimedes principle. Bark-free stems were split longitudinally in order to remove wood pith, submerged to estimate the volume of displaced water, and weighed after being

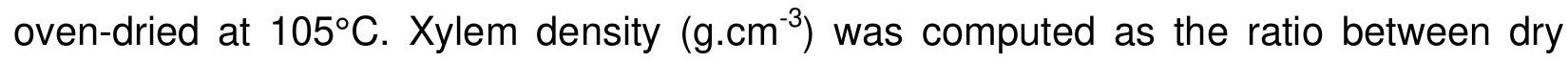
mass and the volume of displaced water (Fichot et al., 2010).

Xylem biochemical composition was evaluated indirectly on stem powders of all plants by using Fourier-Transform mid-Infrared Spectroscopy (FTIR, Spectrum 400, Perkin Elmer, Massachusetts, USA), and home-made calibration models previously developed at the INRAE Genobois phenotyping platform for Klason lignin content, S/G ratio and tension wood content (unpublished data). For each sample, a few milligrams were placed three times on the attenuated total reflectance (ATR) diamond for the scan. Spectra ranged from 650 to $4000 \mathrm{~cm}^{-1}$ wave numbers with a step of $2 \mathrm{~cm}^{-1}$. Spectrum analyses were realized using the $R$ software ( $R$ Core Team, 2015). Spectra were first cut and smoothed by using the 'prospectr' package before applying normalization and first derivative processing (Bertrand \& Dufour, 2006).

\section{Phytohormone quantification}

Shoot apices were immediately frozen in liquid nitrogen upon sampling, and later ground to a fine powder in an automatic ball mill (MM 200 Retsch, Germany). Phytohormone assays for abscisic acid (ABA), free auxin, salicylic acid (SA), jasmonic acid (JA) and cytokinins were performed on the SAMs collected at t1, using LC-MS according to a published procedure (OVCM platform, IJPB, INRAE Versailles, France; Li-Marchetti et al., 2015; Trapet et al., 2016). For each sample, $10 \mathrm{mg}$ of dry powder was extracted with $0.8 \mathrm{~mL}$ of acetone/water/acetic acid (80/19/1 v:v:v). Phytohormone stable labelled isotopes used as internal standards were prepared as described in Roux et al., (2014). Two ng of each and 0,5 ng of cytokinines standard was added to the sample. The extract was vigorously shaken for $1 \mathrm{~min}$, sonicated for $1 \mathrm{~min}$ at $25 \mathrm{~Hz}$, shaken for 10 minutes at $10^{\circ} \mathrm{C}$ in a Thermomixer (Eppendorf囚), and then centrifuged $\left(8000 \mathrm{~g}, 10^{\circ} \mathrm{C}\right.$, $10 \mathrm{~min}$.). The supernatants were collected, and the pellets were re-extracted twice with $0.4 \mathrm{~mL}$ of the same extraction solution, then vigorously shaken ( $1 \mathrm{~min}$ ), and sonicated (1 $\min ; 25 \mathrm{~Hz}$ ). After the centrifugations, the three supernatants were pooled and dried 
867

868

869

870

871

872

873

874

875

876

877

878

879

880

881

882

883

884

885

886

(Final Volume $1.6 \mathrm{~mL}$ ). Each dry extract was dissolved in $100 \mu \mathrm{L}$ of acetonitrile/water $(50 / 50 \mathrm{v} / \mathrm{v})$, filtered, and analyzed using a Waters Acquity ultra performance liquid chromatograph coupled to a Waters Xevo Triple quadrupole mass spectrometer TQS (UPLC-ESI-MS/MS). The compounds were separated on a reverse-phase column (Uptisphere C18 UP3HDO, 100*2.1 mm³ $\mu \mathrm{m}$ particle size; Interchim, France) using a flow rate of $0.4 \mathrm{ml} \mathrm{min}^{-1}$, and a binary gradient: $(\mathrm{A})$ acetic acid $0.1 \%$ in water $(\mathrm{v} / \mathrm{v})$ and (B) acetonitrile with $0.1 \%$ acetic acid, and a column temperature of $40^{\circ} \mathrm{C}$. Mass spectrometry was conducted using electrospray, and Multiple Reaction Monitoring scanning mode (MRM mode), in either positive ion mode (for the indole-3-acetic acid and cytokinins) or negative ion mode (for the other hormones). Relevant instrumental parameters were set as follows: capillary $1.5 \mathrm{kV}$ (negative mode), with source block and desolvation gas temperatures at $130^{\circ} \mathrm{C}$ and $500^{\circ} \mathrm{C}$, respectively. Nitrogen was used to assist the cone and desolvation (150 L.h ${ }^{-1}$ and 800 L.h ${ }^{-1}$, respectively), argon was used as the collision gas at a flow of $0.18 \mathrm{ml} \cdot \mathrm{min}^{-1}$.

\section{DNA extraction and determination of global DNA methylation levels by HPLC}

Genomic DNA was extracted from all SAMs with a CTAB protocol (Doyle \& Doyle, 1987), and stored at $-80^{\circ} \mathrm{C}$. Quantity and quality were approximated using a NanoDrop spectrometer (NanoDrop Instrument, France).

For the determination of global DNA methylation, genomic DNA was enzymatically hydrolyzed into nucleosides, and analyzed by high-performance liquid chromatography (HPLC), as described by Zhu et al., (2013). Controls for this procedure included co-migration with commercial standards (Sigma-Aldrich), confirmation by enzyme restriction analysis, and tests for RNA contamination based on the HPLC detection of ribonucleosides. Global DNA methyl cytosine percentages ( $\% \mathrm{mC})$ were estimated as follows: $\% \mathrm{mC}=(\mathrm{mC} /(\mathrm{C}+\mathrm{mC})) \times 100$, where ' $\mathrm{C}$ ' is 2'-déoxycytidine content, and ' $\mathrm{mC}$ ' is 5-methyl-2'-déoxycytidine content. For each line in each treatment, three biological replicates were randomly chosen out of the six for analyses, with two independent genomic DNA extractions per replicate, three hydrolysis replicates and two HPLC runs. 
898 An equimolar pool of $2 \mu \mathrm{g}$ DNA at approximately $100 \mathrm{ng} / \mu \mathrm{l}$, and extracted from four 899 SAMs was made for each line in each treatment. Whole-genome bisulfite sequencing 900 was performed by the CNRGH laboratory (J. Tost, Evry, France) in accordance with the 901 published procedure (http://www.nugen.com/products/ovation-ultralow-methyl-seq902 library-systems) adapted from Daviaud et al., (2018). The workflow of the library 903 preparation protocol follows the classical library preparation protocol in which methylated 904 adaptors are ligated to the fragmented DNA prior to bisulfite conversion. A total of 200 $905 \mathrm{ng}$ of genomic DNA was fragmented to a size of approximately 200 base pairs (bp), and 906 then purified and methylated adaptors compatible with sequencing on an Illumina HiSeq 907 instrument were ligated. The resulting DNA library was purified and bisulfite converted. A 908 GPCR assay was used to determine the optimal number of PCR amplification cycles 909 (between 10 and 15 cycles) required to obtain a high diversity library with minimal 910 duplicated reads prior to final library amplification. The sequencing was performed with 911 paired ends $(2 \times 150 \mathrm{bp})$ on an Illumina HiSeq4000 platform. Raw data were stored in 912 FASTQ files with a minimal theoretical coverage of 30X (SRA record is under the 913 reference PRJNA611484; https://www.ncbi.nlm.nih.gov/sra/PRJNA611484).

914 The bioinformatics pipeline used in this study is adapted from the ENCODE pipeline 915 (https://www.encodeproject.org/wgbs/) and installed on the Galaxy instance, accessible 916 of IHPE (http://galaxy.univ-perp.fr/, Perpignan, France). First, quality control and 917 cleaning of the raw data were carried out by only considering nucleotides with a quality 918 score over 26 , and reads which had more than $95 \%$ of their nucleotides over this quality 919 threshold. The second step was the alignment of the WGBS reads on the reference 920 genome Populus tremula $\times$ alba (http://aspendb.uga.edu/index.php/databases/spta-717921 genome), by using BISMARK (version 0.16.3, Krueger \& Andrews, 2011) and bowtie 2 922 tools (version 2.1.0; Langmead et al., 2009) or a bisulfite sequence mapping program 923 (BSMAP version 2.74) (Xi \& Li, 2009). The parameters were modified for 'paired-end' 924 alignment, read lengths were between 70 and $500 \mathrm{bp}$, and others were kept by default 925 (See sup. Figure 1 A, B and C). The methylkit $R$ package allowed the identification of 
926 DMRs among lines and treatments. A DMR was defined as a 500 bp region with a 927 minimum coverage of 10X, which highlighted the differential methylation between two 928 samples of at least $10 \%$ for $\mathrm{CHH}$, and $25 \%$ for $\mathrm{CHG}$ and CG (q-value=0.01). Different 929 types of DMRs were identified and are referred to as follows: stress-specific DMRs refer 930 to DMRs between WW and WD-RW treatments, line-specific DMRs refer to DMRs 931 between $d d m 1$ lines and the WT, and common DMRs refer to line-specific DMRs 932 common to both lines $d d m 1-15$ and $d d m 1-23$.

DMR annotation was realized by using reference data available for the Populus 934 tremula $\times$ alba genome from the aspendb database. Gene Ontology (GO) term 935 enrichment was assessed for the methylated genes with Revigo 936 (http://revigo.irb.hr/http://revigo.irb.hr/) software, using default parameters. 'TreeMap' 937 view was performed with rectangle size adjusted to reflect the absolute log10 $P$-value of 938 the GO term, through use of the corresponding poplar model genes from the best v3.0 939 blast hits with Arabidopsis TAIR10 annotations.

\section{Transcriptomics and bioinformatic pipeline}

941 Total RNA (three biological replicates) was extracted from the wild type and one RNAi 942 line in WD-RW condition by using a modified protocol of Chang et al., 1993). Ddm1-23 943 was chosen as the most representative of the two lines as it exhibited a lower decrease 944 in methylation compared to $d d m 15-7$, but nonetheless most of its DMRs were in 945 common among the two lines. In brief, SAMs were ground into fine powder in liquid 946 nitrogen and total RNAs were extracted using a CTAB buffer (Changet al., 1993). RNA 947 was precipitated using lithium chloride (10M) and purified using the Macherey Nagel 948 Nucleospin RNA kit (740955). Sequencing was done using the Illumina NexSeq500 949 (IPS2 POPS platform, Saclay, France). RNA-seq libraries were performed by following 950 the TruSeq_Stranded_mRNA_SamplePrep_Guide_15031047_D protocol (Illumina®, 951 California, USA). The RNA-seq samples have been sequenced in paired-end (PE) with a 952 sizing of $260 \mathrm{bp}$ and a read length of 75 bases. 6 samples by lane of NextSeq500 using 953 individual bar-coded adapters and giving approximately 15 millions of PE reads by 954 sample are generated. To facilitate comparisons, each sample followed the same steps 955 from trimming to counts. RNA-Seq preprocessing included trimming library adapters and 
performing quality controls. The raw data (fastq) were trimmed with the Trimmomatic (Bolger et al., 2014) tool for Phred Quality Score Qscore >20, read length $>30$ bases, and ribosome sequences were removed with the sortMeRNA tool (Kopylova et al., 2012). The genomic mapper STAR (version 2.6, Dobin A. et al 2013) was used to align reads against the Populus tremula $\times$ alba hybrid genome (genotype INRA 717-1B4), with the options outSAMprimaryFlag AllBestScore--outFilterMultimapScoreRange 0, to keep only the best results. The abundance of each gene was calculated with STAR, with paired-end reads only being counted where the reads unambiguously mapped one gene, and multi-hits were removed. Following this pipeline, around $92 \%$ of PE reads were associated to a gene, 3 to $4 \%$ PE reads were unmapped and 3 to $4 \%$ of $P E$ reads with multi-hits were removed.

Differential analyses followed the procedure described in Rigaill et al., (2016). In brief, genes with less than one read, after a count per million normalization in at least one half of the samples, were discarded. Library size was normalized using the trimmed mean of M-value (TMM) method, and count distribution was modeled with a negative binomial generalized linear model. Dispersion was estimated by the edgeR method (Version 1.12.0, McCarthy et al., 2012) in the statistical software 'R' (Version 3.2.5 R

973 Development Core Team (2005)). Expression differences compared two samples using 974 the likelihood ratio test, and p-values were adjusted by the Benjamini-Hochberg 975 procedure to control False Discovery Rate (FDR). A gene was declared differentially 976 expressed if its adjusted p-value was lower than to 0.05 .

All steps of the experiment, from growth conditions to bioinformatic analyses,

978 were managed in CATdb database (Gagnot et al., 2008; http://tools.ips2.u979 psud.fr/CATdb/) with ProjectID NGS2017-01-DDM1 This project is submitted from 980 CATdb into the international repository GEO (Gene Expression Omnibus, Edgard R. et al. 2002, http://www.ncbi.nlm.nih.gov/geo) with ProjetID GSE135313.

\section{Mobilome-seq and copy number variation of TEs}

983 According to their mode of transposition, TEs generate extrachromosomal circular DNAs 984 (eccDNAs) when active. The sequencing of these eccDNAs by the mobilome 985 sequencing was a successfully method to identify active TEs (Lanciano et al., 2017). In 
order to identify the effect of DDM1 knock down and a hydric stress on the release of TE activity we used approximately $6 \mu \mathrm{g}$ of genomic DNA to perform mobilome-seq libraries. eccDNAs were isolated and libraries were prepared and sequenced following Lanciano et al., (2017). Bioinformatics was carried out on the Populus tremula $x$ alba genome (SPta717 v1.1) by using the same pipelines as described in Lanciano et al., (2017). In order to obtain TE database for Populus tremula $x$ alba genome, we used the TE database based on Populus trichocarpa genome (version 3.0). In brief, the sequencing reads were first filtered against the mitochondria and chloroplast genomes before being 994 i) mapped against the $P$. tremula $\times$ alba reference genome using Bowtie2, ii) mapped for split reads (SR) using segemehl software (Hoffmann et al., 2014) and iii) de novo assembled using a5-miseq (Coil et al., 2015). Given the range of variation of the DOC coverage, we assigned TE families to four groups following Lanciano et al., (2017): The first group was named "moderate or not active TEs (group "TE")", and comprised TEs with a DOC ranging from 4 to 199X. The second group was named "active TEs" (group "TE+") and comprised TEs with a DOC ranging from 200-1999X. The third group was named "very active TEs" ("TE ${ }^{++}$) and comprised TEs with a DOC ranging from 2000 to 9999X. The fourth group was named "highly active group" (“TE ${ }^{+++}$), and comprised TEs with a DOC ranging from 10000 to 51000X. Raw and processed data are available with 1004 the

GEO accession

number

GSE147934

1005

(https://www.ncbi.nlm.nih.gov/geo/query/acc.cgi?acc=GSE147934).

Copy number variation of TEs was assessed for all studied lines in both 1007 treatments by qPCR using genomic DNA extracted from SAMs. In summary, primers of 1008 TEs were first designed using corresponding FASTA sequences with Eprimer3 and Netprimer for quality control checking

(http://www.bioinformatics.nl/cgibin/emboss/eprimer3, http://www.premierbiosoft.com/NetPrimer). Primers that passed quality control (Gypsy: F=AAC-AAG-CTG-AAG-CCC-AAG-AA, R=TCG-ACC-TCG-AGTTAG-GTT-CC; DNA-3-3: F=TAG-TGT-GCA-GTG-GAG-CAT-GG， R=AAA-AGC-AGGGTG-TTT-TGC-TG; SAT-1: F=TCA-CCG-GAA-CCC-ACT-TCT-AC, R=GCA-ACG-ACTGAG-TTT-CGT-CA) were used with $10 \mathrm{ng} / \mu \mathrm{l}$ of genomic DNA for qPCR analyses (Platinum $^{\text {TM }}$ SYBR $^{\text {TM }}$ Green qPCR SuperMix-UDG, Invitrogen ${ }^{\text {TM }}$ kit). A standard cycling program was applied $\left(50^{\circ} \mathrm{C}\right.$ for $2 \mathrm{~min}, 95^{\circ} \mathrm{C}$ for $2 \mathrm{~min}$, and 40 cycles of $95^{\circ} \mathrm{C}$ for $15 \mathrm{sec}$ 
1017

1018

1019

1020

1021

1022

1023

1024

1025

1026

1027

1028

1029

1030

1031

1032

1033

1034

1035

1036

1037

1038

1039

1040

1041

1042

1043

1044

1045

1046

1047

and $60{ }^{\circ} \mathrm{C}$ for $30 \mathrm{sec}$ ). Melting curves were obtained using recommended qPCR instrument settings. Copy number variation was assessed by using absolute quantification of cycle threshold values (Schmittgen \& Livak, 2008).

\section{Statistical analyses}

Statistical analyses were performed with $\mathrm{R}$ statistical software under $\mathrm{R}$ Studio integrated development environment (R Core Team, 2015, RStudio: Integrated Development for R. RStudio, Inc., Boston, MA URL http://www.rstudio.com/). Means are expressed with their standard errors (SE). Differences between lines and treatments for phenotypic traits were evaluated by analysis of variance (ANOVA) on individual values adjusted for block effects. Tukey's post-hoc test was used to identify differences between groups when ANOVAs indicated significant effects. Statistical tests were considered significant at $P<$ 0.05 .

\section{Author contributions}

S.M designed and coordinated the research. The plant experimental design was established by S.M, S.S, R.F, and F.B. Ecophysiological measurements were performed by A.L.L.G, R.F, A.D, I.L.J and H.C; analysis was realized by A.L.L.G and R.F. NIRS measurements and analysis were performed by A.L.L.G and V.S. Phytohormones analysis was performed by S.C. DNA, RNA extractions were done by A.D and A.L.L.G and M.D.S. HPLC analysis was done by A.D and S.M. RNA-seq was realized and analyzed by J.C, V.B, L.S.T with M.D.S. J.T, C.D realized WGBS analysis. WGBS data analysis was done by S.M, A.L.L.G and M.D.S. Bioinformatics for WGBS was done with the help of C.C and C.G. Mobilome analysis was done under the supervision of M.M with S.L and A.L.L.G. QPCR analysis were done by M.C.L.D with A.D and M.D.S. Data analysis was done by S.M, A.L.L.G and M.D.S. Statistical analyses were done by R.F, A.L.L.G and M.D.S. S.M, R.F, A.L.L.G and M.D.S conceived and wrote the first draft of the manuscript. All authors approved the final version of the manuscript.

\section{Acknowledgments}

M.D.S and A.L.L.G received Phd grants from the Ministère de la Recherche et Enseignement Supérieur. This work was supported by INRAE (grant PI EFPA-2014 to S.M.), the RTP3E CNRS grants for mobility (http://rtp-3e.wixsite.com/rt3e; A.L.L.G, S.M, C.G and M.M) and access to the IHPE platform (http://galaxy.univ-perp.fr/, Perpignan, France). The LBLGC also benefits from support of the ANR EPITREE (ANR-17-CE32-0009-01) to SM. English editing was done by Infinity English ( $N^{\circ}$ SIRET 
1048 82950710200012). The IJPB benefits from the support of Saclay Plant Sciences-SPS (ANR-17-EUR1049 0007). This work has benefited from the support of IJPB's Plant Observatory technological platforms. SL 1050 and MM were supported by the French National Agency for Research (ANR-13-JSV6-0002 "ExtraChrom") 1051 and the Laboratoire d'Excellence LABEX TULIP (ANR-10-LABX-41). 
Manuscript in preparation

1052

1053

1054

1055

1056

1057

1058

1059

1060

1061

1062

1063

1064

1065

1066

1067

1068

1069

1070

1071

1072

1073

1074

1075

1076

1077

1078

1079

1080

1081

1082

1083

1084

1085

1086

1087

1088

1089

1090

1091

1092

1093

1094

1095

1096

1097

1098

1099

1100

1101

1102

1103

\section{REFERENCES}

Abeysinghe, J. K., Lam, K.-M., \& Ng, D. W.-K. (2019). Differential regulation and interaction of homoeologous WRKY18 and WRKY40 in Arabidopsis allotetraploids and biotic stress responses. The Plant Journal, 97(2), 352- 367. https://doi.org/10.1111/tpj.14124

Allen, C. D., Macalady, A. K., Chenchouni, H., Bachelet, D., McDowell, N., Vennetier, M., Kitzberger, T., Rigling, A., Breshears, D. D., Hogg, E. H. (Ted), Gonzalez, P., Fensham, R., Zhang, Z., Castro, J., Demidova, N., Lim, J.-H., Allard, G., Running, S. W., Semerci, A., \& Cobb, N. (2010). A global overview of drought and heat-induced tree mortality reveals emerging climate change risks for forests. Forest Ecology and Management, 259(4), 660- 684. https://doi.org/10.1016/j.foreco.2009.09.001

Anderegg, W. R. L., Klein, T., Bartlett, M., Sack, L., Pellegrini, A. F. A., Choat, B., \& Jansen, S. (2016). Meta-analysis reveals that hydraulic traits explain cross-species patterns of drought-induced tree mortality across the globe. Proceedings of the National Academy of Sciences, 113(18), 50245029. https://doi.org/10.1073/pnas.1525678113

Awad, H., Herbette, S., Brunel, N., Tixier, A., Pilate, G., Cochard, H., \& Badel, E. (2012). No trade-off between hydraulic and mechanical properties in several transgenic poplars modified for lignins metabolism. Environmental and Experimental Botany, 77, 185- 195. https://doi.org/10.1016/j.envexpbot.2011.11.023

Ayarpadikkannan, S., \& Kim, H.-S. (2014). The Impact of Transposable Elements in Genome Evolution and Genetic Instability and Their Implications in Various Diseases. Genomics \& informatics, 12, 98- 104. https://doi.org/10.5808/GI.2014.12.3.98

Azooz, M. M., \& Youssef, M. M. (2010). Evaluation of Heat Shock and Salicylic Acid Treatments as Inducers of Drought Stress Tolerance in Hassawi Wheat. American Journal of Plant Physiology, 5(2), 56- 70. https://doi.org/10.3923/ajpp.2010.56.70

Badmi, R., Zhang, Y., Tengs, T., Brurberg, M. B., Krokene, P., Fossdal, C. G., Hytönen, T., \& Thorstensen, T. (2019). Induced and primed defence responses of Fragaria vesca to Botrytis cinerea infection. BioRxiv, 692491. https://doi.org/10.1101/692491

Bandurska, H., \& Stroi ski, A. (2005). The effect of salicylic acid on barley response to water deficit. Acta Physiologiae Plantarum, 27(3), 379- 386. https://doi.org/10.1007/s11738-005-0015-5

Barigah, T. S., Charrier, O., Douris, M., Bonhomme, M., Herbette, S., Améglio, T., Fichot, R., Brignolas, F., \& Cochard, H. (2013). Water stress-induced xylem hydraulic failure is a causal factor of tree mortality in beech and poplar. Annals of Botany, 112(7), 1431- 1437. https://doi.org/10.1093/aob/mct204

Basu, S., Ramegowda, V., Kumar, A., \& Pereira, A. (2016). Plant adaptation to drought stress. F1000Research, 5. https://doi.org/10.12688/f1000research.7678.1

Baubec, T., Finke, A., Mittelsten Scheid, O., \& Pecinka, A. (2014). Meristem-specific expression of epigenetic regulators safeguards transposon silencing in Arabidopsis. EMBO Reports, 15(4), 446452. https://doi.org/10.1002/embr.201337915

Bechtold, U., Penfold, C. A., Jenkins, D. J., Legaie, R., Moore, J. D., Lawson, T., Matthews, J. S. A., Vialet-Chabrand, S. R. M., Baxter, L., Subramaniam, S., Hickman, R., Florance, H., Sambles, C., Salmon, D. L., Feil, R., Bowden, L., Hill, C., Baker, N. R., Lunn, J. E., ... Mullineaux, P. M. (2016). Time-Series Transcriptomics Reveals That AGAMOUS-LIKE22 Affects Primary Metabolism and Developmental Processes in Drought-Stressed Arabidopsis. The Plant Cell, 28(2), 345- 366. https://doi.org/10.1105/tpc.15.00910

Bertrand, D., \& Dufour, É. (2006). La Spectroscopie Infrarouge et ses Applications Analytiques. Tec \& Doc / Lavoisier. http://www.lavoisier.fr/notice/fr2743008090.html

Bewick, A. J., \& Schmitz, R. J. (2017). Gene body DNA methylation in plants. Current Opinion in Plant Biology, 36, 103- 110. https://doi.org/10.1016/j.pbi.2016.12.007

Bogeat-Triboulot, M.-B., Brosché, M., Renaut, J., Jouve, L., Thiec, D. L., Fayyaz, P., Vinocur, B., Witters, E., Laukens, K., Teichmann, T., Altman, A., Hausman, J.-F., Polle, A., Kangasjärvi, J., \& Dreyer, E. (2007). Gradual Soil Water Depletion Results in Reversible Changes of Gene Expression, Protein Profiles, Ecophysiology, and Growth Performance in Populus euphratica, a Poplar 
Manuscript in preparation

1104

1105

1106

1107

1108

1109

1110

1111

1112

1113

1114

1115

1116

1117

1118

1119

1120

1121

1122

1123

1124

1125

1126

1127

1128

1129

1130

1131

1132

1133

1134

1135

1136

1137

1138

1139

1140

1141

1142

1143

1144

1145

1146

1147

1148

1149

1150

1151

1152

1153

1154

1155

1156

1157

1158
Growing in Arid Regions. Plant Physiology, 143(2), 876https://doi.org/10.1104/pp.106.088708

Bolger, A. M., Lohse, M., \& Usadel, B. (2014). Trimmomatic: A flexible trimmer for lllumina sequence $\begin{array}{llll}\text { data. Bioinformatics (Oxford, England), } & 30(15), \quad 2114-\end{array}$ https://doi.org/10.1093/bioinformatics/btu170

Bradshaw, A. D. (2006). Unravelling phenotypic plasticity - why should we bother? New Phytologist, 170(4), 644- 648. https://doi.org/10.1111/j.1469-8137.2006.01761.x

Bräutigam, K., Vining, K. J., Lafon-Placette, C., Fossdal, C. G., Mirouze, M., Marcos, J. G., Fluch, S., Fraga, M. F., Guevara, M. Á., Abarca, D., Johnsen, Ø., Maury, S., Strauss, S. H., Campbell, M. M., Rohde, A., Díaz-Sala, C., \& Cervera, M.-T. (2013). Epigenetic regulation of adaptive responses of forest tree species to the environment. Ecology and Evolution, 3(2), 399- 415. https://doi.org/10.1002/ece3.461

Brodribb, T. J., \& Cochard, H. (2009). Hydraulic Failure Defines the Recovery and Point of Death in Water-Stressed Conifers. Plant Physiology, 149(1), 575- 584. https://doi.org/10.1104/pp.108.129783

Cambiagno, D. A., Nota, F., Zavallo, D., Rius, S., Casati, P., Asurmendi, S., \& Alvarez, M. E. (2018). Immune receptor genes and pericentromeric transposons as targets of common epigenetic regulatory elements. The Plant Journal, 96(6), 1178- 1190. https://doi.org/10.1111/tpj.14098

Carneros, E., Yakovlev, I., Viejo, M., Olsen, J. E., \& Fossdal, C. G. (2017). The epigenetic memory of temperature during embryogenesis modifies the expression of bud burst-related genes in Norway spruce epitypes. Planta, 246(3), 553- 566. https://doi.org/10.1007/s00425-017-2713-9

Champigny, M. J., Unda, F., Skyba, O., Soolanayakanahally, R. Y., Mansfield, S. D., \& Campbell, M. M. (s. d.). Learning from methylomes: Epigenomic correlates of Populus balsamifera traits based on deep learning models of natural DNA methylation. Plant Biotechnology Journal, n/a(n/a). https://doi.org/10.1111/pbi.13299

Chang, S., Puryear, J., \& Cairney, J. (1993). A simple and efficient method for isolating RNA from pine trees. Plant Molecular Biology Reporter, 11(2), 113- 116. https://doi.org/10.1007/BF02670468

Chen, C., \& Chen, Z. (2002). Potentiation of Developmentally Regulated Plant Defense Response by AtWRKY18, a Pathogen-Induced Arabidopsis Transcription Factor. Plant Physiology, 129(2), 706716. https://doi.org/10.1104/pp.001057

Chen, G., Komatsuda, T., Ma, J. F., Li, C., Yamaji, N., \& Nevo, E. (2011). A functional cutin matrix is required for plant protection against water loss. Plant Signaling \& Behavior, 6(9), 1297- 1299. https://doi.org/10.4161/psb.6.9.17507

Cho, E. J., Choi, S. H., Kim, J. H., Kim, J. E., Lee, M. H., Chung, B. Y., Woo, H. R., \& Kim, J.-H. (2016). A Mutation in Plant-Specific SWI2/SNF2-Like Chromatin-Remodeling Proteins, DRD1 and DDM1, Delays Leaf Senescence in Arabidopsis thaliana. PLoS ONE, 11(1). https://doi.org/10.1371/journal.pone.0146826

Choat, B., Brodribb, T. J., Brodersen, C. R., Duursma, R. A., López, R., \& Medlyn, B. E. (2018). Triggers of tree mortality under drought. Nature, 558(7711), 531- 539. https://doi.org/10.1038/s41586018-0240-x

Chujo, T., Takai, R., Akimoto-Tomiyama, C., Ando, S., Minami, E., Nagamura, Y., Kaku, H., Shibuya, N., Yasuda, M., Nakashita, H., Umemura, K., Okada, A., Okada, K., Nojiri, H., \& Yamane, H. (2007). Involvement of the elicitor-induced gene OsWRKY53 in the expression of defense-related genes in rice. Biochimica et Biophysica Acta (BBA) - Gene Structure and Expression, 1769(7), 497505. https://doi.org/10.1016/j.bbaexp.2007.04.006

Chwialkowska, K., Nowakowska, U., Mroziewicz, A., Szarejko, I., \& Kwasniewski, M. (2016). Waterdeficiency conditions differently modulate the methylome of roots and leaves in barley (Hordeum vulgare L.). Journal of Experimental Botany, 67(4), 1109- 1121. https://doi.org/10.1093/jxb/erv552

Cochard, H., Casella, E., \& Mencuccini, M. (2007). Xylem vulnerability to cavitation varies among poplar and willow clones and correlates with yield. Tree Physiology, 27(12), 1761- 1767. https://doi.org/10.1093/treephys/27.12.1761

Cochard, H., Damour, G., Bodet, C., Tharwat, I., Poirier, M., \& Glio, T. (2005). Evaluation of a new centrifuge technique for rapid generation of xylem vulnerability curves. Physiologia Plantarum PHYSIOL PLANT, 124. https://doi.org/10.1111/j.1399-3054.2005.00526.x 
Manuscript in preparation

1159

1160

1161

1162

1163

1164

1165

1166

1167

1168

1169

1170

1171

1172

1173

1174

1175

1176

1177

1178

1179

1180

1181

1182

1183

1184

1185

1186

1187

1188

1189

1190

1191

1192

1193

1194

1195

1196

1197

1198

1199

1200

1201

1202

1203

1204

1205

1206

1207

1208

1209

1210

1211

1212

1213

Cohen, D., Bogeat-Triboulot, M.-B., Tisserant, E., Balzergue, S., Martin-Magniette, M.-L., Lelandais, G., Ningre, N., Renou, J.-P., Tamby, J.-P., Le Thiec, D., \& Hummel, I. (2010). Comparative transcriptomics of drought responses in Populus: A meta-analysis of genome-wide expression profiling in mature leaves and root apices across two genotypes. BMC Genomics, 11(1), 630. https://doi.org/10.1186/1471-2164-11-630

Coil, D., Jospin, G., \& Darling, A. E. (2015). A5-miseq: An updated pipeline to assemble microbial genomes from Illumina MiSeq data. Bioinformatics (Oxford, England), 31(4), 587- 589. https://doi.org/10.1093/bioinformatics/btu661

Colomé-Tatché, M., Cortijo, S., Wardenaar, R., Morgado, L., Lahouze, B., Sarazin, A., Etcheverry, M., Martin, A., Feng, S., Duvernois-Berthet, E., Labadie, K., Wincker, P., Jacobsen, S. E., Jansen, R. C., Colot, V., \& Johannes, F. (2012). Features of the Arabidopsis recombination landscape resulting from the combined loss of sequence variation and DNA methylation. Proceedings of the National Academy of Sciences, 109(40), 16240- 16245. https://doi.org/10.1073/pnas.1212955109

Conde, D., Le Gac, A.-L., Perales, M., Dervinis, C., Kirst, M., Maury, S., González-Melendi, P., \& Allona, I. (2017). Chilling-responsive DEMETER-LIKE DNA demethylase mediates in poplar bud break: Role of active DNA demethylase in trees' bud break. Plant, Cell \& Environment, 40(10), 22362249. https://doi.org/10.1111/pce.13019

Corem, S., Doron-Faigenboim, A., Jouffroy, O., Maumus, F., Arazi, T., \& Bouché, N. (2018). Redistribution of $\mathrm{CHH}$ Methylation and Small Interfering RNAs across the Genome of Tomato ddm1 Mutants. The Plant Cell, 30(7), 1628- 1644. https://doi.org/10.1105/tpc.18.00167

Correia, B., Pintó-Marijuan, M., Castro, B. B., Brossa, R., López-Carbonell, M., \& Pinto, G. (2014). Hormonal dynamics during recovery from drought in two Eucalyptus globulus genotypes: From root to leaf. Plant Physiology and Biochemistry, 82, 151- 160. https://doi.org/10.1016/j.plaphy.2014.05.016

Cortijo, S., Wardenaar, R., Colome-Tatche, M., Gilly, A., Etcheverry, M., Labadie, K., Caillieux, E., Hospital, F., Aury, J.-M., Wincker, P., Roudier, F., Jansen, R. C., Colot, V., \& Johannes, F. (2014). Mapping the Epigenetic Basis of Complex Traits. Science, 343(6175), 1145- 1148. https://doi.org/10.1126/science.1248127

Cotrozzi, L., Pellegrini, E., Guidi, L., Landi, M., Lorenzini, G., Massai, R., Remorini, D., Tonelli, M., Trivellini, A., Vernieri, P., \& Nali, C. (2017). Losing the Warning Signal : Drought Compromises the Cross-Talk of Signaling Molecules in Quercus ilex Exposed to Ozone. Frontiers in Plant Science, 8. https://doi.org/10.3389/fpls.2017.01020

Daviaud, C., Renault, V., Mauger, F., Deleuze, J.-F., \& Tost, J. (2018). Whole-Genome Bisulfite Sequencing Using the Ovation® Ultralow Methyl-Seq Protocol. Methods in Molecular Biology (Clifton, N.J.), 1708, 83- 104. https://doi.org/10.1007/978-1-4939-7481-8_5

Dong, X. (2004). NPR1, all things considered. Current Opinion in Plant Biology, 7(5), 547- 552. https://doi.org/10.1016/j.pbi.2004.07.005

Durand, M., Brendel, O., Buré, C., \& Le Thiec, D. (2019). Altered stomatal dynamics induced by changes in irradiance and vapour-pressure deficit under drought: Impacts on the whole plant transpiration efficiency of poplar genotypes. New Phytologist, 222. https://doi.org/10.1111/nph.15710

Dusotoit-Coucaud, A., Brunel, N., Tixier, A., Cochard, H., \& Herbette, S. (2014). Hydrolase treatments help unravel the function of intervessel pits in xylem hydraulics. Physiologia Plantarum, 150(3), 388- 396. https://doi.org/10.1111/ppl.12092

Farquhar, G. D., Ehleringer, J. R., \& Hubick, K. T. (1989). Carbon Isotope Discrimination and Photosynthesis. Annual Review of Plant Physiology and Plant Molecular Biology, 40(1), 503537. https://doi.org/10.1146/annurev.pp.40.060189.002443

Farquhar, G., O'Leary, M. H., \& Berry, J. (1982). On the Relationship Between Carbon Isotope Discrimination and the Intercellular Carbon Dioxide Concentration in Leaves. Australian Journal of Plant Physiology, 13, 281- 292. https://doi.org/10.1071/PP9820121

Feng, S., Jacobsen, S. E., \& Reik, W. (2010). Epigenetic Reprogramming in Plant and Animal Development. Science, 330(6004), 622- 627. https://doi.org/10.1126/science.1190614

Fernando, V. C. D., \& Schroeder, D. F. (2016). Role of ABA in Arabidopsis Salt, Drought, and Desiccation Tolerance. Abiotic and Biotic Stress in Plants - Recent Advances and Future Perspectives. https://doi.org/10.5772/61957 
Manuscript in preparation

1214

1215

1216

1217

1218

1219

1220

1221

1222

1223

1224

1225

1226

1227

1228

1229

1230

1231

1232

1233

1234

1235

1236

1237

1238

1239

1240

1241

1242

1243

1244

1245

1246

1247

1248

1249

1250

1251

1252

1253

1254

1255

1256

1257

1258

1259

1260

1261

1262

1263

1264

1265

1266

1267

1268

Fichot, R., Barigah, T. S., Chamaillard, S., Thiec, D. L., Laurans, F., Cochard, H., \& Brignolas, F. (2010). Common trade-offs between xylem resistance to cavitation and other physiological traits do not hold among unrelated Populus deltoides $\times$ Populus nigra hybrids. Plant, Cell \& Environment, 33(9), 1553- 1568. https://doi.org/10.1111/j.1365-3040.2010.02164.x

Fichot, R., Brignolas, F., Cochard, H., \& Ceulemans, R. (2015). Vulnerability to drought-induced cavitation in poplars: Synthesis and future opportunities. Plant, Cell \& Environment, 38(7), 1233- 1251. https://doi.org/10.1111/pce.12491

Forgione, I., Woloszynska, M., Pacenza, M., Chiappetta, A., Greco, M., Araniti, F., Abenavoli, M. R., Van Lijsebettens, M., Bitonti, M. B., \& Bruno, L. (2019). Hypomethylated drm1 drm2 cmt3 mutant phenotype of Arabidopsis thaliana is related to auxin pathway impairment. PLANT SCIENCE, 280, 383- 396. http://dx.doi.org/10.1016/j.plantsci.2018.12.029

Fujimoto, R., Sasaki, T., Inoue, H., \& Nishio, T. (2008). Hypomethylation and transcriptional reactivation of retrotransposon-like sequences in ddm1 transgenic plants of Brassica rapa. Plant Molecular Biology, 66(5), 463- 473. https://doi.org/10.1007/s11103-007-9285-1

Fujimoto, S. Y., Ohta, M., Usui, A., Shinshi, H., \& Ohme-Takagi, M. (2000). Arabidopsis EthyleneResponsive Element Binding Factors Act as Transcriptional Activators or Repressors of GCC Box-Mediated Gene Expression. The Plant Cell, 12(3), 393- 405.

Fultz, D., Choudury, S. G., \& Slotkin, R. K. (2015). Silencing of active transposable elements in plants. Current opinion in plant biology, 27, 67- 76. https://doi.org/10.1016/j.pbi.2015.05.027

Furci, L., Jain, R., Stassen, J., Berkowitz, O., Whelan, J., Roquis, D., Baillet, V., Colot, V., Johannes, F., \& Ton, J. (2019). Identification and characterisation of hypomethylated DNA loci controlling quantitative resistance in Arabidopsis. ELife, 8, e40655. https://doi.org/10.7554/eLife.40655

Gagnot, S., Tamby, J.-P., Martin-Magniette, M.-L., Bitton, F., Taconnat, L., Balzergue, S., Aubourg, S., Renou, J.-P., Lecharny, A., \& Brunaud, V. (2008). CATdb: A public access to Arabidopsis transcriptome data from the URGV-CATMA platform. Nucleic Acids Research, 36(Database issue), D986-990. https://doi.org/10.1093/nar/gkm757

Gaillochet, C., \& Lohmann, J. U. (2015). The never-ending story: From pluripotency to plant developmental plasticity. Development (Cambridge, England), 142(13), 2237- 2249. https://doi.org/10.1242/dev.117614

Garg, R., Narayana Chevala, V., Shankar, R., \& Jain, M. (2015). Divergent DNA methylation patterns associated with gene expression in rice cultivars with contrasting drought and salinity stress response. Scientific Reports, 5. https://doi.org/10.1038/srep14922

Gebreselassie, M. N., Ader, K., Boizot, N., Millier, F., Charpentier, J.-P., Alves, A., Simões, R., Rodrigues, J. C., Bodineau, G., Fabbrini, F., Sabatti, M., Bastien, C., \& Segura, V. (2017). Near-infrared spectroscopy enables the genetic analysis of chemical properties in a large set of wood samples from Populus nigra (L.) natural populations. Industrial Crops and Products, 107, 159- 171. https://doi.org/10.1016/j.indcrop.2017.05.013

Gendrel, A.-V., Lippman, Z., Yordan, C., Colot, V., \& Martienssen, R. A. (2002). Dependence of Heterochromatic Histone H3 Methylation Patterns on the Arabidopsis Gene DDM1. Science, 297(5588), 1871- 1873. https://doi.org/10.1126/science.1074950

Gömöry, D., Hrivnák, M., Krajmerova, D., \& Longauer, R. (2017). Epigenetic memory effects in forest trees: A victory of "Michurinian biology? Central European Forestry Journal, 63. https://doi.org/10.1515/forj-2017-0024

Gourcilleau, D., Bogeat-Triboulot, M.-B., Le Thiec, D., Lafon-Placette, C., Delaunay, A., El-Soud, W. A., Brignolas, F., \& Maury, S. (2010). DNA methylation and histone acetylation: Genotypic variations in hybrid poplars, impact of water deficit and relationships with productivity. Annals of Forest Science, 67(2), 208.

Grandbastien, M.-A. (1998). Activation of plant retrotransposons under stress conditions. Trends in Plant Science, 3(5), 181- 187. https://doi.org/10.1016/S1360-1385(98)01232-1

Guo, Y., Ping, W., Chen, J., Zhu, L., Zhao, Y., Guo, J., \& Huang, Y. (2019). Meta-analysis of the effects of overexpression of WRKY transcription factors on plant responses to drought stress. BMC Genetics, 20(1), 63. https://doi.org/10.1186/s12863-019-0766-4

Ha, S., Vankova, R., Yamaguchi-Shinozaki, K., Shinozaki, K., \& Tran, L.-S. P. (2012). Cytokinins: Metabolism and function in plant adaptation to environmental stresses. Trends in Plant Science, 17(3), 172- 179. https://doi.org/10.1016/j.tplants.2011.12.005 
Manuscript in preparation

1269

1270

1271

1272

1273

1274

1275

1276

1277

1278

1279

1280

1281

1282

1283

1284

1285

1286

1287

1288

1289

1290

1291

1292

1293

1294

1295

1296

1297

1298

1299

1300

1301

1302

1303

1304

1305

1306

1307

1308

1309

1310

1311

1312

1313

1314

1315

1316

1317

1318

1319

1320

1321

1322

1323

1324

Hamanishi, E. T., Thomas, B. R., \& Campbell, M. M. (2012). Drought induces alterations in the stomatal development program in Populus. Journal of Experimental Botany, 63(13), 4959- 4971. https://doi.org/10.1093/jxb/ers177

Havlová, M., Dobrev, P. I., Motyka, V., Štorchová, H., Libus, J., Dobrá, J., Malbeck, J., Gaudinová, A., \& Vanková, R. (2008). The role of cytokinins in responses to water deficit in tobacco plants overexpressing trans-zeatin O-glucosyltransferase gene under 35S or SAG12 promoters. Plant, Cell \& Environment, 31(3), 341- 353. https://doi.org/10.1111/j.1365-3040.2007.01766.x

He, G.-H., Xu, J.-Y., Wang, Y.-X., Liu, J.-M., Li, P.-S., Chen, M., Ma, Y.-Z., \& Xu, Z.-S. (2016). Droughtresponsive WRKY transcription factor genes TaWRKY1 and TaWRKY33 from wheat confer drought and/or heat resistance in Arabidopsis. BMC Plant Biology, 16. https://doi.org/10.1186/s12870-016-0806-4

Herbette, S., Bouchet, B., Brunel, N., Bonnin, E., Cochard, H., \& Guillon, F. (2015). Immunolabelling of intervessel pits for polysaccharides and lignin helps in understanding their hydraulic properties in Populus tremula $\times$ alba. Annals of Botany, 115(2), 187- 199. https://doi.org/10.1093/aob/mcu232

Heyman, J., Canher, B., Bisht, A., Christiaens, F., \& De Veylder, L. (2018). Emerging role of the plant ERF transcription factors in coordinating wound defense responses and repair. Journal of Cell Science, 131(2). https://doi.org/10.1242/jcs.208215

Higo, H., Tahir, M., Takashima, K., Miura, A., Watanabe, K., Tagiri, A., Ugaki, M., Ishikawa, R., Eiguchi, M., Kurata, N., Sasaki, T., Richards, E., Takano, M., Kishimoto, N., Kakutani, T., \& Habu, Y. (2012). DDM1 (Decrease in DNA Methylation) genes in rice (Oryza sativa). Molecular Genetics and Genomics, 287(10), 785- 792. https://doi.org/10.1007/s00438-012-0717-5

Hirsch, C. D., \& Springer, N. M. (2017). Transposable element influences on gene expression in plants. Biochimica et Biophysica Acta - Gene Regulatory Mechanisms, 1860(1), 157- 165. https://doi.org/10.1016/j.bbagrm.2016.05.010

Hoffmann, S., Otto, C., Doose, G., Tanzer, A., Langenberger, D., Christ, S., Kunz, M., Holdt, L. M., Teupser, D., Hackermüller, J., \& Stadler, P. F. (2014). A multi-split mapping algorithm for circular RNA, splicing, trans-splicing and fusion detection. Genome Biology, 15(2), R34. https://doi.org/10.1186/gb-2014-15-2-r34

Ikeda, Y., \& Nishimura, T. (2015). The role of DNA methylation in transposable element silencing and genomic imprinting. Nuclear Functions in Plant Transcription, Signaling and Development, 1329. https://doi.org/10.1007/978-1-4939-2386-1_2

Ito, T., Tarutani, Y., To, T. K., Kassam, M., Duvernois-Berthet, E., Cortijo, S., Takashima, K., Saze, H., Toyoda, A., Fujiyama, A., \& others. (2015). Genome-wide negative feedback drives transgenerational DNA methylation dynamics in Arabidopsis. PLoS Genet, 11(4), e1005154.

Jansson, S., \& Douglas, C. J. (2007). Populus : A Model System for Plant Biology. Annual Review of Plant Biology, 58(1), 435- 458. https://doi.org/10.1146/annurev.arplant.58.032806.103956

Jeddeloh, J. A., Bender, J., \& Richards, E. J. (1998). The DNA methylation locusDDM1 is required for maintenance of gene silencing in Arabidopsis. Genes \& Development, 12(11), 1714-1725.

Jiang, Y., Guo, L., Ma, X., Zhao, X., Jiao, B., Li, C., \& Luo, K. (2017). The WRKY transcription factors PtrWRKY18 and PtrWRKY35 promote Melampsora resistance in Populus. Tree Physiology, 37(5), 665- 675. https://doi.org/10.1093/treephys/tpx008

Johannes, F., Porcher, E., Teixeira, F. K., Saliba-Colombani, V., Simon, M., Agier, N., Bulski, A., Albuisson, J., Heredia, F., Audigier, P., Bouchez, D., Dillmann, C., Guerche, P., Hospital, F., \& Colot, V. (2009). Assessing the Impact of Transgenerational Epigenetic Variation on Complex Traits. PLOS Genetics, 5(6), e1000530. https://doi.org/10.1371/journal.pgen.1000530

Kakutani, T. (1997). Genetic characterization of late-flowering traits induced by DNA hypomethylation mutation in Arabidopsis thaliana. The Plant Journal, 12(6), 1447- 1451. https://doi.org/10.1046/j.1365-313x.1997.12061447.x

Kakutani, T., Jeddeloh, J. A., \& Richards, E. J. (1995). Characterization of an Arabidopsis thaliana DNA hypomethylation mutant. Nucleic acids research, 23(1), 130-137.

Karan, R., DeLeon, T., Biradar, H., \& Subudhi, P. K. (2012). Salt Stress Induced Variation in DNA Methylation Pattern and Its Influence on Gene Expression in Contrasting Rice Genotypes. PLoS ONE, 7(6). https://doi.org/10.1371/journal.pone.0040203

Kawakatsu, T., \& Ecker, J. R. (2019). Diversity and dynamics of DNA methylation : Epigenomic resources and tools for crop breeding. Breeding Science, 69(2), 191- 204. https://doi.org/10.1270/jsbbs. 19005 
Manuscript in preparation

Kawakatsu, T., Huang, S. C., Jupe, F., Sasaki, E., Schmitz, R. J., Urich, M. A., Castanon, R., Nery, J. R., Barragan, C., He, Y., Chen, H., Dubin, M., Lee, C.-R., Wang, C., Bemm, F., Becker, C., O'Neil, R., O'Malley, R. C., Quarless, D. X., ... Zhou, X. (2016). Epigenomic Diversity in a Global Collection of Arabidopsis thaliana Accessions. Cell, 166(2), 492- 505. https://doi.org/10.1016/j.cell.2016.06.044

Kawanabe, T., Ishikura, S., Miyaji, N., Sasaki, T., Wu, L. M., Itabashi, E., Takada, S., Shimizu, M., Takasaki-Yasuda, T., Osabe, K., Peacock, W. J., Dennis, E. S., \& Fujimoto, R. (2016). Role of DNA methylation in hybrid vigor in Arabidopsis thaliana. Proceedings of the National Academy of Sciences, 113(43), E6704- E6711. https://doi.org/10.1073/pnas.1613372113

Kejnovsky, E., Hawkins, J. S., \& Feschotte, C. (2012). Plant Transposable Elements: Biology and Evolution. In J. F. Wendel, J. Greilhuber, J. Dolezel, \& I. J. Leitch (Éd.), Plant Genome Diversity Volume 1 (p. 17- 34). Springer Vienna. https://doi.org/10.1007/978-3-7091-1130-7_2

Koo, A. J., Thireault, C., Zemelis, S., Poudel, A. N., Zhang, T., Kitaoka, N., Brandizzi, F., Matsuura, H., \& Howe, G. A. (2014). Endoplasmic reticulum-associated inactivation of the hormone jasmonoyl-Lisoleucine by multiple members of the cytochrome P450 94 family in Arabidopsis. The Journal of Biological Chemistry, 289(43), 29728- 29738. https://doi.org/10.1074/jbc.M114.603084

Kooke, R., Johannes, F., Wardenaar, R., Becker, F., Etcheverry, M., Colot, V., Vreugdenhil, D., \& Keurentjes, J. J. B. (2015). Epigenetic Basis of Morphological Variation and Phenotypic Plasticity in Arabidopsis thaliana. The Plant Cell Online, 27(2), 337- 348. https://doi.org/10.1105/tpc.114.133025

Kopylova, E., Noé, L., \& Touzet, H. (2012). SortMeRNA : Fast and accurate filtering of ribosomal RNAs in metatranscriptomic data. Bioinformatics (Oxford, England), 28(24), 3211- 3217. https://doi.org/10.1093/bioinformatics/bts611

Krueger, F., \& Andrews, S. R. (2011). Bismark: A flexible aligner and methylation caller for Bisulfite-Seq applications. Bioinformatics, 27(11), 1571- 1572. https://doi.org/10.1093/bioinformatics/btr167

Lafon-Placette, C., Faivre-Rampant, P., Delaunay, A., Street, N., Brignolas, F., \& Maury, S. (2013). Methylome of DNase I sensitive chromatin in Populus trichocarpa shoot apical meristematic cells: A simplified approach revealing characteristics of gene-body DNA methylation in open chromatin state. New Phytologist, 197(2), 416- 430. https://doi.org/10.1111/nph.12026

Lafon-Placette, C., Le Gac, A.-L., Chauveau, D., Segura, V., Delaunay, A., Lesage-Descauses, M.-C., Hummel, I., Cohen, D., Jesson, B., Le Thiec, D., Bogeat-Triboulot, M.-B., Brignolas, F., \& Maury, S. (2018). Changes in the epigenome and transcriptome of the poplar shoot apical meristem in response to water availability affect preferentially hormone pathways. Journal of Experimental Botany, 69(3), 537- 551. https://doi.org/10.1093/jxb/erx409

Lanciano, S., Carpentier, M.-C., Llauro, C., Jobet, E., Robakowska-Hyzorek, D., Lasserre, E., Ghesquière, A., Panaud, O., \& Mirouze, M. (2017). Sequencing the extrachromosomal circular mobilome reveals retrotransposon activity in plants. PLOS Genetics, 13(2). https://doi.org/10.1371/journal.pgen.1006630

Langmead, B., Trapnell, C., Pop, M., \& Salzberg, S. L. (2009). Ultrafast and memory-efficient alignment of short DNA sequences to the human genome. Genome Biology, 10(3), R25. https://doi.org/10.1186/gb-2009-10-3-r25

Latzel, V., Allan, E., Bortolini Silveira, A., Colot, V., Fischer, M., \& Bossdorf, O. (2013). Epigenetic diversity increases the productivity and stability of plant populations. Nature Communications, 4. https://doi.org/10.1038/ncomms3875

Latzel, V., Zhang, Y., Karlsson Moritz, K., Fischer, M., \& Bossdorf, O. (2012). Epigenetic variation in plant responses to defence hormones. Annals of Botany, 110(7), 1423- 1428. https://doi.org/10.1093/aob/mcs088

Le Gac, A.-L., Lafon-Placette, C., Chauveau, D., Segura, V., Delaunay, A., Fichot, R., Marron, N., Le Jan, I., Berthelot, A., Bodineau, G., Bastien, J.-C., Brignolas, F., \& Maury, S. (2018). Winter-dormant shoot apical meristem in poplar trees shows environmental epigenetic memory. Journal of Experimental Botany, 69(20), 4821- 4837. https://doi.org/10.1093/jxb/ery271

Le Gac, A.-L., Lafon-Placette, C., Delaunay, A., \& Maury, S. (2019). Developmental, genetic and environmental variations of global DNA methylation in the first leaves emerging from the shoot apical meristem in poplar trees. Plant Signaling \& Behavior, 14. https://doi.org/10.1080/15592324.2019.1596717 
Manuscript in preparation

1380

1381

1382

1383

1384

1385

1386

1387

1388

1389

1390

1391

1392

1393

1394

1395

1396

1397

1398

1399

1400

1401

1402

1403

1404

1405

1406

1407

1408

1409

1410

1411

1412

1413

1414

1415

1416

1417

1418

1419

1420

1421

1422

1423

1424

1425

1426

1427

1428

1429

1430

1431

1432

1433

1434

Lee, S.-I., \& Kim, N.-S. (2014). Transposable Elements and Genome Size Variations in Plants. Genomics \& Informatics, 12(3), 87. https://doi.org/10.5808/GI.2014.12.3.87

Li, J., Brader, G., \& Palva, E. T. (2004). The WRKY70 Transcription Factor: A Node of Convergence for Jasmonate-Mediated and Salicylate-Mediated Signals in Plant Defense. The Plant Cell, 16(2), 319- 331. https://doi.org/10.1105/tpc. 016980

Li, Q., Eichten, S. R., Hermanson, P. J., \& Springer, N. M. (2014). Inheritance Patterns and Stability of DNA Methylation Variation in Maize Near-Isogenic Lines. Genetics, 196(3), 667- 676. https://doi.org/10.1534/genetics.113.158980

Liang, D., Zhang, Z., Wu, H., Huang, C., Shuai, P., Ye, C.-Y., Tang, S., Wang, Y., Yang, L., \& Wang, J. (2014). Single-base-resolution methylomes of Populus trichocarpa reveal the association between DNA methylation and drought stress. BMC genetics, 15, S9.

Li-Marchetti, C., Le Bras, C., Relion, D., Citerne, S., Huché-Thélier, L., Sakr, S., Morel, P., \& Crespel, L. (2015). Genotypic differences in architectural and physiological responses to water restriction in rose bush. Frontiers in Plant Science, 6. https://doi.org/10.3389/fpls.2015.00355

Lippman, Z., Gendrel, A.-V., Black, M., Vaughn, M. W., Dedhia, N., Richard McCombie, W., Lavine, K., Mittal, V., May, B., Kasschau, K. D., Carrington, J. C., Doerge, R. W., Colot, V., \& Martienssen, R. (2004). Role of transposable elements in heterochromatin and epigenetic control. Nature, 430(6998), 471- 476. https://doi.org/10.1038/nature02651

Lisch, D. (2012). How important are transposons for plant evolution? Nature Reviews Genetics, 14(1), 4961. https://doi.org/10.1038/nrg3374

Liu, G., Ji, Y., Bhuiyan, N. H., Pilot, G., Selvaraj, G., Zou, J., \& Wei, Y. (2010). Amino acid homeostasis modulates salicylic acid-associated redox status and defense responses in Arabidopsis. The Plant Cell, 22(11), 3845- 3863. https://doi.org/10.1105/tpc.110.079392

Long, J. C., Xia, A. A., Liu, J. H., Jing, J. L., Wang, Y. Z., Qi, C. Y., \& He, Y. (2019). Decrease in DNA methylation 1 (DDM1) is required for the formation of $\mathrm{mCHH}$ islands in maize. Journal of Integrative Plant Biology, 61(6), 749- 764. https://doi.org/10.1111/jipb.12733

López Sánchez, A., Stassen, J. H. M., Furci, L., Smith, L. M., \& Ton, J. (2016). The role of DNA (de)methylation in immune responsiveness of Arabidopsis. The Plant Journal, 88(3), 361- 374. https://doi.org/10.1111/tpj.13252

Lorrain, S., Vailleau, F., Balagué, C., \& Roby, D. (2003). Lesion mimic mutants : Keys for deciphering cell death and defense pathways in plants? Trends in Plant Science, 8(6), 263- 271. https://doi.org/10.1016/S1360-1385(03)00108-0

Makarevitch, I., Waters, A. J., West, P. T., Stitzer, M., Hirsch, C. N., Ross-lbarra, J., \& Springer, N. M. (2015). Transposable Elements Contribute to Activation of Maize Genes in Response to Abiotic Stress. PLoS Genetics, 11(1). https://doi.org/10.1371/journal.pgen.1004915

Maor, G. L., Yearim, A., \& Ast, G. (2015). The alternative role of DNA methylation in splicing regulation. Trends in Genetics, 31(5), 274- 280. https://doi.org/10.1016/j.tig.2015.03.002

Marcel, S., Sawers, R., Oakeley, E., Angliker, H., \& Paszkowski, U. (2010). Tissue-Adapted Invasion Strategies of the Rice Blast Fungus Magnaporthe oryzae[W]. The Plant Cell, 22(9), 3177- 3187. https://doi.org/10.1105/tpc.110.078048

Mauch-Mani, B., Baccelli, I., Luna, E., \& Flors, V. (2017). Defense Priming: An Adaptive Part of Induced Resistance. Annual Review of Plant Biology, 68(1), 485- 512. https://doi.org/10.1146/annurevarplant-042916-041132

Maury, S., Sow, M. D., Le Gac, A.-L., Genitoni, J., Lafon-Placette, C., \& Mozgova, I. (2019). Phytohormone and Chromatin Crosstalk: The Missing Link For Developmental Plasticity? Frontiers in Plant Science, 10. https://doi.org/10.3389/fpls.2019.00395

McCarthy, D. J., Chen, Y., \& Smyth, G. K. (2012). Differential expression analysis of multifactor RNA-Seq experiments with respect to biological variation. Nucleic Acids Research, 40(10), 4288- 4297. https://doi.org/10.1093/nar/gks042

McDowell, N., Pockman, W. T., Allen, C. D., Breshears, D. D., Cobb, N., Kolb, T., Plaut, J., Sperry, J., West, A., Williams, D. G., \& Yepez, E. A. (2008). Mechanisms of plant survival and mortality during drought: Why do some plants survive while others succumb to drought? New Phytologist, 178(4), 719- 739. https://doi.org/10.1111/j.1469-8137.2008.02436.x

Meyer, P. (2015). Epigenetic variation and environmental change : Fig. 1. Journal of Experimental Botany, 66(12), 3541- 3548. https://doi.org/10.1093/jxb/eru502 
Manuscript in preparation

1435

1436

1437

1438

1439

1440

1441

1442

1443

1444

1445

1446

1447

1448

1449

1450

1451

1452

1453

1454

1455

1456

1457

1458

1459

1460

1461

1462

1463

1464

1465

1466

1467

1468

1469

1470

1471

1472

1473

1474

1475

1476

1477

1478

1479

1480

1481

1482

1483

1484

1485

1486

1487

1488

1489

Mirouze, M., \& Paszkowski, J. (2011). Epigenetic contribution to stress adaptation in plants. Current Opinion in Plant Biology, 14(3), 267- 274. https://doi.org/10.1016/j.pbi.2011.03.004

Mirouze, M., Reinders, J., Bucher, E., Nishimura, T., Schneeberger, K., Ossowski, S., Cao, J., Weigel, D., Paszkowski, J., \& Mathieu, O. (2009). Selective epigenetic control of retrotransposition in Arabidopsis. Nature, 461(7262), 427- 430. https://doi.org/10.1038/nature08328

Miura, A., Yonebayashi, S., Watanabe, K., Toyama, T., Shimada, H., \& Kakutani, T. (2001). Mobilization of transposons by a mutation abolishing full DNA methylation in Arabidopsis. Nature, 411(6834), 212- 214. https://doi.org/10.1038/35075612

Mofatto, L. S., Carneiro, F. de A., Vieira, N. G., Duarte, K. E., Vidal, R. O., Alekcevetch, J. C., Cotta, M. G., Verdeil, J.-L., Lapeyre-Montes, F., Lartaud, M., Leroy, T., De Bellis, F., Pot, D., Rodrigues, G. C., Carazzolle, M. F., Pereira, G. A. G., Andrade, A. C., \& Marraccini, P. (2016). Identification of candidate genes for drought tolerance in coffee by high-throughput sequencing in the shoot apex of different Coffea arabica cultivars. BMC Plant Biology, 16. https://doi.org/10.1186/s12870-0160777-5

Monclus, R., Dreyer, E., Villar, M., Delmotte, F. M., Delay, D., Petit, J.-M., Barbaroux, C., Le Thiec, D., Bréchet, C., \& Brignolas, F. (2006). Impact of drought on productivity and water use efficiency in 29 genotypes of Populus deltoides×Populus nigra. New Phytologist, 169(4), 765- 777. https://doi.org/10.1111/j.1469-8137.2005.01630.x

Munné-Bosch, S., \& Peñuelas, J. (2003). Photo- and antioxidative protection, and a role for salicylic acid during drought and recovery in field-grown Phillyrea angustifolia plants. Planta, 217(5), 758- 766. https://doi.org/10.1007/s00425-003-1037-0

Nicotra, A.B., Atkin, O. K., Bonser, S. P., Davidson, A. M., Finnegan, E. J., Mathesius, U., Poot, P., Purugganan, M. D., Richards, C. L., Valladares, F., \& van Kleunen, M. (2010). Plant phenotypic plasticity in a changing climate. Trends in Plant Science, 15(12), 684- 692. https://doi.org/10.1016/j.tplants.2010.09.008

Nicotra, Adrienne B., Segal, D. L., Hoyle, G. L., Schrey, A. W., Verhoeven, K. J. F., \& Richards, C. L. (2015). Adaptive plasticity and epigenetic variation in response to warming in an Alpine plant. Ecology and Evolution, 5(3), 634- 647. https://doi.org/10.1002/ece3.1329

Niederhuth, C. E., \& Schmitz, R. J. (2017). Putting DNA methylation in context: From genomes to gene expression in plants. Biochimica et Biophysica Acta (BBA) - Gene Regulatory Mechanisms, 1860(1), 149- 156. https://doi.org/10.1016/j.bbagrm.2016.08.009

Nishiyama, R., Watanabe, Y., Fujita, Y., Le, D. T., Kojima, M., Werner, T., Vankova, R., YamaguchiShinozaki, K., Shinozaki, K., Kakimoto, T., Sakakibara, H., Schmülling, T., \& Tran, L.-S. P. (2011). Analysis of cytokinin mutants and regulation of cytokinin metabolic genes reveals important regulatory roles of cytokinins in drought, salt and abscisic acid responses, and abscisic acid biosynthesis. The Plant Cell, 23(6), 2169- 2183. https://doi.org/10.1105/tpc.111.087395

Ojolo, S. P., Cao, S., Priyadarshani, S. V. G. N., Li, W., Yan, M., Aslam, M., Zhao, H., \& Qin, Y. (2018). Regulation of Plant Growth and Development: A Review From a Chromatin Remodeling Perspective. Frontiers in Plant Science, 9. https://doi.org/10.3389/fpls.2018.01232

Ong-Abdullah, M., Ordway, J. M., Jiang, N., Ooi, S.-E., Kok, S.-Y., Sarpan, N., Azimi, N., Hashim, A. T., Ishak, Z., Rosli, S. K., Malike, F. A., Bakar, N. A. A., Marjuni, M., Abdullah, N., Yaakub, Z., Amiruddin, M. D., Nookiah, R., Singh, R., Low, E.-T. L., ... Martienssen, R. A. (2015). Loss of Karma transposon methylation underlies the mantled somaclonal variant of oil palm. Nature, 525(7570), 533- 537. https://doi.org/10.1038/nature15365

Oshima, Y., \& Mitsuda, N. (2013). The MIXTA-like Transcription factor MYB16 is a major regulator of cuticle formation in vegetative organs. Plant Signaling \& Behavior, $8(11)$. https://doi.org/10.4161/psb.26826

Oshima, Y., \& Mitsuda, N. (2016). Enhanced cuticle accumulation by employing MIXTA-like transcription factors. Plant Biotechnology, 33, 161- 168. https://doi.org/10.5511/plantbiotechnology.16.0627a

Pandey, S., \& Chakraborty, D. (2015). Salicylic Acid and Drought Stress Response: Biochemical to Molecular Crosstalk. In B. N. Tripathi \& M. Müller (Éd.), Stress Responses in Plants : Mechanisms of Toxicity and Tolerance (p. 247- 265). Springer International Publishing. https://doi.org/10.1007/978-3-319-13368-3_10

Pandey, S. P., Srivastava, S., Goel, R., Lakhwani, D., Singh, P., Asif, M. H., \& Sane, A. P. (2017). Simulated herbivory in chickpea causes rapid changes in defense pathways and hormonal 
Manuscript in preparation

1490

1491

1492

1493

1494

1495

1496

1497

1498

1499

1500

1501

1502

1503

1504

1505

1506

1507

1508

1509

1510

1511

1512

1513

1514

1515

1516

1517

1518

1519

1520

1521

1522

1523

1524

1525

1526

1527

1528

1529

1530

1531

1532

1533

1534

1535

1536

1537

1538

1539

1540

1541

1542

1543 transcription networks of JA/ethylene/GA/auxin within minutes of wounding. Scientific Reports, 7(1), 1- 14. https://doi.org/10.1038/srep44729

Plavcová, L., \& Hacke, U. G. (2011). Heterogeneous distribution of pectin epitopes and calcium in different pit types of four angiosperm species. New Phytologist, 192(4), 885- 897. https://doi.org/10.1111/j.1469-8137.2011.03842.x

Plomion, C., Bastien, C., Bogeat-Triboulot, M.-B., Bouffier, L., Déjardin, A., Duplessis, S., Fady, B., Heuertz, M., Le Gac, A.-L., Le Provost, G., Legué, V., Lelu-Walter, M.-A., Leplé, J.-C., Maury, S., Morel, A., Oddou-Muratorio, S., Pilate, G., Sanchez, L., Scotti, I., ... Vacher, C. (2016). Forest tree genomics: 10 achievements from the past 10 years and future prospects. Annals of Forest Science, 73(1), 77- 103. https://doi.org/10.1007/s13595-015-0488-3

Quadrana, L., \& Colot, V. (2016). Plant Transgenerational Epigenetics. Annual Review of Genetics, 50, 467- 491. https://doi.org/10.1146/annurev-genet-120215-035254

Quadrana, L., Etcheverry, M., Gilly, A., Caillieux, E., Madoui, M.-A., Guy, J., Bortolini Silveira, A., Engelen, S., Baillet, V., Wincker, P., Aury, J.-M., \& Colot, V. (2019). Transposition favors the generation of large effect mutations that may facilitate rapid adaption. Nature Communications, 10(1), 1- 10. https://doi.org/10.1038/s41467-019-11385-5

Qüesta, J. I., Fina, J. P., \& Casati, P. (2013). DDM1 and ROS1 have a role in UV-B induced- and oxidative DNA damage in A. thaliana. Frontiers in Plant Science, 4. https://doi.org/10.3389/fpls.2013.00420

Raj, S., Bräutigam, K., Hamanishi, E. T., Wilkins, O., Thomas, B. R., Schroeder, W., Mansfield, S. D., Plant, A. L., \& Campbell, M. M. (2011). Clone history shapes Populus drought responses. Proceedings of the National Academy of Sciences, 108(30), 12521-12526.

Raju, S. K. K., Shao, M.-R., Sanchez, R., Xu, Y.-Z., Sandhu, A., Graef, G., \& Mackenzie, S. (2018). An epigenetic breeding system in soybean for increased yield and stability. Plant Biotechnology Journal, 16(11), 1836- 1847. https://doi.org/10.1111/pbi.12919

Reinders, J., Wulff, B. B. H., Mirouze, M., Marí-Ordóñez, A., Dapp, M., Rozhon, W., Bucher, E., Theiler, G., \& Paszkowski, J. (2009). Compromised stability of DNA methylation and transposon immobilization in mosaic Arabidopsis epigenomes. Genes \& Development, 23(8), 939- 950. https://doi.org/10.1101/gad.524609

Richards, C. L., Alonso, C., Becker, C., Bossdorf, O., Bucher, E., Colomé-Tatché, M., Durka, W., Engelhardt, J., Gaspar, B., Gogol-Döring, A., Grosse, I., van Gurp, T. P., Heer, K., Kronholm, I., Lampei, C., Latzel, V., Mirouze, M., Opgenoorth, L., Paun, O., ... Verhoeven, K. J. F. (2017). Ecological plant epigenetics : Evidence from model and non-model species, and the way forward. Ecology Letters, 20(12), 1576- 1590. https://doi.org/10.1111/ele.12858

Rigaill, G., Balzergue, S., Brunaud, V., Blondet, E., Rau, A., Rogier, O., Caius, J., Maugis-Rabusseau, C., Soubigou-Taconnat, L., Aubourg, S., Lurin, C., Martin-Magniette, M.-L., \& Delannoy, E. (2018). Synthetic data sets for the identification of key ingredients for RNA-seq differential analysis. Briefings in Bioinformatics, 19(1), 65- 76. https://doi.org/10.1093/bib/bbw092

Roux, B., Rodde, N., Jardinaud, M.-F., Timmers, T., Sauviac, L., Cottret, L., Carrère, S., Sallet, E., Courcelle, E., Moreau, S., Debellé, F., Capela, D., de Carvalho-Niebel, F., Gouzy, J., Bruand, C., \& Gamas, P. (2014). An integrated analysis of plant and bacterial gene expression in symbiotic root nodules using laser-capture microdissection coupled to RNA sequencing. The Plant Journal: For Cell and Molecular Biology, 77(6), 817- 837. https://doi.org/10.1111/tpj.12442

Roux, F., Colomé-Tatché, M., Edelist, C., Wardenaar, R., Guerche, P., Hospital, F., Colot, V., Jansen, R. C., \& Johannes, F. (2011). Genome-Wide Epigenetic Perturbation Jump-Starts Patterns of Heritable Variation Found in Nature. Genetics, 188(4), 1015- 1017. https://doi.org/10.1534/genetics.111.128744

Russo, V. E. A., Riggs, A. D., \& Martienssen, R. A. (1996). Epigenetic mechanisms of gene regulation. Cold Spring Harbour, NY: Cold Spring Harbour Laboratory Press. https://trove.nla.gov.au/version/27736760

Sasaki, T., Kobayashi, A., Saze, H., \& Kakutani, T. (2012). RNAi-independent de novo DNA methylation revealed in Arabidopsis mutants of chromatin remodeling gene DDM1. The Plant Journal, 70(5), 750- 758. https://doi.org/10.1111/j.1365-313X.2012.04911.x

Saze, H., \& Kakutani, T. (2007). Heritable epigenetic mutation of a transposon-flanked Arabidopsis gene due to lack of the chromatin-remodeling factor DDM1. The EMBO Journal, 26(15), 3641-3652. 
Manuscript in preparation

1544

1545

1546

1547

1548

1549

1550

1551

1552

1553

1554

1555

1556

1557

1558

1559

1560

1561

1562

1563

1564

1565

1566

1567

1568

1569

1570

1571

1572

1573

1574

1575

1576

1577

1578

1579

1580

1581

1582

1583

1584

1585

1586

1587

1588

1589

1590

1591

1592

1593

1594

1595

1596

1597

1598

1599

Schmid, M. W., Giraldo-Fonseca, A., Rövekamp, M., Smetanin, D., Bowman, J. L., \& Grossniklaus, U. (2018). Extensive epigenetic reprogramming during the life cycle of Marchantia polymorpha. Genome Biology, 19(1). https://doi.org/10.1186/s13059-017-1383-z

Schmittgen, T. D., \& Livak, K. J. (2008). Analyzing real-time PCR data by the comparative C(T) method. Nature Protocols, 3(6), 1101- 1108. https://doi.org/10.1038/nprot.2008.73

Schneider, C. A., Rasband, W. S., \& Eliceiri, K. W. (2012). NIH Image to ImageJ : 25 years of image analysis. Nature Methods, 9(7), 671- 675. https://doi.org/10.1038/nmeth.2089

Sedaghat, M., Tahmasebi-Sarvestani, Z., Emam, Y., \& Mokhtassi-Bidgoli, A. (2017). Physiological and antioxidant responses of winter wheat cultivars to strigolactone and salicylic acid in drought. Plant Physiology and Biochemistry, 119, 59- 69. https://doi.org/10.1016/j.plaphy.2017.08.015

Seymour, D. K., \& Becker, C. (2017). The causes and consequences of DNA methylome variation in plants. Current Opinion in Plant Biology, 36, 56- 63. https://doi.org/10.1016/j.pbi.2017.01.005

Shi, H., Chen, L., Ye, T., Liu, X., Ding, K., \& Chan, Z. (2014). Modulation of auxin content in Arabidopsis confers improved drought stress resistance. Plant Physiology and Biochemistry, 82, 209- 217. https://doi.org/10.1016/j.plaphy.2014.06.008

Slotkin, R. K., \& Martienssen, R. (2007). Transposable elements and the epigenetic regulation of the genome. Nature Reviews. Genetics, 8(4), 272- 285. https://doi.org/10.1038/nrg2072

Solano, R., Stepanova, A., Chao, Q., \& Ecker, J. R. (1998). Nuclear events in ethylene signaling: A transcriptional cascade mediated by ETHYLENE-INSENSITIVE3 and ETHYLENE-RESPONSEFACTOR1. Genes \& Development, 12(23), 3703- 3714.

Song, J. T., Lu, H., McDowell, J. M., \& Greenberg, J. T. (2004). A key role for ALD1 in activation of local and systemic defenses in Arabidopsis. The Plant Journal, 40(2), 200- 212. https://doi.org/10.1111/j.1365-313X.2004.02200.x

Sow, M. D., Allona, I., Ambroise, C., Conde, D., Fichot, R., Gribkova, S., Jorge, V., Le-Provost, G., Pâques, L., Plomion, C., Salse, J., Sanchez-Rodriguez, L., Segura, V., Tost, J., \& Maury, S. (2018). Epigenetics in Forest Trees. In Advances in Botanical Research (Vol. 88, p. 387- 453). Elsevier. https://doi.org/10.1016/bs.abr.2018.09.003

Sow, M. D., Segura, V., Chamaillard, S., Jorge, V., Delaunay, A., Lafon-Placette, C., Fichot, R., FaivreRampant, P., Villar, M., Brignolas, F., \& Maury, S. (2018). Narrow-sense heritability and PST estimates of DNA methylation in three Populus nigra L. populations under contrasting water availability. Tree Genetics \& Genomes, 14(5). https://doi.org/10.1007/s11295-018-1293-6

Springer, N. M., \& Schmitz, R. J. (2017). Exploiting induced and natural epigenetic variation for crop improvement. Nature Reviews Genetics, 18(9), 563- 575. https://doi.org/10.1038/nrg.2017.45

Stokes, T. L., Kunkel, B. N., \& Richards, E. J. (2002). Epigenetic variation in Arabidopsis disease resistance. Genes \& Development, 16(2), 171- 182. https://doi.org/10.1101/gad.952102

Street, N. R., Skogström, O., Sjödin, A., Tucker, J., Rodríguez- Acosta, M., Nilsson, P., Jansson, S., \& Taylor, G. (2006a). The genetics and genomics of the drought response in Populus. The Plant Journal, 48(3), 321- 341. https://doi.org/10.1111/j.1365-313X.2006.02864.x

Street, N. R., Skogström, O., Sjödin, A., Tucker, J., Rodríguez- Acosta, M., Nilsson, P., Jansson, S., \& Taylor, G. (2006b). The genetics and genomics of the drought response in Populus. The Plant Journal, 48(3), 321- 341. https://doi.org/10.1111/j.1365-313X.2006.02864.X

Sun, Y., \& Yu, D. (2015). Activated expression of AtWRKY53 negatively regulates drought tolerance by mediating stomatal movement. Plant Cell Reports, 34(8), 1295- 1306. https://doi.org/10.1007/s00299-015-1787-8

Tan, F., Zhou, C., Zhou, Q., Zhou, S., Yang, W., Zhao, Y., Li, G., \& Zhou, D.-X. (2016). Analysis of Chromatin Regulators Reveals Specific Features of Rice DNA Methylation Pathways. Plant Physiology, 171(3), 2041- 2054. https://doi.org/10.1104/pp.16.00393

Trapet, P., Avoscan, L., Klinguer, A., Pateyron, S., Citerne, S., Chervin, C., Mazurier, S., Lemanceau, P., Wendehenne, D., \& Besson-Bard, A. (2016). The Pseudomonas fluorescens Siderophore Pyoverdine Weakens Arabidopsis thaliana Defense in Favor of Growth in Iron-Deficient Conditions. Plant Physiology, 171(1), 675- 693. https://doi.org/10.1104/pp.15.01537

Tsukahara, S., Kobayashi, A., Kawabe, A., Mathieu, O., Miura, A., \& Kakutani, T. (2009). Bursts of retrotransposition reproduced in Arabidopsis. Nature, 461(7262), 423- 426. https://doi.org/10.1038/nature08351

Tuskan, G. A., DiFazio, S., Jansson, S., Bohlmann, J., Grigoriev, I., Hellsten, U., Putnam, N., Ralph, S., Rombauts, S., Salamov, A., Schein, J., Sterck, L., Aerts, A., Bhalerao, R. R., Bhalerao, R. P., 
Manuscript in preparation

1600

1601

1602

1603

1604

1605

1606

1607

1608

1609

1610

1611

1612

1613

1614

1615

1616

1617

1618

1619

1620

1621

1622

1623

1624

1625

1626

1627

1628

1629

1630

1631

1632

1633

1634

1635

1636

1637

1638

1639

1640

1641

1642

1643

1644

1645

1646

1647

1648

1649

1650

1651

1652

1653

1654

Blaudez, D., Boerjan, W., Brun, A., Brunner, A., ... Rokhsar, D. (2006). The Genome of Black Cottonwood, Populus trichocarpa (Torr. \& Gray). Science, 313(5793), 1596- 1604. https://doi.org/10.1126/science.1128691

Vassileva, V., Hollwey, E., Todorov, D., \& Meyer, P. (s. $\quad$ d.). Leaf epidermal profiling as a phenotyping tool for DNA methylation mutants. 18.

Vining, K. J., Pomraning, K. R., Wilhelm, L. J., Priest, H. D., Pellegrini, M., Mockler, T. C., Freitag, M., \& Strauss, S. H. (2012). Dynamic DNA cytosine methylation in the Populus trichocarpa genome: Tissue-level variation and relationship to gene expression. Bmc Genomics, 13(1), 27.

Volaire, F., Lens, F., Cochard, H., Xu, H., Chacon-Doria, L., Bristiel, P., Balachowski, J., Rowe, N., Violle, C., \& Picon-Cochard, C. (2018). Embolism and mechanical resistances play a key role in dehydration tolerance of a perennial grass Dactylis glomerata L. Annals of Botany, 122(2), 325336. https://doi.org/10.1093/aob/mcy073

Vongs, A., Kakutani, T., Martienssen, R. A., \& Richards, E. J. (1993). Arabidopsis thaliana DNA methylation mutants. Science (New York, N.Y.), 260(5116), 1926- 1928. https://doi.org/10.1126/science.8316832

Wang, J., Tao, F., An, F., Zou, Y., Tian, W., Chen, X., Xu, X., \& Hu, X. (2017). Wheat transcription factor TaWRKY70 is positively involved in high-temperature seedling plant resistance to Puccinia $\begin{array}{lllll}\text { strifformis f. Sp. Tritici. Molecular Plant Pathology, 18(5), 649- } & 661 .\end{array}$ https://doi.org/10.1111/mpp.12425

Wang, Yan, Wang, Q., Liu, M., Bo, C., Wang, X., Ma, Q., Cheng, B., \& Cai, R. (2017). Overexpression of a maize MYB48 gene confers drought tolerance in transgenic arabidopsis plants. Journal of Plant Biology, 60(6), 612- 621. https://doi.org/10.1007/s12374-017-0273-y

Wang, Yushuai, Liang, W., \& Tang, T. (2018). Constant conflict between Gypsy LTR retrotransposons and $\mathrm{CHH}$ methylation within a stress-adapted mangrove genome. New Phytologist, 220(3), 922- 935. https://doi.org/10.1111/nph.15209

Wang, Zhen, Wang, F., Hong, Y., Yao, J., Ren, Z., Shi, H., \& Zhu, J.-K. (2018). The Flowering Repressor SVP Confers Drought Resistance in Arabidopsis by Regulating Abscisic Acid Catabolism. Molecular Plant, 11(9), 1184- 1197. https://doi.org/10.1016/j.molp.2018.06.009

Wang, Zheng, Fang, H., Chen, Y., Chen, K., Li, G., Gu, S., \& Tan, X. (2014). Overexpression of BnWRKY33 in oilseed rape enhances resistance to Sclerotinia sclerotiorum. Molecular Plant Pathology, 15(7), 677- 689. https://doi.org/10.1111/mpp.12123

Wasternack, C., \& Hause, B. (2018). A Bypass in Jasmonate Biosynthesis - the OPR3-independent $\begin{array}{lllll}\text { Formation. Trends in Plant Science, 23(4), 276- } & 279 .\end{array}$ https://doi.org/10.1016/j.tplants.2018.02.011

Wettstein- Knowles, P. von. (2016). Plant Waxes. In ELS (p. 1- 13). American Cancer Society. https://doi.org/10.1002/9780470015902.a0001919.pub3

Wu, C., Bordeos, A., Madamba, Ma. R. S., Baraoidan, M., Ramos, M., Wang, G., Leach, J. E., \& Leung, $H$. (2008). Rice lesion mimic mutants with enhanced resistance to diseases. Molecular Genetics and Genomics, 279(6), 605- 619. https://doi.org/10.1007/s00438-008-0337-2

$\mathrm{Xi}, \mathrm{Y}$., \& Li, W. (2009). BSMAP: Whole genome bisulfite sequence MAPping program. BMC Bioinformatics, 10, 232. https://doi.org/10.1186/1471-2105-10-232

Xu, Z., \& Zhou, G. (2008). Responses of leaf stomatal density to water status and its relationship with photosynthesis in a grass. Journal of Experimental Botany, 59(12), 3317- 3325. https://doi.org/10.1093/jxb/ern185

Yakovlev, I. A., Carneros, E., Lee, Y., Olsen, J. E., \& Fossdal, C. G. (2016). Transcriptional profiling of epigenetic regulators in somatic embryos during temperature induced formation of an epigenetic memory in Norway spruce. Planta, 243(5), 1237- 1249. https://doi.org/10.1007/s00425-0162484-8

Yakovlev, I. A., \& Fossdal, C. G. (2017). In Silico Analysis of Small RNAs Suggest Roles for Novel and Conserved miRNAs in the Formation of Epigenetic Memory in Somatic Embryos of Norway Spruce. Frontiers in Physiology, 8. https://doi.org/10.3389/fphys.2017.00674

Yakovlev, I. A., Lee, Y., Rotter, B., Olsen, J. E., Skrøppa, T., Johnsen, Ø., \& Fossdal, C. G. (2014). Temperature-dependent differential transcriptomes during formation of an epigenetic memory in Norway spruce embryogenesis. Tree Genetics \& Genomes, 10(2), 355- 366. https://doi.org/10.1007/s11295-013-0691-z 
Manuscript in preparation

Yakovlev, I., Fossdal, C. G., Skrøppa, T., Olsen, J. E., Jahren, A. H., \& Johnsen, Ø. (2012). An adaptive epigenetic memory in conifers with important implications for seed production. Seed Science Research, 22(02), 63- 76. https://doi.org/10.1017/S0960258511000535

Yamamuro, C., Zhu, J.-K., \& Yang, Z. (2016). Epigenetic modifications and plant hormone action. Molecular plant, 9(1), 57- 70. https://doi.org/10.1016/j.molp.2015.10.008

Yao, Y., Bilichak, A., Golubov, A., \& Kovalchuk, I. (2012). Ddm1 plants are sensitive to methyl methane sulfonate and $\mathrm{NaCl}$ stresses and are deficient in DNA repair. Plant Cell Reports, 31(9), 15491561. https://doi.org/10.1007/s00299-012-1269-1

Yona, A. H., Frumkin, I., \& Pilpel, Y. (2015). A Relay Race on the Evolutionary Adaptation Spectrum. Cell, 163(3), 549- 559. https://doi.org/10.1016/j.cell.2015.10.005

Zemach, A., Kim, M. Y., Hsieh, P.-H., Coleman-Derr, D., Eshed-Williams, L., Thao, K., Harmer, S. L., \& Zilberman, D. (2013). The Arabidopsis Nucleosome Remodeler DDM1 Allows DNA Methyltransferases to Access H1-Containing Heterochromatin. Cell, 153(1), 193- 205. https://doi.org/10.1016/j.cell.2013.02.033

Zemach, A., McDaniel, I. E., Silva, P., \& Zilberman, D. (2010). Genome-Wide Evolutionary Analysis of $\begin{array}{lllll}\text { Eukaryotic DNA Methylation. Science, 328(5980), } & 916-\end{array}$ https://doi.org/10.1126/science.1186366

Zhang, J., Jia, W., Yang, J., \& Ismail, A. M. (2006). Role of ABA in integrating plant responses to drought $\begin{array}{lllll}\text { and salt stresses. Field Crops Research, 97(1), 111- } & 119 .\end{array}$ https://doi.org/10.1016/j.fcr.2005.08.018

Zhang, Q., Li, Y., Xu, T., Srivastava, A. K., Wang, D., Zeng, L., Yang, L., He, L., Zhang, H., Zheng, Z., Yang, D.-L., Zhao, C., Dong, J., Gong, Z., Liu, R., \& Zhu, J.-K. (2016). The chromatin remodeler DDM1 promotes hybrid vigor by regulating salicylic acid metabolism. Cell Discovery, 2, 16027. https://doi.org/10.1038/celldisc.2016.27

Zhang, Y.-Y., Fischer, M., Colot, V., \& Bossdorf, O. (2013). Epigenetic variation creates potential for evolution of plant phenotypic plasticity. New Phytologist, 197(1), 314- 322. https://doi.org/10.1111/nph.12010

Zhang, Y.-Y., Latzel, V., Fischer, M., \& Bossdorf, O. (2018). Understanding the evolutionary potential of epigenetic variation: A comparison of heritable phenotypic variation in epiRILs, RILs, and natural ecotypes of Arabidopsis thaliana. Heredity, 121(3), 257- 265. https://doi.org/10.1038/s41437018-0095-9

Zhu, H., Wang, G., \& Qian, J. (2016). Transcription factors as readers and effectors of DNA methylation. Nature Reviews Genetics, 17(9), 551- 565. https://doi.org/10.1038/nrg.2016.83

Zhu, L.-Y., Zhu, Y.-R., Dai, D.-J., Wang, X., \& Jin, H.-C. (2018). Epigenetic regulation of alternative splicing. American Journal of Cancer Research, 8(12), 2346- 2358.

Zhu, R., Shevchenko, O., Ma, C., Maury, S., Freitag, M., \& Strauss, S. H. (2013). Poplars with a PtDDM1RNAi transgene have reduced DNA methylation and show aberrant post-dormancy morphology. Planta, 237(6), 1483- 1493. https://doi.org/10.1007/s00425-013-1858-4 
Manuscript in preparation

\section{Figure \& Table legends}

1695 Figure 1: Time course of soil relative extractable water (REW) during the experiment for the wild type and 1696 the two RNAi-ddm1 (ddm1-15, ddm1-23) poplar lines in control (well-watered, WW) and stress (moderate 1697 water deficit followed by rewatering, WD-RW) treatments. Open symbols and dashed lines for WW 1698 treatment; closed symbols and solid lines for WD-RW treatment. Circles for the wild type; triangles for the 1699 RNAi-ddm1-15 line; squares for the RNAi-ddm1-23 line. The arrows represent the end of the water deficit 1700 and the onset of rewatering. Values are genotypic means \pm SE ( $n=6$ per line for WW, $n=12$ per line for 1701 WD-RW).

1702 Figure 2: Phenotypic and physiological characterization of the wild type and the two RNAi-ddm1 (ddm11703 15, ddm1-23) poplar lines in control (well-watered, WW) and stress (moderate water deficit followed by 1704 rewatering, WD-RW) treatments. Open symbols and open bars for WW; closed symbols and closed bars 1705 for WD-RW. Values are genotypic means \pm SE. A. Time course of stem height and diameter $(n=6$ per 1706 line in WW, $n=12$ per line in WD-RW). The arrows represent the end of the water deficit and the onset of 1707 rewatering. B. Xylem vulnerability to drought-induced cavitation measured at the end of the experiment $(n$ $1708=6$ per line $)$. C. Time course of leaf gas exchange $\left(A_{\text {net }}\right.$, net $\mathrm{CO}_{2}$ assimilation rate, $g_{s}$, stomatal 1709 conductance to water vapour, WUE are those of WD-RW plants relative to WW controls ( $n=5$ per line per treatment). Treatment effects were evaluated within each line using a t-test. Levels of significance are ${ }^{*}, 0.01<P<0.05 ;{ }^{* *}, 0.001<P<0.01$; ${ }^{* * *}, P<0.001 ;$ ns, non-significant.

Figure 3: Phytohormone contents (cytokinins, abscisic acid, salicylic acid and free auxin) measured in shoot apex just after rewatering $\left(\mathrm{t}_{1}\right)$. Values are genotypic means \pm SE $(n=3$ per line in WW and in WDRW). Treatment effects were evaluated within each line by using t-test. Levels of significance are *: $p<$ $0.05,{ }^{* *}: p<0.01,{ }^{* * *}: p<0.001$ and ns: non-significant. The different letters indicate the differences between lines within a water regime following a Tukey's post hoc test (lower case letters for WW, capital letters for WD-RW).

1719

Figure 4: Variations in DNA methylation among RNAi and WT lines in shoot apical meristem one week after rewatering (t2). A. Common DMRs between WW and WD-RW conditions. Black bars for hypomethylated DMRs and grey bars for hypermethylated DMRs. B. Common DMRs between the two

1722 RNAi lines (ddm1_15 \& ddm1_23) vs. the WT lines in all contexts (CG, CHG \& CHH) and in WW and WD1723 RW conditions. Black bars for hypomethylated DMRs and grey bars for hypermethylated DMRs. C. DNA 1724 methylation variation of the common DMRs in the RNAi lines vs. the WT line in WW and WD-RW per 1725 context of methylation. Only DMRs with at least a $25 \%$ difference were kept except for $\mathrm{CHH}$ where a 1726 threshold of $10 \%$ was applied due to the low proportion of DMRs in that context.

1727 Figure 5: Gene expression variations in ddm1-23 vs. the WT line in non-irrigated condition (WD-RW) in 1728 shoot apical meristem collected one week after rewatering (t2). A. GO annotation of the differentially 
Manuscript in preparation

1729

1730

1731

1732

1733

1734

1735

1736

1737

1738

1739

1740

1741

1742

1743

1744

1745

1746

1747

1748

1749

1750

1751

1752

1753

\section{Supplemental materials:}

1755

1756

1757

1758

1759

1760

1761

1762

1763

expressed genes (genes with an adjusted $p$-value by FDR, false discovery rate $<0.05=136$ DEGs identified) between ddm1-23 and the WT line. GO labels were retrieved from popgenie and treemap realized with REVIGO. B. Annotation of DEGs with expression variation values (log2FoldChange) using GO labels retrieved from popgenie. Blue for downregulated genes and red for upregulated genes. The * indicates hormone related genes found in DEGs. The numbers (1), (31), (8), (25), (19), (17), (35) represent respectively the number of DEGs found in Cell death, Defense \& Cell wall, Immune response, Metabolism, Signalization, Transcription factors and Unknown processes respectively. Log2FoldChange = log-ratio of normalized mean read counts in RNAi vs. WT lines.

Figure 6: Transposable elements activity among RNAi and WT lines in shoot apical meristem collected one week after rewatering (t2). A. Depth of coverage (read per million, rpm) of different TE families in the three different lines and in both WW (white) and WD-RW (black) regimes. TE, TE+, TE++, TE+++ represent different groups of TE families according to their coverage. TE ranges from 0 to 200X; TE+ = $200 \mathrm{X}-2000 \mathrm{X} ; \mathrm{TE}++=2000 \mathrm{X}-10000 \mathrm{X}$; $\mathrm{TE}+++=10000 \mathrm{X}-55000 \mathrm{X}$. B. DNA methylation variations in TEs for each context of methylation in WW (white) and WD-RW (black) conditions. C. Copy number variations of three different TEs (DNA-3-3, Gypsy23 and SAT-1) in the three different lines in both WW and WD-RW regimes. White cicles for WW and black circles for WD-RW.

Table 1: Xylem structural, functional and biochemical traits measured for the wild type and the two RNAi$d d m 1$ (ddm1-15, ddm1-23) poplar lines in control (well-watered, WW) and stress (moderate water deficit followed by rewatering, WD-RW) treatments. Values are genotypic means \pm SE $(n=6$ per line per treatment). The $P_{50}$ is the xylem tension inducing $50 \%$ loss of hydraulic conductance estimated from vulnerability curves (see Materials and Methods for additional information). S/G corresponds to the ratio between syringyl-like (S) and guaiacyl-like lignin monomeric units $(G)$. Treatment effects were evaluated within each line by using a t-test. Different letters indicate significant differences between genotypes within treatments following Tukey's post hoc test. Levels of significance are ${ }^{*}, 0.01<P<0.05 ;{ }^{* *}, 0.001<P<$ $0.01 ;{ }^{* * *}, P<0.001 ;$ ns, non-significant; na, not available.

Supplemental Figure 1: Strategies for methylome bioinformatic analysis A. Impact of different types of quality controls on the percentage of mapped reads on two distinct genomes: $P$. trichocarpa and $P$. tremula $\times P$. alba. Dots shapes are quality control specific. 1. Circles for quality control with trimming, 2 . Triangular for sample with only trimming control and 3. Squared for sample without any quality control. Colors are distinct between the two genomes (black for $P$. trichocarpa and white for P. tremula $\times$ P.alba). On the left, the results for Well-Watered (WW) conditions and on the other side Water Deficit and ReWatering (WD-RW). B. Impact of two different tools for mapping reads, BISMARK and BSMAP on the percentage of mapped reads on two distinct genomes: $P$. trichocarpa and $P$. tremula $\times P$. alba. Dark bars are for BISMARK and light bars for BSMAP software. On the left, the results for Well-Watered (WW) 
Manuscript in preparation

1764 conditions and on the other side Water Deficit and ReWatering (WD-RW). Values are 'QC' means quality 1765 control with trimming and filtering. C. Percentages of cytosine considered by BISMARK after quality 1766 control and 10X minimal coverage filtering on the two genomes: $P$. trichocarpa and $P$. tremula $\times P$. alba. 1767 Bars are for methylation percentage and dots are for coverage values. Black color is for Well-Watered 1768 (WW) conditions and white for Water Deficit and Re-Watering one (WD-RW). D. Percentages of cytosine 1769 considered by BISMARK after quality control and 10X minimal coverage filtering for the three methylation 1770 contexts (CG, $\mathrm{CHG}$ and $\mathrm{CHH})$ for $P$. tremula $\times P$. alba.

1771 Supplemental Figure 2: Phenotypic and physiological characterization of the wild type and the two RNAi$1772 d d m 1$ (ddm1-15, ddm1-23) poplar lines in control (well-watered, WW) and stress (moderate water deficit 1773 followed by rewatering, WD-RW) treatments. Open symbols and open bars for WW; closed symbols and 1774 closed bars for WD-RW. Values are genotypic means \pm SE. A. Predawn and minimum leaf water potential 1775 measured before rewatering ( $n=5$ per line per treatment). B. Bulk leaf carbon isotope composition $\left(\delta^{13} \mathrm{C}\right)$ 1776 measured on leaves sampled at the end of the experiment $(n=6$ per line in WW, $n=12$ per line in WD$1777 \mathrm{RW}$ ). C. Total stomatal density measured at the end of the experiment ( $n=3$ per line per treatment). 1778 Treatment effects were evaluated within each line using a t-test. Levels of significance are *, $0.01<P<$ $17790.05 ;{ }^{* *}, 0.001<P<0.01 ;{ }^{* * *}, P<0.001$; ns, non-significant.

1780 Supplemental Figure 3: A. Variation among Populus RNAi ddm1 lines concerning the effect of leaf 1781 position on the stem on leaf area. White dots for control line and black dots for RNAi lines. Values are line 1782 means ( \pm SE, $n=3$ by lines WW). For each line the rank effect was evaluated using a T-test (IF: leaf 1783 index). B. Total leaf area variations among Populus RNAi ddm1 lines. White bars represent well-watered 1784 conditions. Values are line mean ( \pm SE, $n=3$ by lines $W W$ ). Global line effect was evaluated using a T-test 1785 (L: line). Levels of significance are ${ }^{*}: p<0.05,{ }^{* *}: p<0.01,{ }^{* * *}: p<0.001$ and ns: non-significant

Supplemental Figure 4: Particular leaf phenotypes among Populus RNAi ddm1 lines. Open symbols for control (well-watered, WW) condition; closed symbols for stress (moderate water deficit followed by rewatering, WD-RW) condition. Values are genotypic means \pm SE ( $n=6$ per line for WW and WD-RW). Treatment effects were evaluated within each line by using a t-test. The different letters indicate the differences between lines within a water regime following a Tukey's post hoc test (small letter, wellwatered condition and capital letter water deficit follow by rewatering condition). Levels of significance are ${ }^{*}: p<0.05,{ }^{* *}: p<0.01,{ }^{* *}: p<0.001$ and ns: non-significant.

1793 Supplemental Figure 5: Variations in DNA methylation among RNAi and WT lines in shoot apical 1794 meristem one week after rewatering (t2). A. Global DNA methylation percentage calculated by HPLC in 1795 WT and RNAi lines in both Well-Watered (WW, white bars) and water-deficit followed by ReWatering 1796 conditions (WD-RW, black bars). Values are genotypic mean ( \pm SE, $n=3$ by lines in $W W$ and $n=3$ by lines 1797 in WD-RW). Global genetic variations and the effect of water deficit re-watering were evaluated using 1798 ANOVA. Different letters indicate the differences between genotypes within WW and WD-RW conditions 
Manuscript in preparation

1799

1800

1801

1802

1803

1804

1805

1806

1807

1808

1809

1810

1811

1812

1813

1814

1815

1816

1817

1818

1819

1820

1821

1822

1823

1824

1825

1826

1827

1828

1829

1830

1831

following a Tukey's post hoc test. Levels of significance are ${ }^{*}: p<0.05,{ }^{* *}: p<0.01,{ }^{* * *}: p<0.001$ and ns: non-significant. B. Differentially methylated regions (DMRs) between treatment and lines. Black bars for hypomethylated DMRs and white bars for hypermethylated DMRs. DMRs represented are mapped against Populus tremula $\mathrm{x}$ alba reference genome and have passed 10X of coverage and show a cut-off of methylation of $25 \%$ with qvalue 0.01 . C. DMRs count between ddm1_15 and WT line. D. DMRs count between ddm1_23 the WT line. E. Distributions of the DMRs between the RNAi and the WT lines in the different contexts of methylation.

Supplemental figure 6: Identification of differentially methylated genes. A. Annotation of the common DMRs between the RNAi and the WT lines in WW and WD-RW regimes. Gene annotation was retrieved from $P$. tremula $\times$. alba v1.1 annotation. Promoters correspond to $+/-2 \mathrm{~kb}$ from TSS (transcription start site). TE (Transposable element) annotations were retrieved from $P$. trichocarpa annotation and blasted against $P$. tremula $\times \mathrm{P}$. reference genome. B. Identification of common differentially methylated genes (DMGs) between the two RNAi lines vs. the WT line in both WW and WD-RW regimes. In DMRs = Genes that overlapped with the common DMRs, $2 \mathrm{~kb}=$ Genes in $+/-2 \mathrm{~kb}$ of DMR, $5 \mathrm{~kb}=$ Genes in $+/-5 \mathrm{~kb}$ of DMR, $10 \mathrm{~kb}=$ Genes in +/- $10 \mathrm{~kb}$ of DMR and $25 \mathrm{~kb}=$ Genes that are found in $+/-25 \mathrm{~kb}$ of DMR. C. Genes Ontology (GO) annotation of the common DMRs in WD-RW regimes for all contexts. GO labels were retrieved from $A$. thaliana annotation and a treemap was realized using REVIGO software.

Supplemental figure 7: Relationship between variation in DNA methylation and gene expression. A. Overlap between DEGs and DMRs. DEGs that are localized in DMRs or in the proximity of DMRs are represented: In DMRs = DEGs that overlapped with the DMRs, $2 \mathrm{~kb}=\mathrm{DEGs}$ in $+/-2 \mathrm{~kb}$ of DMR, $5 \mathrm{~kb}=$ DEGs in +/- $5 \mathrm{~kb}$ of DMR, $10 \mathrm{~kb}=$ DEGs in $+/-10 \mathrm{~kb}$ of DMR and $25 \mathrm{~kb}=$ DEGs that are found in $+/-25 \mathrm{~kb}$ of DMR. B. Covariation between DNA methylation and gene expression. DEGs found in or near $+/-10 \mathrm{~kb}$ of DMRs were used for correlation (spearman t test correlation, pvalue $=0.0004$ ).

Supplemental figure 8: Transposable elements activity among RNAi and WT lines in shoot apical meristem collected one week after rewatering (t2). A. Counts of transposable element families found in the mobilome-seq analysis in the three different lines and in WW and WD-RW regimes. White bars for WW and black bars for WD-RW. B. GO annotation of biological process of genes found in or near $+/-25 \mathrm{~kb}$ of mobilome-seq TE families. The treemap was realized using REVIGO. C. Overlap between TE families vs. DMRs and Genes. In = TEs that overlapped with the DMRs, $2 \mathrm{~kb}=$ TEs in $+/-2 \mathrm{~kb}$ of DMR, $5 \mathrm{~kb}=\mathrm{TEs}$ in $+/-5 \mathrm{~kb}$ of DMR, $10 \mathrm{~kb}=$ TEs in +/- $10 \mathrm{~kb}$ of DMR and $25 \mathrm{~kb}=$ TEs that are found in +/- $25 \mathrm{~kb}$ of DMR.

Supplemental Table 1: Mean methylation level in ddm1 and WT lines in both WW and WD-RW conditions, Values are the average of methylation (in \%) for each lines in the three different contexts (CG, $\mathrm{CHG}$ and $\mathrm{CHH}$ ). 


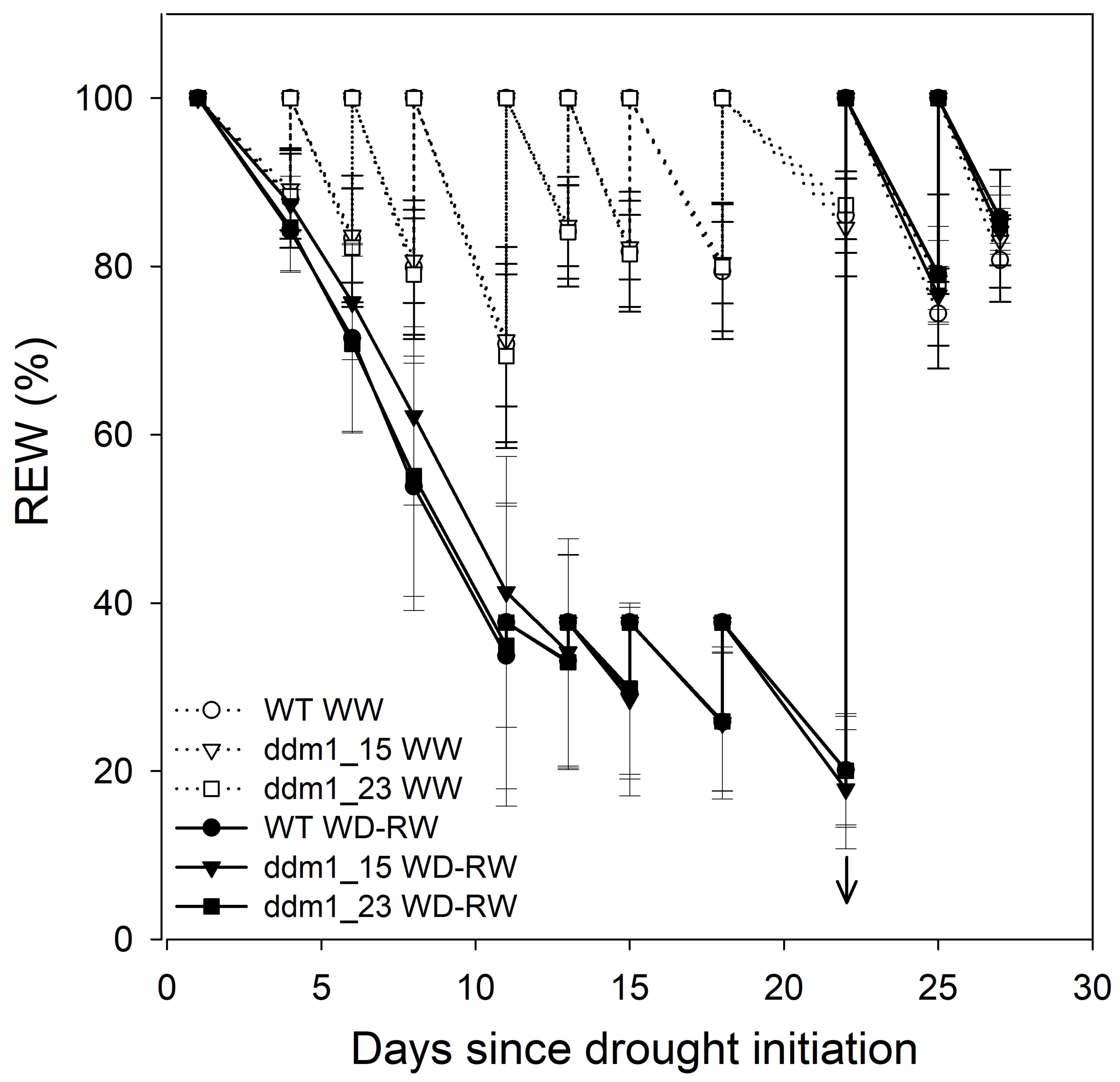

Figure 1: Time course of soil relative extractable water (REW) during the experiment for the wild type and the two RNAiddm1 (ddm1-15, ddm1-23) poplar lines in control (well-watered, WW) and stress (moderate water deficit followed by rewatering, WD-RW) treatments. Open symbols and dashed lines for WW treatment; closed symbols and solid lines for WD-RW treatment. Circles for the wild type; triangles for the RNAi-ddm1-15 line; squares for the RNAi-ddm1-23 line. The arrows represent the end of the water deficit and the onset of rewatering. Values are genotypic means \pm SE ( $n=6$ per line for WW, $n=12$ per line for WD-RW). 




Figure 3: Phytohormone contents (cytokinins, abscisic acid, salicylic acid and free auxin) measured in shoot apex just after rewatering $\left(\mathrm{t}_{1}\right)$. Values are genotypic means \pm SE $(n=3$ per line in WW and in WD-RW). Treatment effects were evaluated within each line by using t-test. Levels of significance are ${ }^{*}: p<0.05,{ }^{* *}: p<0.01,{ }^{* * *}: p<0.001$ and ns: nonsignificant. The different letters indicate the differences between lines within a water regime following a Tukey's post hoc test (lower case letters for WW, capital letters for WD-RW). 


\section{Parsed Citations}

Abeysinghe, J. K., Lam, K.-M., \& Ng, D. W.-K. (2019). Differential regulation and interaction of homoeologous WRKY18 and WRKY40 in Arabidopsis allotetraploids and biotic stress responses. The Plant Journal, 97(2), 352- 367. https://doi.org/10.1111/tpj.14124

Pubmed: Author and Title

Google Scholar: Author Only Title Only Author and Title

Alen, C. D., Macalady, A K., Chenchouni, H., Bachelet, D., McDowell, N., Vennetier, M., Kitzberger, T., Rigling, A, Breshears, D. D., Hogg, E. H. (Ted), Gonzalez, P., Fensham, R., Zhang, Z, Castro, J., Demidova, N., Lim, J.-H., Alard, G., Running, S. W., Semerci, A, \& Cobb, N. (2010). A global overview of drought and heat-induced tree mortality reveals emerging climate change risks for forests. Forest Ecology and Management, 259(4), 660- 684. https://doi.org/10.1016/j.foreco.2009.09.001

Pubmed: Author and Title

Google Scholar: Author Only Title Only Author and Title

Anderegg, W. R. L., Klein, T., Bartlett, M., Sack, L., Pellegrini, A F. A, Choat, B., \& Jansen, S. (2016). Meta-analysis reveals that hydraulic traits explain cross-species patterns of drought-induced tree mortality across the globe. Proceedings of the National Academy of Sciences, 113(18), 5024- 5029. https://doi.org/10.1073/pnas.1525678113

Pubmed: Author and Title

Google Scholar: Author Only Title Only Author and Title

Awad, H., Herbette, S., Brunel, N., Tixier, A, Pilate, G., Cochard, H., \& Badel, E. (2012). No trade-off between hydraulic and mechanical properties in several transgenic poplars modified for lignins metabolism. Environmental and Experimental Botany, 77, $185-195$.

https://doi.org/10.1016/j.envexpbot.2011.11.023

Pubmed: Author and Title

Google Scholar: Author Only Title Only Author and Title

Ayarpadikkannan, S., \& Kim, H.-S. (2014). The Impact of Transposable Elements in Genome Evolution and Genetic Instability and Their Implications in Various Diseases. Genomics \& informatics, 12, 98- 104. https://doi.org/10.5808/GI.2014.12.3.98

Pubmed: Author and Title

Google Scholar: Author Only Title Only Author and Title

Azooz, M. M., \& Youssef, M. M. (2010). Evaluation of Heat Shock and Salicylic Acid Treatments as Inducers of Drought Stress

Tolerance in Hassawi Wheat. American Journal of Plant Physiology, 5(2), 56- 70. https://doi.org/10.3923/ajpp.2010.56.70

Pubmed: Author and Title

Google Scholar: Author Only Title Only Author and Title

Badmi, R., Zhang, Y., Tengs, T., Brurberg, M. B., Krokene, P., Fossdal, C. G., Hytönen, T., \& Thorstensen, T. (2019). Induced and primed defence responses of Fragaria vesca to Botrytis cinerea infection. BioRxiv, 692491. https://doi.org/10.1101/692491

Pubmed: Author and Title

Google Scholar: Author Only Title Only Author and Title

Bandurska, H., \& Stroi ski, A (2005). The effect of salicylic acid on barley response to water deficit. Acta Physiologiae Plantarum, 27(3), 379- 386. https://doi.org/10.1007/s11738-005-0015-5

Pubmed: Author and Title

Google Scholar: Author Only Title Only Author and Title

Barigah, T. S., Charrier, O., Douris, M., Bonhomme, M., Herbette, S., Améglio, T., Fichot, R., Brignolas, F., \& Cochard, H. (2013). Water stress-induced xylem hydraulic failure is a causal factor of tree mortality in beech and poplar. Annals of Botany, $112(7), 1431-1437$. https://doi.org/10.1093/aob/mct204

Pubmed: Author and Title

Google Scholar: Author Only Title Only Author and Title

Basu, S., Ramegowda, V., Kumar, A, \& Pereira, A (2016). Plant adaptation to drought stress. F1000Research, 5. https://doi.org/10.12688/f1000research.7678.1

Pubmed: Author and Title

Google Scholar: Author Only Title Only Author and Title

Baubec, T., Finke, A, Mittelsten Scheid, O., \& Pecinka, A (2014). Meristem-specific expression of epigenetic regulators safeguards transposon silencing in Arabidopsis. EMBO Reports, 15(4), 446- 452. https://doi.org/10.1002/embr.201337915

Pubmed: Author and Title

Google Scholar: Author Only Title Only Author and Title

Bechtold, U., Penfold, C. A, Jenkins, D. J., Legaie, R., Moore, J. D., Lawson, T., Matthews, J. S. A, Vialet-Chabrand, S. R. M., Baxter, L., Subramaniam, S., Hickman, R., Florance, H., Sambles, C., Salmon, D. L., Feil, R., Bowden, L., Hill, C., Baker, N. R., Lunn, J. E., ...

Mullineaux, P. M. (2016). Time-Series Transcriptomics Reveals That AGAMOUS-LIKE22 Affects Primary Metabolism and Developmental Processes in Drought-Stressed Arabidopsis. The Plant Cell, 28(2), 345- 366. https://doi.org/10.1105/tpc.15.00910

Pubmed: Author and Title

Google Scholar: Author Only Title Only Author and Title

Bertrand, D., \& Dufour, É. (2006). La Spectroscopie Infrarouge et ses Applications Analytiques. Tec \& Doc / Lavoisier. http://uww.lavoisier.fr/notice/fr2743008090.html

Pubmed: Author and Title

Google Scholar: Author Only Title Only Author and Title 
Bewick, A J., \& Schmitz, R. J. (2017). Gene body DNAmethylation in plants. Current Opinion in Plant Biology, 36, $103-110$. https://doi.org/10.1016/j.pbi.2016.12.007

Pubmed: Author and Title

Google Scholar: Author Only Title Only Author and Title

Bogeat-Triboulot, M.-B., Brosché, M., Renaut, J., Jouve, L., Thiec, D. L., Fayyaz, P., Vinocur, B., Witters, E., Laukens, K., Teichmann, T., Altman, A, Hausman, J.-F., Polle, A, Kangasjärvi, J., \& Dreyer, E. (2007). Gradual Soil Water Depletion Results in Reversible Changes of Gene Expression, Protein Profiles, Ecophysiology, and Growth Performance in Populus euphratica, a Poplar Growing in Arid Regions. Plant Physiology, 143(2), 876- 892. https://doi.org/10.1104/pp.106.088708

Pubmed: Author and Title

Google Scholar: Author Only Title Only Author and Title

Bolger, A M., Lohse, M., \& Usadel, B. (2014). Trimmomatic : A flexible trimmer for Illumina sequence data. Bioinformatics (Oxford, England), 30(15), 2114- 2120. https://doi.org/10.1093/bioinformatics/btu170

Pubmed: Author and Title

Google Scholar: Author Only Title Only Author and Title

Bradshaw, A D. (2006). Unravelling phenotypic plasticity-why should we bother? New Phytologist, 170(4), 644- 648. https://doi.org/10.1111/j.1469-8137.2006.01761.x

Pubmed: Author and Title

Google Scholar: Author Only Title Only Author and Title

Bräutigam, K., Vining, K. J., Lafon-Placette, C., Fossdal, C. G., Mirouze, M., Marcos, J. G., Fluch, S., Fraga, M. F., Guevara, M. Á, Abarca, D., Johnsen, Ø., Maury, S., Strauss, S. H., Campbell, M. M., Rohde, A, Díaz-Sala, C., \& Cervera, M.-T. (2013). Epigenetic regulation of adaptive responses of forest tree species to the environment. Ecology and Evolution, 3(2), 399- 415. https://doi.org/10.1002/ece3.461 Pubmed: Author and Title

Google Scholar: Author Only Title Only Author and Title

Brodribb, T. J., \& Cochard, H. (2009). Hydraulic Failure Defines the Recovery and Point of Death in Water-Stressed Conifers. Plant Physiology, 149(1), 575- 584. https://doi.org/10.1104/pp.108.129783

Pubmed: Author and Title

Google Scholar: Author Only Title Only Author and Title

Cambiagno, D. A, Nota, F., Zavallo, D., Rius, S., Casati, P., Asurmendi, S., \& Avarez, M. E. (2018). Immune receptor genes and pericentromeric transposons as targets of common epigenetic regulatory elements. The Plant Journal, 96(6), 1178- 1190.

https://doi.org/10.1111/tpj.14098

Pubmed: Author and Title

Google Scholar: Author Only Title Only Author and Title

Carneros, E., Yakovlev, I., Viejo, M., Olsen, J. E., \& Fossdal, C. G. (2017). The epigenetic memory of temperature during embryogenesis modifies the expression of bud burst-related genes in Norway spruce epitypes. Planta, 246(3), 553- 566. https://doi.org/10.1007/s00425017-2713-9

Pubmed: Author and Title

Google Scholar: Author Only Title Only Author and Title

Champigny, M. J., Unda, F., Skyba, O., Soolanayakanahally, R. Y., Mansfield, S. D., \& Campbell, M. M. (s. d.). Learning from methylomes : Epigenomic correlates of Populus balsamifera traits based on deep learning models of natural DNAmethylation. Plant Biotechnology Journal, n/a(n/a). https://doi.org/10.1111/pbi.13299

Pubmed: Author and Title

Google Scholar: Author Only Title Only Author and Title

Chang, S., Puryear, J., \& Cairney, J. (1993). A simple and efficient method for isolating RNA from pine trees. Plant Molecular Biology

Reporter, 11(2), 113- 116. https://doi.org/10.1007/BF02670468

Pubmed: Author and Title

Google Scholar: Author Only Title Only Author and Title

Chen, C., \& Chen, Z (2002). Potentiation of Developmentally Regulated Plant Defense Response by AtWRKY18, a Pathogen-Induced Arabidopsis Transcription Factor. Plant Physiology, 129(2), 706- 716. https://doi.org/10.1104/pp.001057

Pubmed: Author and Title

Google Scholar: Author Only Title Only Author and Title

Chen, G., Komatsuda, T., Ma, J. F., Li, C., Yamaji, N., \& Nevo, E. (2011). A functional cutin matrix is required for plant protection against water loss. Plant Signaling \& Behavior, 6(9), 1297- 1299. https://doi.org/10.4161/psb.6.9.17507

Pubmed: Author and Title

Google Scholar: Author Only Title Only Author and Title

Cho, E. J., Choi, S. H., Kim, J. H., Kim, J. E., Lee, M. H., Chung, B. Y., Woo, H. R., \& Kim, J.-H. (2016). AMutation in Plant-Specific

SW2/SNF2-Like Chromatin-Remodeling Proteins, DRD1 and DDM1, Delays Leaf Senescence in Arabidopsis thaliana. PLoS ONE, 11(1). https://doi.org/10.1371/journal.pone.0146826

Pubmed: Author and Title

Google Scholar: Author Only Title Only Author and Title

Choat, B., Brodribb, T. J., Brodersen, C. R., Duursma, R. A, López, R., \& Medlyn, B. E. (2018). Triggers of tree mortality under drought. Nature, 558(7711), 531- 539. https://doi.org/10.1038/s41586-018-0240-x 
Pubmed: Author and Title

Google Scholar: Author Only Title Only Author and Title

Chujo, T., Takai, R., Akimoto-Tomiyama, C., Ando, S., Minami, E., Nagamura, Y., Kaku, H., Shibuya, N., Yasuda, M., Nakashita, H., Umemura, K., Okada, A, Okada, K., Nojiri, H., \& Yamane, H. (2007). Involvement of the elicitor-induced gene OsWRKY53 in the expression of defense-related genes in rice. Biochimica et Biophysica Acta (BBA) - Gene Structure and Expression, $1769(7), 497-505$. https://doi.org/10.1016/j.bbaexp.2007.04.006

Pubmed: Author and Title

Google Scholar: Author Only Title Only Author and Title

Chwialkowska, K., Nowakowska, U., Mroziewicz, A, Szarejko, I., \& Kwasniewski, M. (2016). Water-deficiency conditions differently modulate the methylome of roots and leaves in barley ( Hordeum vulgare L.). Journal of Experimental Botany, 67(4), $1109-1121$. https://doi.org/10.1093/jxb/erv552

Pubmed: Author and Title

Google Scholar: Author Only Title Only Author and Title

Cochard, H., Casella, E., \& Mencuccini, M. (2007). Xylem vulnerability to cavitation varies among poplar and willow clones and correlates with yield. Tree Physiology, 27(12), 1761- 1767. https://doi.org/10.1093/treephys/27.12.1761

Pubmed: Author and Title

Google Scholar: Author Only Title Only Author and Title

Cochard, H., Damour, G., Bodet, C., Tharwat, I., Poirier, M., \& Glio, T. (2005). Evaluation of a new centrifuge technique for rapid generation of xylem vulnerability curves. Physiologia Plantarum - PHYSIOL PLANT, 124. https://doi.org/10.1111/j.1399-3054.2005.00526.x

Pubmed: Author and Title

Google Scholar: Author Only Title Only Author and Title

Cohen, D., Bogeat-Triboulot, M.-B., Tisserant, E., Balzergue, S., Martin-Magniette, M.-L., Lelandais, G., Ningre, N., Renou, J.-P., Tamby, J.-P., Le Thiec, D., \& Hummel, I. (2010). Comparative transcriptomics of drought responses in Populus : Ameta-analysis of genomewide expression profiling in mature leaves and root apices across two genotypes. BMC Genomics, $11(1), 630$.

https://doi.org/10.1186/1471-2164-11-630

Pubmed: Author and Title

Google Scholar: Author Only Title Only Author and Title

Coil, D., Jospin, G., \& Darling, A E. (2015). A5-miseq : An updated pipeline to assemble microbial genomes from Illumina MiSeq data. Bioinformatics (Oxford, England), 31(4), 587- 589. https://doi.org/10.1093/bioinformatics/btu661

Pubmed: Author and Title

Google Scholar: Author Only Title Only Author and Title

Colomé-Tatché, M., Cortijo, S., Wardenaar, R., Morgado, L., Lahouze, B., Sarazin, A, Etcheverry, M., Martin, A, Feng, S., DuvernoisBerthet, E., Labadie, K., Wincker, P., Jacobsen, S. E., Jansen, R. C., Colot, V., \& Johannes, F. (2012). Features of the Arabidopsis recombination landscape resulting from the combined loss of sequence variation and DNAmethylation. Proceedings of the National Academy of Sciences, 109(40), 16240- 16245. https://doi.org/10.1073/pnas.1212955109

Pubmed: Author and Title

Google Scholar: Author Only Title Only Author and Title

Conde, D., Le Gac, A-L., Perales, M., Dervinis, C., Kirst, M., Maury, S., González-Melendi, P., \& Alona, I. (2017). Chilling-responsive DEMETER-LIKE DNAdemethylase mediates in poplar bud break: Role of active DNAdemethylase in trees' bud break. Plant, Cell \& Environment, 40(10), 2236- 2249. https://doi.org/10.1111/pce.13019

Pubmed: Author and Title

Google Scholar: Author Only Title Only Author and Title

Corem, S., Doron-Faigenboim, A, Jouffroy, O., Maumus, F., Arazi, T., \& Bouché, N. (2018). Redistribution of CHH Methylation and Small Interfering RNAs across the Genome of Tomato ddm1 Mutants. The Plant Cell, 30(7), 1628- 1644. https://doi.org/10.1105/tpc.18.00167

Pubmed: Author and Title

Google Scholar: Author Only Title Only Author and Title

Correia, B., Pintó-Marijuan, M., Castro, B. B., Brossa, R., López-Carbonell, M., \& Pinto, G. (2014). Hormonal dynamics during recovery from drought in two Eucalyptus globulus genotypes : From root to leaf. Plant Physiology and Biochemistry, 82, $151-160$.

https://doi.org/10.1016/j.plaphy.2014.05.016

Pubmed: Author and Title

Google Scholar: Author Only Title Only Author and Title

Cortijo, S., Wardenaar, R., Colome-Tatche, M., Gilly, A, Etcheverry, M., Labadie, K., Caillieux, E., Hospital, F., Aury, J.-M., Wincker, P., Roudier, F., Jansen, R. C., Colot, V., \& Johannes, F. (2014). Mapping the Epigenetic Basis of Complex Traits. Science, 343(6175), 11451148. https://doi.org/10.1126/science.1248127

Pubmed: Author and Title

Google Scholar: Author Only Title Only Author and Title

Cotrozzi, L., Pellegrini, E., Guidi, L., Landi, M., Lorenzini, G., Massai, R., Remorini, D., Tonelli, M., Trivellini, A, Vernieri, P., \& Nali, C. (2017). Losing the Warning Signal : Drought Compromises the Cross-Talk of Signaling Molecules in Quercus ilex Exposed to Ozone. Frontiers in Plant Science, 8. https://doi.org/10.3389/fpls.2017.01020

Pubmed: Author and Title

Google Scholar: Author Only Title Only Author and Title 
Daviaud, C., Renault, V., Mauger, F., Deleuze, J.-F., \& Tost, J. (2018). Whole-Genome Bisulfite Sequencing Using the Ovation® Ultralow Methyl-Seq Protocol. Methods in Molecular Biology (Clifton, N.J.), 1708, 83- 104. https://doi.org/10.1007/978-1-4939-7481-8_5

Pubmed: Author and Title

Google Scholar: Author Only Title Only Author and Title

Dong, X. (2004). NPR1, all things considered. Current Opinion in Plant Biology, 7(5), 547- 552. https://doi.org/10.1016/j.pbi.2004.07.005

Pubmed: Author and Title

Google Scholar: Author Only Title Only Author and Title

Durand, M., Brendel, O., Buré, C., \& Le Thiec, D. (2019). Altered stomatal dynamics induced by changes in irradiance and vapourpressure deficit under drought : Impacts on the whole plant transpiration efficiency of poplar genotypes. New Phytologist, 222.

https://doi.org/10.1111/nph.15710

Pubmed: Author and Title

Google Scholar: Author Only Title Only Author and Title

Dusotoit-Coucaud, A, Brunel, N., Tixier, A, Cochard, H., \& Herbette, S. (2014). Hydrolase treatments help unravel the function of intervessel pits in xylem hydraulics. Physiologia Plantarum, 150(3), 388- 396. https://doi.org/10.1111/ppl.12092

Pubmed: Author and Title

Google Scholar: Author Only Title Only Author and Title

Farquhar, G. D., Ehleringer, J. R., \& Hubick, K. T. (1989). Carbon Isotope Discrimination and Photosynthesis. Annual Review of Plant Physiology and Plant Molecular Biology, 40(1), 503- 537. https://doi.org/10.1146/annurev.pp.40.060189.002443

Pubmed: Author and Title

Google Scholar: Author Only Title Only Author and Title

Farquhar, G., O'Leary, M. H., \& Berry, J. (1982). On the Relationship Between Carbon Isotope Discrimination and the Intercellular Carbon Dioxide Concentration in Leaves. Australian Journal of Plant Physiology, 13, 281- 292. https://doi.org/10.1071/PP9820121

Pubmed: Author and Title

Google Scholar: Author Only Title Only Author and Title

Feng, S., Jacobsen, S. E., \& Reik, W. (2010). Epigenetic Reprogramming in Plant and Animal Development. Science, 330(6004), 622- 627. https://doi.org/10.1126/science.1190614

Pubmed: Author and Title

Google Scholar: Author Only Title Only Author and Title

Fernando, V. C. D., \& Schroeder, D. F. (2016). Role of ABA in Arabidopsis Salt, Drought, and Desiccation Tolerance. Abiotic and Biotic Stress in Plants - Recent Advances and Future Perspectives. https://doi.org/10.5772/61957

Pubmed: Author and Title

Google Scholar: Author Only Title Only Author and Title

Fichot, R., Barigah, T. S., Chamaillard, S., Thiec, D. L., Laurans, F., Cochard, H., \& Brignolas, F. (2010). Common trade-offs between xylem resistance to cavitation and other physiological traits do not hold among unrelated Populus deltoides $\times$ Populus nigra hybrids. Plant, Cell \& Environment, 33(9), 1553- 1568. https://doi.org/10.1111/j.1365-3040.2010.02164.x

Pubmed: Author and Title

Google Scholar: Author Only Title Only Author and Title

Fichot, R., Brignolas, F., Cochard, H., \& Ceulemans, R. (2015). Vulnerability to drought-induced cavitation in poplars : Synthesis and future opportunities. Plant, Cell \& Environment, 38(7), 1233- 1251. https://doi.org/10.1111/pce.12491

Pubmed: Author and Title

Google Scholar: Author Only Title Only Author and Title

Forgione, I., Woloszynska, M., Pacenza, M., Chiappetta, A, Greco, M., Araniti, F., Abenavoli, M. R., Van Lijsebettens, M., Bitonti, M. B., \& Bruno, L. (2019). Hypomethylated drm1 drm2 cmt3 mutant phenotype of Arabidopsis thaliana is related to auxin pathway impairment.

PLANT SCIENCE, 280, 383- 396. http://dx.doi.org/10.1016/j.plantsci.2018.12.029

Pubmed: Author and Title

Google Scholar: Author Only Title Only Author and Title

Fujimoto, R., Sasaki, T., Inoue, H., \& Nishio, T. (2008). Hypomethylation and transcriptional reactivation of retrotransposon-like sequences in ddm1 transgenic plants of Brassica rapa. Plant Molecular Biology, 66(5), 463- 473. https://doi.org/10.1007/s11103-007-92851

Pubmed: Author and Title

Google Scholar: Author Only Title Only Author and Title

Fujimoto, S. Y., Ohta, M., Usui, A, Shinshi, H., \& Ohme-Takagi, M. (2000). Arabidopsis Ethylene-Responsive Element Binding Factors Act as Transcriptional Activators or Repressors of GCC Box-Mediated Gene Expression. The Plant Cell, $12(3), 393-405$.

Pubmed: Author and Title

Google Scholar: Author Only Title Only Author and Title

Fultz, D., Choudury, S. G., \& Slotkin, R. K. (2015). Silencing of active transposable elements in plants. Current opinion in plant biology, 27, 67- 76. https://doi.org/10.1016/j.pbi.2015.05.027

Pubmed: Author and Title

Google Scholar: Author Only Title Only Author and Title

Furci, L., Jain, R., Stassen, J., Berkowitz, O., Whelan, J., Roquis, D., Baillet, V., Colot, V., Johannes, F., \& Ton, J. (2019). Identification 
and characterisation of hypomethylated DNA loci controlling quantitative resistance in Arabidopsis. ELife, 8, e40655.

https://doi.org/10.7554/eLife.40655

Pubmed: Author and Title

Google Scholar: Author Only Title Only Author and Title

Gagnot, S., Tamby, J.-P., Martin-Magniette, M.-L., Bitton, F., Taconnat, L., Balzergue, S., Aubourg, S., Renou, J.-P., Lecharny, A, \& Brunaud, V. (2008). CATdb : A public access to Arabidopsis transcriptome data from the URGV-CATMA platform Nucleic Acids

Research, 36(Database issue), D986-990. https://doi.org/10.1093/nar/gkm757

Pubmed: Author and Title

Google Scholar: Author Only Title Only Author and Title

Gaillochet, C., \& Lohmann, J. U. (2015). The never-ending story: From pluripotency to plant developmental plasticity. Development (Cambridge, England), 142(13), 2237- 2249. https://doi.org/10.1242/dev.117614

Pubmed: Author and Title

Google Scholar: Author Only Title Only Author and Title

Garg, R., Narayana Chevala, V., Shankar, R., \& Jain, M. (2015). Divergent DNA methylation patterns associated with gene expression in rice cultivars with contrasting drought and salinity stress response. Scientific Reports, 5. https://doi.org/10.1038/srep14922

Pubmed: Author and Title

Google Scholar: Author Only Title Only Author and Title

Gebreselassie, M. N., Ader, K., Boizot, N., Millier, F., Charpentier, J.-P., Aves, A, Simões, R., Rodrigues, J. C., Bodineau, G., Fabbrini, F., Sabatti, M., Bastien, C., \& Segura, V. (2017). Near-infrared spectroscopy enables the genetic analysis of chemical properties in a large set of wood samples from Populus nigra (L.) natural populations. Industrial Crops and Products, 107, $159-171$.

https://doi.org/10.1016/j.indcrop.2017.05.013

Pubmed: Author and Title

Google Scholar: Author Only Title Only Author and Title

Gendrel, A-V., Lippman, Z, Yordan, C., Colot, V., \& Martienssen, R. A (2002). Dependence of Heterochromatic Histone H3 Methylation Patterns on the Arabidopsis Gene DDM1. Science, 297(5588), 1871- 1873. https://doi.org/10.1126/science.1074950

Pubmed: Author and Title

Google Scholar: Author Only Title Only Author and Title

Gömöry, D., Hrivnák, M., Krajmerova, D., \& Longauer, R. (2017). Epigenetic memory effects in forest trees : Avictory of "Michurinian biology? Central European Forestry Journal, 63. https://doi.org/10.1515/forj-2017-0024

Pubmed: Author and Title

Google Scholar: Author Only Title Only Author and Title

Gourcilleau, D., Bogeat-Triboulot, M.-B., Le Thiec, D., Lafon-Placette, C., Delaunay, A, El-Soud, W. A, Brignolas, F., \& Maury, S. (2010). DNA methylation and histone acetylation: Genotypic variations in hybrid poplars, impact of water deficit and relationships with productivity. Annals of Forest Science, 67(2), 208.

Pubmed: Author and Title

Google Scholar: Author Only Title Only Author and Title

Grandbastien, M.-A (1998). Activation of plant retrotransposons under stress conditions. Trends in Plant Science, 3(5), $181-187$. https://doi.org/10.1016/S1360-1385(98)01232-1

Pubmed: Author and Title

Google Scholar: Author Only Title Only Author and Title

Guo, Y., Ping, W., Chen, J., Zhu, L., Zhao, Y., Guo, J., \& Huang, Y. (2019). Meta-analysis of the effects of overexpression of WRKY transcription factors on plant responses to drought stress. BMC Genetics, 20(1), 63. https://doi.org/10.1186/s12863-019-0766-4

Pubmed: Author and Title

Google Scholar: Author Only Title Only Author and Title

Ha, S., Vankova, R., Yamaguchi-Shinozaki, K., Shinozaki, K., \& Tran, L.-S. P. (2012). Cytokinins : Metabolism and function in plant adaptation to environmental stresses. Trends in Plant Science, 17(3), 172- 179. https://doi.org/10.1016/j.tplants.2011.12.005

Pubmed: Author and Title

Google Scholar: Author Only Title Only Author and Title

Hamanishi, E. T., Thomas, B. R., \& Campbell, M. M. (2012). Drought induces alterations in the stomatal development program in Populus. Journal of Experimental Botany, 63(13), 4959- 4971. https://doi.org/10.1093/jxb/ers177

Pubmed: Author and Title

Google Scholar: Author Only Title Only Author and Title

Havlová, M., Dobrev, P. I., Motyka, V., Štorchová, H., Libus, J., Dobrá, J., Malbeck, J., Gaudinová, A, \& Vanková, R. (2008). The role of cytokinins in responses to water deficit in tobacco plants over-expressing trans-zeatin O-glucosyltransferase gene under 35S or SAG12 promoters. Plant, Cell \& Environment, 31(3), 341- 353. https://doi.org/10.1111/j.1365-3040.2007.01766.x

Pubmed: Author and Title

Google Scholar: Author Only Title Only Author and Title

He, G.-H., Xu, J.-Y., Wang, Y.-X., Liu, J.-M., Li, P.-S., Chen, M., Ma, Y.-Z, \& Xu, Z-S. (2016). Drought-responsive WRKY transcription factor genes TaWRKY1 and TaWRKY33 from wheat confer drought and/or heat resistance in Arabidopsis. BMC Plant Biology, 16. https://doi.org/10.1186/s12870-016-0806-4

Pubmed: $\underline{\text { Author and Title }}$ 
Google Scholar: Author Only Title Only Author and Title

Herbette, S., Bouchet, B., Brunel, N., Bonnin, E., Cochard, H., \& Guillon, F. (2015). Immunolabelling of intervessel pits for polysaccharides and lignin helps in understanding their hydraulic properties in Populus tremula $\times$ alba. Annals of Botany, 115(2), 187199. https://doi.org/10.1093/aob/mcu232

Pubmed: Author and Title

Google Scholar: Author Only Title Only Author and Title

Heyman, J., Canher, B., Bisht, A, Christiaens, F., \& De Veylder, L. (2018). Emerging role of the plant ERF transcription factors in coordinating wound defense responses and repair. Journal of Cell Science, 131(2). https://doi.org/10.1242/jcs.208215

Pubmed: Author and Title

Google Scholar: Author Only Title Only Author and Title

Higo, H., Tahir, M., Takashima, K., Miura, A, Watanabe, K., Tagiri, A, Ugaki, M., Ishikawa, R., Eiguchi, M., Kurata, N., Sasaki, T., Richards, E., Takano, M., Kishimoto, N., Kakutani, T., \& Habu, Y. (2012). DDM1 (Decrease in DNA Methylation) genes in rice (Oryza sativa). Molecular Genetics and Genomics, 287(10), 785- 792. https://doi.org/10.1007/s00438-012-0717-5

Pubmed: Author and Title

Google Scholar: Author Only Title Only Author and Title

Hirsch, C. D., \& Springer, N. M. (2017). Transposable element influences on gene expression in plants. Biochimica et Biophysica Acta Gene Regulatory Mechanisms, 1860(1), 157- 165. https://doi.org/10.1016/j.bbagrm2016.05.010

Pubmed: Author and Title

Google Scholar: Author Only Title Only Author and Title

Hoffmann, S., Otto, C., Doose, G., Tanzer, A, Langenberger, D., Christ, S., Kunz, M., Holdt, L. M., Teupser, D., Hackermüller, J., \& Stadler, P. F. (2014). Amulti-split mapping algorithm for circular RNA splicing, trans-splicing and fusion detection. Genome Biology, 15(2), R34. https://doi.org/10.1186/gb-2014-15-2-r34

Pubmed: Author and Title

Google Scholar: Author Only Title Only Author and Title

Ikeda, Y., \& Nishimura, T. (2015). The role of DNAmethylation in transposable element silencing and genomic imprinting. Nuclear Functions in Plant Transcription, Signaling and Development, 13- 29. https://doi.org/10.1007/978-1-4939-2386-1_2

Pubmed: Author and Title

Google Scholar: Author Only Title Only Author and Title

Ito, T., Tarutani, Y., To, T. K., Kassam, M., Duvernois-Berthet, E., Cortijo, S., Takashima, K., Saze, H., Toyoda, A, Fujiyama, A, \& others. (2015). Genome-wide negative feedback drives transgenerational DNA methylation dynamics in Arabidopsis. PLoS Genet, 11(4), e1005154.

Pubmed: Author and Title

Google Scholar: Author Only Title Only Author and Title

Jansson, S., \& Douglas, C. J. (2007). Populus : A Model System for Plant Biology. Annual Review of Plant Biology, 58(1), $435-458$. https://doi.org/10.1146/annurev.arplant.58.032806.103956

Pubmed: Author and Title

Google Scholar: Author Only Title Only Author and Title

Jeddeloh, J. A, Bender, J., \& Richards, E. J. (1998). The DNAmethylation locusDDM1 is required for maintenance of gene silencing in Arabidopsis. Genes \& Development, 12(11), 1714-1725.

Pubmed: Author and Title

Google Scholar: Author Only Title Only Author and Title

Jiang, Y., Guo, L., Ma, X., Zhao, X., Jiao, B., Li, C., \& Luo, K. (2017). The WRKY transcription factors PtrWRKY18 and PtrWRKY35 promote Melampsora resistance in Populus. Tree Physiology, 37(5), 665- 675. https://doi.org/10.1093/treephys/tpx008

Pubmed: Author and Title

Google Scholar: Author Only Title Only Author and Title

Johannes, F., Porcher, E., Teixeira, F. K., Saliba-Colombani, V., Simon, M., Agier, N., Bulski, A, Abuisson, J., Heredia, F., Audigier, P., Bouchez, D., Dillmann, C., Guerche, P., Hospital, F., \& Colot, V. (2009). Assessing the Impact of Transgenerational Epigenetic Variation on Complex Traits. PLOS Genetics, 5(6), e1000530. https://doi.org/10.1371/journal.pgen.1000530

Pubmed: Author and Title

Google Scholar: Author Only Title Only Author and Title

Kakutani, T. (1997). Genetic characterization of late-flowering traits induced by DNA hypomethylation mutation in Arabidopsis thaliana. The Plant Journal, 12(6), 1447- 1451. https://doi.org/10.1046/j.1365-313x.1997.12061447.x

Pubmed: Author and Title

Google Scholar: Author Only Title Only Author and Title

Kakutani, T., Jeddeloh, J. A, \& Richards, E. J. (1995). Characterization of an Arabidopsis thaliana DNA hypomethylation mutant. Nucleic acids research, 23(1), 130-137.

Pubmed: Author and Title

Google Scholar: Author Only Title Only Author and Title

Karan, R., DeLeon, T., Biradar, H., \& Subudhi, P. K. (2012). Salt Stress Induced Variation in DNA Methylation Pattern and Its Influence on Gene Expression in Contrasting Rice Genotypes. PLoS ONE, 7(6). https://doi.org/10.1371/journal.pone.0040203 
Pubmed: Author and Title

Google Scholar: Author Only Title Only Author and Title

Kawakatsu, T., \& Ecker, J. R. (2019). Diversity and dynamics of DNA methylation : Epigenomic resources and tools for crop breeding. Breeding Science, 69(2), 191- 204. https://doi.org/10.1270/jsbbs.19005

Pubmed: Author and Title

Google Scholar: Author Only Title Only Author and Title

Kawakatsu, T., Huang, S. C., Jupe, F., Sasaki, E., Schmitz, R. J., Urich, M. A, Castanon, R., Nery, J. R., Barragan, C., He, Y., Chen, H., Dubin, M., Lee, C.-R., Wang, C., Bemm, F., Becker, C., O'Neil, R., O'Malley, R. C., Quarless, D. X., ... Zhou, X. (2016). Epigenomic Diversity in a Global Collection of Arabidopsis thaliana Accessions. Cell, 166(2), 492- 505. https://doi.org/10.1016/j.cell.2016.06.044

Pubmed: Author and Title

Google Scholar: Author Only Title Only Author and Title

Kawanabe, T., Ishikura, S., Miyaji, N., Sasaki, T., Wu, L. M., Itabashi, E., Takada, S., Shimizu, M., Takasaki-Yasuda, T., Osabe, K., Peacock, W. J., Dennis, E. S., \& Fujimoto, R. (2016). Role of DNAmethylation in hybrid vigor in Arabidopsis thaliana. Proceedings of the National Academy of Sciences, 113(43), E6704- E6711. https://doi.org/10.1073/pnas.1613372113

Pubmed: Author and Title

Google Scholar: Author Only Title Only Author and Title

Kejnovsky, E., Hawkins, J. S., \& Feschotte, C. (2012). Plant Transposable Elements : Biology and Evolution. In J. F. Wendel, J. Greilhuber, J. Dolezel, \& I. J. Leitch (Éd.), Plant Genome Diversity Volume 1 (p. 17- 34). Springer Vienna. https://doi.org/10.1007/978-37091-1130-7_2

Pubmed: Author and Title

Google Scholar: Author Only Title Only Author and Title

Koo, A J., Thireault, C., Zemelis, S., Poudel, A N., Zhang, T., Kitaoka, N., Brandizzi, F., Matsuura, H., \& Howe, G. A (2014). Endoplasmic reticulum-associated inactivation of the hormone jasmonoyl-L-isoleucine by multiple members of the cytochrome P450 94 family in Arabidopsis. The Journal of Biological Chemistry, 289(43), 29728- 29738. https://doi.org/10.1074/jbc.M114.603084

Pubmed: Author and Title

Google Scholar: Author Only Title Only Author and Title

Kooke, R., Johannes, F., Wardenaar, R., Becker, F., Etcheverry, M., Colot, V., Vreugdenhil, D., \& Keurentjes, J. J. B. (2015). Epigenetic Basis of Morphological Variation and Phenotypic Plasticity in Arabidopsis thaliana. The Plant Cell Online, 27(2), $337-348$.

https://doi.org/10.1105/tpc.114.133025

Pubmed: Author and Title

Google Scholar: Author Only Title Only Author and Title

Kopylova, E., Noé, L., \& Touzet, H. (2012). SortMeRNA: Fast and accurate filtering of ribosomal RNAs in metatranscriptomic data. Bioinformatics (Oxford, England), 28(24), 3211- 3217. https://doi.org/10.1093/bioinformatics/bts611

Pubmed: Author and Title

Google Scholar: Author Only Title Only Author and Title

Krueger, F., \& Andrews, S. R. (2011). Bismark : A flexible aligner and methylation caller for Bisulfite-Seq applications. Bioinformatics, 27(11), 1571- 1572. https://doi.org/10.1093/bioinformatics/btr167

Pubmed: Author and Title

Google Scholar: Author Only Title Only Author and Title

Lafon-Placette, C., Faivre-Rampant, P., Delaunay, A, Street, N., Brignolas, F., \& Maury, S. (2013). Methylome of DNase I sensitive chromatin in Populus trichocarpa shoot apical meristematic cells : A simplified approach revealing characteristics of gene-body DNA methylation in open chromatin state. New Phytologist, 197(2), 416- 430. https://doi.org/10.1111/nph.12026

Pubmed: Author and Title

Google Scholar: Author Only Title Only Author and Title

Lafon-Placette, C., Le Gac, A-L., Chauveau, D., Segura, V., Delaunay, A, Lesage-Descauses, M.-C., Hummel, I., Cohen, D., Jesson, B., Le Thiec, D., Bogeat-Triboulot, M.-B., Brignolas, F., \& Maury, S. (2018). Changes in the epigenome and transcriptome of the poplar shoot apical meristem in response to water availability affect preferentially hormone pathways. Journal of Experimental Botany, 69(3), 537- 551. https://doi.org/10.1093/jxb/erx409

Pubmed: Author and Title

Google Scholar: Author Only Title Only Author and Title

Lanciano, S., Carpentier, M.-C., Llauro, C., Jobet, E., Robakowska-Hyzorek, D., Lasserre, E., Ghesquière, A, Panaud, O., \& Mirouze, M. (2017). Sequencing the extrachromosomal circular mobilome reveals retrotransposon activity in plants. PLoS Genetics, 13(2).

https://doi.org/10.1371/journal.pgen.1006630

Pubmed: Author and Title

Google Scholar: Author Only Title Only Author and Title

Langmead, B., Trapnell, C., Pop, M., \& Salzberg, S. L. (2009). Ultrafast and memory-efficient alignment of short DNA sequences to the human genome. Genome Biology, 10(3), R25. https://doi.org/10.1186/gb-2009-10-3-r25

Pubmed: Author and Title

Google Scholar: Author Only Title Only Author and Title

Latzel, V., Alan, E., Bortolini Silveira, A, Colot, V., Fischer, M., \& Bossdorf, O. (2013). Epigenetic diversity increases the productivity and stability of plant populations. Nature Communications, 4. https://doi.org/10.1038/ncomms3875 
Pubmed: Author and Title

Google Scholar: Author Only Title Only Author and Title

Latzel, V., Zhang, Y., Karlsson Moritz, K., Fischer, M., \& Bossdorf, O. (2012). Epigenetic variation in plant responses to defence hormones. Annals of Botany, 110(7), 1423- 1428. https://doi.org/10.1093/aob/mcs088

Pubmed: Author and Title

Google Scholar: Author Only Title Only Author and Title

Le Gac, A-L., Lafon-Placette, C., Chauveau, D., Segura, V., Delaunay, A, Fichot, R., Marron, N., Le Jan, I., Berthelot, A, Bodineau, G., Bastien, J.-C., Brignolas, F., \& Maury, S. (2018). Winter-dormant shoot apical meristem in poplar trees shows environmental epigenetic memory. Journal of Experimental Botany, 69(20), 4821- 4837. https://doi.org/10.1093/jxb/ery271

Pubmed: Author and Title

Google Scholar: Author Only Title Only Author and Title

Le Gac, A-L., Lafon-Placette, C., Delaunay, A, \& Maury, S. (2019). Developmental, genetic and environmental variations of global DNA methylation in the first leaves emerging from the shoot apical meristem in poplar trees. Plant Signaling \& Behavior, 14.

https://doi.org/10.1080/15592324.2019.1596717

Pubmed: Author and Title

Google Scholar: Author Only Title Only Author and Title

Lee, S.-I., \& Kim, N.-S. (2014). Transposable Elements and Genome Size Variations in Plants. Genomics \& Informatics, $12(3)$, 87. https://doi.org/10.5808/GI.2014.12.3.87

Pubmed: Author and Title

Google Scholar: Author Only Title Only Author and Title

Li, J., Brader, G., \& Palva, E. T. (2004). The WRKY70 Transcription Factor : ANode of Convergence for Jasmonate-Mediated and Salicylate-Mediated Signals in Plant Defense. The Plant Cell, 16(2), 319- 331. https://doi.org/10.1105/tpc.016980

Pubmed: Author and Title

Google Scholar: Author Only Title Only Author and Title

Li, Q., Eichten, S. R., Hermanson, P. J., \& Springer, N. M. (2014). Inheritance Patterns and Stability of DNA Methylation Variation in Maize Near-Isogenic Lines. Genetics, 196(3), 667- 676. https://doi.org/10.1534/genetics.113.158980

Pubmed: Author and Title

Google Scholar: Author Only Title Only Author and Title

Liang, D., Zhang, Z, Wu, H., Huang, C., Shuai, P., Ye, C.-Y., Tang, S., Wang, Y., Yang, L., \& Wang, J. (2014). Single-base-resolution methylomes of Populus trichocarpa reveal the association between DNAmethylation and drought stress. BMC genetics, 15 , S9.

Pubmed: Author and Title

Google Scholar: Author Only Title Only Author and Title

Li-Marchetti, C., Le Bras, C., Relion, D., Citerne, S., Huché-Thélier, L., Sakr, S., Morel, P., \& Crespel, L. (2015). Genotypic differences in architectural and physiological responses to water restriction in rose bush. Frontiers in Plant Science, 6.

https://doi.org/10.3389/fpls.2015.00355

Pubmed: Author and Title

Google Scholar: Author Only Title Only Author and Title

Lippman, Z, Gendrel, A-V., Black, M., Vaughn, M. W., Dedhia, N., Richard McCombie, W., Lavine, K., Mittal, V., May, B., Kasschau, K. D., Carrington, J. C., Doerge, R. W., Colot, V., \& Martienssen, R. (2004). Role of transposable elements in heterochromatin and epigenetic control. Nature, 430(6998), 471- 476. https://doi.org/10.1038/nature02651

Pubmed: Author and Title

Google Scholar: Author Only Title Only Author and Title

Lisch, D. (2012). How important are transposons for plant evolution? Nature Reviews Genetics, $14(1), 49-61$.

https://doi.org/10.1038/nrg3374

Pubmed: Author and Title

Google Scholar: Author Only Title Only Author and Title

Liu, G., Ji, Y., Bhuiyan, N. H., Pilot, G., Selvaraj, G., Zou, J., \& Wei, Y. (2010). Amino acid homeostasis modulates salicylic acid-associated redox status and defense responses in Arabidopsis. The Plant Cell, 22(11), 3845- 3863. https://doi.org/10.1105/tpc.110.079392

Pubmed: Author and Title

Google Scholar: Author Only Title Only Author and Title

Long, J. C., Xia, A A, Liu, J. H., Jing, J. L., Wang, Y. Z, Qi, C. Y., \& He, Y. (2019). Decrease in DNAmethylation 1 (DDM1) is required for the formation of $\mathrm{mCHH}$ islands in maize. Journal of Integrative Plant Biology, 61(6), 749- 764. https://doi.org/10.1111/jipb.12733

Pubmed: Author and Title

Google Scholar: Author Only Title Only Author and Title

López Sánchez, A, Stassen, J. H. M., Furci, L., Smith, L. M., \& Ton, J. (2016). The role of DNA(de)methylation in immune responsiveness of Arabidopsis. The Plant Journal, 88(3), 361- 374. https://doi.org/10.1111/tpj.13252

Pubmed: Author and Title

Google Scholar: Author Only Title Only Author and Title

Lorrain, S., Vailleau, F., Balagué, C., \& Roby, D. (2003). Lesion mimic mutants : Keys for deciphering cell death and defense pathways in plants? Trends in Plant Science, 8(6), 263- 271. https://doi.org/10.1016/S1360-1385(03)00108-0

Pubmed: Author and Title 
Google Scholar: Author Only Title Only Author and Title

Makarevitch, I., Waters, A J., West, P. T., Stitzer, M., Hirsch, C. N., Ross-Ibarra, J., \& Springer, N. M. (2015). Transposable Elements Contribute to Activation of Maize Genes in Response to Abiotic Stress. PLoS Genetics, 11(1).

https://doi.org/10.1371/journal.pgen.1004915

Pubmed: Author and Title

Google Scholar: Author Only Title Only Author and Title

Maor, G. L., Yearim, A, \& Ast, G. (2015). The alternative role of DNA methylation in splicing regulation. Trends in Genetics, 31(5), 274280. https://doi.org/10.1016/j.tig.2015.03.002

Pubmed: Author and Title

Google Scholar: Author Only Title Only Author and Title

Marcel, S., Sawers, R., Oakeley, E., Angliker, H., \& Paszkowski, U. (2010). Tissue-Adapted Invasion Strategies of the Rice Blast Fungus Magnaporthe oryzae[W]. The Plant Cell, 22(9), 3177- 3187. https://doi.org/10.1105/tpc.110.078048

Pubmed: Author and Title

Google Scholar: Author Only Title Only Author and Title

Mauch-Mani, B., Baccelli, I., Luna, E., \& Flors, V. (2017). Defense Priming : An Adaptive Part of Induced Resistance. Annual Review of Plant Biology, 68(1), 485- 512. https://doi.org/10.1146/annurev-arplant-042916-041132

Pubmed: Author and Title

Google Scholar: Author Only Title Only Author and Title

Maury, S., Sow, M. D., Le Gac, A-L., Genitoni, J., Lafon-Placette, C., \& Mozgova, I. (2019). Phytohormone and Chromatin Crosstalk : The Missing Link For Developmental Plasticity? Frontiers in Plant Science, 10. https://doi.org/10.3389/fpls.2019.00395

Pubmed: Author and Title

Google Scholar: Author Only Title Only Author and Title

McCarthy, D. J., Chen, Y., \& Smyth, G. K. (2012). Differential expression analysis of multifactor RNASeq experiments with respect to biological variation. Nucleic Acids Research, 40(10), 4288- 4297. https://doi.org/10.1093/nar/gks042

Pubmed: Author and Title

Google Scholar: Author Only Title Only Author and Title

McDowell, N., Pockman, W. T., Allen, C. D., Breshears, D. D., Cobb, N., Kolb, T., Plaut, J., Sperry, J., West, A, Williams, D. G., \& Yepez, E. A (2008). Mechanisms of plant survival and mortality during drought: Why do some plants survive while others succumb to drought? New Phytologist, 178(4), 719- 739. https://doi.org/10.1111/j.1469-8137.2008.02436.x

Pubmed: Author and Title

Google Scholar: Author Only Title Only Author and Title

Meyer, P. (2015). Epigenetic variation and environmental change : Fig. 1. Journal of Experimental Botany, 66(12), 3541- 3548. https://doi.org/10.1093/jxb/eru502

Pubmed: Author and Title

Google Scholar: Author Only Title Only Author and Title

Mirouze, M., \& Paszkowski, J. (2011). Epigenetic contribution to stress adaptation in plants. Current Opinion in Plant Biology, 14(3), 267- 274. https://doi.org/10.1016/j.pbi.2011.03.004

Pubmed: Author and Title

Google Scholar: Author Only Title Only Author and Title

Mirouze, M., Reinders, J., Bucher, E., Nishimura, T., Schneeberger, K., Ossowski, S., Cao, J., Weigel, D., Paszkowski, J., \& Mathieu, O. (2009). Selective epigenetic control of retrotransposition in Arabidopsis. Nature, 461(7262), 427- 430.

https://doi.org/10.1038/nature08328

Pubmed: Author and Title

Google Scholar: Author Only Title Only Author and Title

Miura, A, Yonebayashi, S., Watanabe, K., Toyama, T., Shimada, H., \& Kakutani, T. (2001). Mobilization of transposons by a mutation abolishing full DNA methylation in Arabidopsis. Nature, 411(6834), 212- 214. https://doi.org/10.1038/35075612

Pubmed: Author and Title

Google Scholar: Author Only Title Only Author and Title

Mofatto, L. S., Carneiro, F. de A, Vieira, N. G., Duarte, K. E., Vidal, R. O., Alekcevetch, J. C., Cotta, M. G., Verdeil, J.-L., Lapeyre-Montes, F., Lartaud, M., Leroy, T., De Bellis, F., Pot, D., Rodrigues, G. C., Carazzolle, M. F., Pereira, G. A G., Andrade, A C., \& Marraccini, P. (2016). Identification of candidate genes for drought tolerance in coffee by high-throughput sequencing in the shoot apex of different Coffea arabica cultivars. BMC Plant Biology, 16. https://doi.org/10.1186/s12870-016-0777-5

Pubmed: Author and Title

Google Scholar: Author Only Title Only Author and Title

Monclus, R., Dreyer, E., Villar, M., Delmotte, F. M., Delay, D., Petit, J.-M., Barbaroux, C., Le Thiec, D., Bréchet, C., \& Brignolas, F. (2006). Impact of drought on productivity and water use efficiency in 29 genotypes of Populus deltoides×Populus nigra. New Phytologist, 169(4), 765- 777. https://doi.org/10.1111/j.1469-8137.2005.01630.x

Pubmed: Author and Title

Google Scholar: Author Only Title Only Author and Title

Munné-Bosch, S., \& Peñuelas, J. (2003). Photo- and antioxidative protection, and a role for salicylic acid during drought and recovery 
in field-grown Phillyrea angustifolia plants. Planta, 217(5), 758- 766. https://doi.org/10.1007/s00425-003-1037-0

Pubmed: Author and Title

Google Scholar: Author Only Title Only Author and Title

Nicotra, AB., Atkin, O. K., Bonser, S. P., Davidson, A M., Finnegan, E. J., Mathesius, U., Poot, P., Purugganan, M. D., Richards, C. L., Valladares, F., \& van Kleunen, M. (2010). Plant phenotypic plasticity in a changing climate. Trends in Plant Science, 15(12), 684- 692. https://doi.org/10.1016/j.tplants.2010.09.008

Pubmed: Author and Title

Google Scholar: Author Only Title Only Author and Title

Nicotra, Adrienne B., Segal, D. L., Hoyle, G. L., Schrey, A W., Verhoeven, K. J. F., \& Richards, C. L. (2015). Adaptive plasticity and epigenetic variation in response to warming in an Apine plant. Ecology and Evolution, 5(3), 634- 647. https://doi.org/10.1002/ece3.1329

Pubmed: Author and Title

Google Scholar: Author Only Title Only Author and Title

Niederhuth, C. E., \& Schmitz, R. J. (2017). Putting DNA methylation in context : From genomes to gene expression in plants. Biochimica et Biophysica Acta (BBA) - Gene Regulatory Mechanisms, 1860(1), 149- 156. https://doi.org/10.1016/j.bbagrm2016.08.009

Pubmed: Author and Title

Google Scholar: Author Only Title Only Author and Title

Nishiyama, R., Watanabe, Y., Fujita, Y., Le, D. T., Kojima, M., Werner, T., Vankova, R., Yamaguchi-Shinozaki, K., Shinozaki, K., Kakimoto, T., Sakakibara, H., Schmülling, T., \& Tran, L.-S. P. (2011). Analysis of cytokinin mutants and regulation of cytokinin metabolic genes reveals important regulatory roles of cytokinins in drought, salt and abscisic acid responses, and abscisic acid biosynthesis. The Plant Cell, 23(6), 2169- 2183. https://doi.org/10.1105/tpc.111.087395

Pubmed: Author and Title

Google Scholar: Author Only Title Only Author and Title

Ojolo, S. P., Cao, S., Priyadarshani, S. V. G. N., Li, W., Yan, M., Aslam, M., Zhao, H., \& Qin, Y. (2018). Regulation of Plant Growth and Development : AReview From a Chromatin Remodeling Perspective. Frontiers in Plant Science, 9.

https://doi.org/10.3389/fpls.2018.01232

Pubmed: Author and Title

Google Scholar: Author Only Title Only Author and Title

Ong-Abdullah, M., Ordway, J. M., Jiang, N., Ooi, S.-E., Kok, S.-Y., Sarpan, N., Azimi, N., Hashim, A T., Ishak, Z, Rosli, S. K., Malike, F. A, Bakar, N. A A, Marjuni, M., Abdullah, N., Yaakub, Z, Amiruddin, M. D., Nookiah, R., Singh, R., Low, E.-T. L., ... Martienssen, R. A (2015). Loss of Karma transposon methylation underlies the mantled somaclonal variant of oil palm Nature, 525(7570), 533- 537.

https://doi.org/10.1038/nature15365

Pubmed: Author and Title

Google Scholar: Author Only Title Only Author and Title

Oshima, Y., \& Mitsuda, N. (2013). The MIXTAlike Transcription factor MYB16 is a major regulator of cuticle formation in vegetative organs. Plant Signaling \& Behavior, 8(11). https://doi.org/10.4161/psb.26826

Pubmed: Author and Title

Google Scholar: Author Only Title Only Author and Title

Oshima, Y., \& Mitsuda, N. (2016). Enhanced cuticle accumulation by employing MIXTAlike transcription factors. Plant Biotechnology, 33, 161- 168. https://doi.org/10.5511/plantbiotechnology.16.0627a

Pubmed: Author and Title

Google Scholar: Author Only Title Only Author and Title

Pandey, S., \& Chakraborty, D. (2015). Salicylic Acid and Drought Stress Response : Biochemical to Molecular Crosstalk. In B. N. Tripathi \& M. Müller (Éd.), Stress Responses in Plants : Mechanisms of Toxicity and Tolerance (p. 247- 265). Springer International Publishing. https://doi.org/10.1007/978-3-319-13368-3_10

Pubmed: Author and Title

Google Scholar: Author Only Title Only Author and Title

Pandey, S. P., Srivastava, S., Goel, R., Lakhwani, D., Singh, P., Asif, M. H., \& Sane, A P. (2017). Simulated herbivory in chickpea causes rapid changes in defense pathways and hormonal transcription networks of JAlethylene/GAlauxin within minutes of wounding.

Scientific Reports, 7(1), 1- 14. https://doi.org/10.1038/srep44729

Pubmed: Author and Title

Google Scholar: Author Only Title Only Author and Title

Plavcová, L., \& Hacke, U. G. (2011). Heterogeneous distribution of pectin epitopes and calcium in different pit types of four angiosperm species. New Phytologist, 192(4), 885- 897. https://doi.org/10.1111/j.1469-8137.2011.03842.x

Pubmed: Author and Title

Google Scholar: Author Only Title Only Author and Title

Plomion, C., Bastien, C., Bogeat-Triboulot, M.-B., Bouffier, L., Déjardin, A, Duplessis, S., Fady, B., Heuertz, M., Le Gac, A-L., Le Provost, G., Legué, V., Lelu-Walter, M.-A, Leplé, J.-C., Maury, S., Morel, A, Oddou-Muratorio, S., Pilate, G., Sanchez, L., Scotti, I., ... Vacher, C. (2016). Forest tree genomics : 10 achievements from the past 10 years and future prospects. Annals of Forest Science, 73(1), 77- 103. https://doi.org/10.1007/s13595-015-0488-3

Pubmed: Author and Title

Google Scholar: Author Only Title Only Author and Title 
Quadrana, L., \& Colot, V. (2016). Plant Transgenerational Epigenetics. Annual Review of Genetics, 50, 467- 491.

https://doi.org/10.1146/annurev-genet-120215-035254

Pubmed: Author and Title

Google Scholar: Author Only Title Only Author and Title

Quadrana, L., Etcheverry, M., Gilly, A, Caillieux, E., Madoui, M.-A, Guy, J., Bortolini Silveira, A, Engelen, S., Baillet, V., Wincker, P., Aury, J.-M., \& Colot, V. (2019). Transposition favors the generation of large effect mutations that may facilitate rapid adaption. Nature Communications, 10(1), 1- 10. https://doi.org/10.1038/s41467-019-11385-5

Pubmed: Author and Title

Google Scholar: Author Only Title Only Author and Title

Qüesta, J. I., Fina, J. P., \& Casati, P. (2013). DDM1 and ROS1 have a role in UV-B induced- and oxidative DNA damage in A thaliana. Frontiers in Plant Science, 4. https://doi.org/10.3389/fpls.2013.00420

Pubmed: Author and Title

Google Scholar: Author Only Title Only Author and Title

Raj, S., Bräutigam, K., Hamanishi, E. T., Wilkins, O., Thomas, B. R., Schroeder, W., Mansfield, S. D., Plant, A L., \& Campbell, M. M. (2011). Clone history shapes Populus drought responses. Proceedings of the National Academy of Sciences, $108(30), 12521-12526$.

Pubmed: Author and Title

Google Scholar: Author Only Title Only Author and Title

Raju, S. K. K., Shao, M.-R., Sanchez, R., Xu, Y.-Z, Sandhu, A, Graef, G., \& Mackenzie, S. (2018). An epigenetic breeding system in soybean for increased yield and stability. Plant Biotechnology Journal, 16(11), 1836- 1847. https://doi.org/10.1111/pbi.12919

Pubmed: Author and Title

Google Scholar: Author Only Title Only Author and Title

Reinders, J., Wulff, B. B. H., Mirouze, M., Marí-Ordóñez, A, Dapp, M., Rozhon, W., Bucher, E., Theiler, G., \& Paszkowski, J. (2009). Compromised stability of DNA methylation and transposon immobilization in mosaic Arabidopsis epigenomes. Genes \& Development, 23(8), 939- 950. https://doi.org/10.1101/gad.524609

Pubmed: Author and Title

Google Scholar: Author Only Title Only Author and Title

Richards, C. L., Alonso, C., Becker, C., Bossdorf, O., Bucher, E., Colomé-Tatché, M., Durka, W., Engelhardt, J., Gaspar, B., GogolDöring, A, Grosse, I., van Gurp, T. P., Heer, K., Kronholm, I., Lampei, C., Latzel, V., Mirouze, M., Opgenoorth, L., Paun, O., ...

Verhoeven, K. J. F. (2017). Ecological plant epigenetics : Evidence from model and non-model species, and the way forward. Ecology Letters, 20(12), 1576- 1590. https://doi.org/10.1111/ele.12858

Pubmed: Author and Title

Google Scholar: Author Only Title Only Author and Title

Rigaill, G., Balzergue, S., Brunaud, V., Blondet, E., Rau, A, Rogier, O., Caius, J., Maugis-Rabusseau, C., Soubigou-Taconnat, L., Aubourg, S., Lurin, C., Martin-Magniette, M.-L., \& Delannoy, E. (2018). Synthetic data sets for the identification of key ingredients for RNAseq differential analysis. Briefings in Bioinformatics, 19(1), 65- 76. https://doi.org/10.1093/bib/bbw092

Pubmed: Author and Title

Google Scholar: Author Only Title Only Author and Title

Roux, B., Rodde, N., Jardinaud, M.-F., Timmers, T., Sauviac, L., Cottret, L., Carrère, S., Sallet, E., Courcelle, E., Moreau, S., Debellé, F., Capela, D., de Carvalho-Niebel, F., Gouzy, J., Bruand, C., \& Gamas, P. (2014). An integrated analysis of plant and bacterial gene expression in symbiotic root nodules using laser-capture microdissection coupled to RNA sequencing. The Plant Journal: For Cell and Molecular Biology, 77(6), 817- 837. https://doi.org/10.1111/tpj.12442

Pubmed: Author and Title

Google Scholar: Author Only Title Only Author and Title

Roux, F., Colomé-Tatché, M., Edelist, C., Wardenaar, R., Guerche, P., Hospital, F., Colot, V., Jansen, R. C., \& Johannes, F. (2011). Genome-Wide Epigenetic Perturbation Jump-Starts Patterns of Heritable Variation Found in Nature. Genetics, $188(4), 1015-1017$. https://doi.org/10.1534/genetics.111.128744

Pubmed: Author and Title

Google Scholar: Author Only Title Only Author and Title

Russo, V. E. A, Riggs, A D., \& Martienssen, R. A (1996). Epigenetic mechanisms of gene regulation. Cold Spring Harbour, NY : Cold Spring Harbour Laboratory Press. https://trove.nla.gov.au/version/27736760

Pubmed: Author and Title

Google Scholar: Author Only Title Only Author and Title

Sasaki, T., Kobayashi, A, Saze, H., \& Kakutani, T. (2012). RNAi-independent de novo DNA methylation revealed in Arabidopsis mutants of chromatin remodeling gene DDM1. The Plant Journal, 70(5), 750- 758. https://doi.org/10.1111/j.1365-313X.2012.04911.x

Pubmed: Author and Title

Google Scholar: Author Only Title Only Author and Title

Saze, H., \& Kakutani, T. (2007). Heritable epigenetic mutation of a transposon-flanked Arabidopsis gene due to lack of the chromatinremodeling factor DDM1. The EMBO Journal, 26(15), 3641-3652.

Pubmed: Author and Title

Google Scholar: Author Only Title Only Author and Title

Schmid, M. W., Giraldo-Fonseca, A, Rövekamp, M., Smetanin, D., Bowman, J. L., \& Grossniklaus, U. (2018). Extensive epigenetic 
reprogramming during the life cycle of Marchantia polymorpha. Genome Biology, 19(1). https://doi.org/10.1186/s13059-017-1383-z

Pubmed: Author and Title

Google Scholar: Author Only Title Only Author and Title

Schmittgen, T. D., \& Livak, K. J. (2008). Analyzing real-time PCR data by the comparative C(T) method. Nature Protocols, 3(6), 11011108. https://doi.org/10.1038/nprot.2008.73

Pubmed: Author and Title

Google Scholar: Author Only Title Only Author and Title

Schneider, C. A, Rasband, W. S., \& Eliceiri, K. W. (2012). NIH Image to Image : 25 years of image analysis. Nature Methods, 9(7), 671675. https://doi.org/10.1038/nmeth.2089

Pubmed: Author and Title

Google Scholar: Author Only Title Only Author and Title

Sedaghat, M., Tahmasebi-Sarvestani, Z, Emam, Y., \& Mokhtassi-Bidgoli, A (2017). Physiological and antioxidant responses of winter wheat cultivars to strigolactone and salicylic acid in drought. Plant Physiology and Biochemistry, 119, 59- 69.

https://doi.org/10.1016/j.plaphy.2017.08.015

Pubmed: Author and Title

Google Scholar: Author Only Title Only Author and Title

Seymour, D. K., \& Becker, C. (2017). The causes and consequences of DNAmethylome variation in plants. Current Opinion in Plant Biology, 36, 56- 63. https://doi.org/10.1016/j.pbi.2017.01.005

Pubmed: Author and Title

Google Scholar: Author Only Title Only Author and Title

Shi, H., Chen, L., Ye, T., Liu, X., Ding, K., \& Chan, Z (2014). Modulation of auxin content in Arabidopsis confers improved drought stress resistance. Plant Physiology and Biochemistry, 82, 209- 217. https://doi.org/10.1016/j.plaphy.2014.06.008

Pubmed: Author and Title

Google Scholar: Author Only Title Only Author and Title

Slotkin, R. K., \& Martienssen, R. (2007). Transposable elements and the epigenetic regulation of the genome. Nature Reviews.

Genetics, 8(4), 272- 285. https://doi.org/10.1038/nrg2072

Pubmed: Author and Title

Google Scholar: Author Only Title Only Author and Title

Solano, R., Stepanova, A, Chao, Q., \& Ecker, J. R. (1998). Nuclear events in ethylene signaling: A transcriptional cascade mediated by ETHYLENE-INSENSITIVE3 and ETHYLENE-RESPONSE-FACTOR1. Genes \& Development, 12(23), $3703-3714$.

Pubmed: Author and Title

Google Scholar: Author Only Title Only Author and Title

Song, J. T., Lu, H., McDowell, J. M., \& Greenberg, J. T. (2004). A key role for ALD1 in activation of local and systemic defenses in Arabidopsis. The Plant Journal, 40(2), 200- 212. https://doi.org/10.1111/j.1365-313X.2004.02200.x

Pubmed: Author and Title

Google Scholar: Author Only Title Only Author and Title

Sow, M. D., Allona, I., Ambroise, C., Conde, D., Fichot, R., Gribkova, S., Jorge, V., Le-Provost, G., Pâques, L., Plomion, C., Salse, J., Sanchez-Rodriguez, L., Segura, V., Tost, J., \& Maury, S. (2018). Epigenetics in Forest Trees. In Advances in Botanical Research (Vol. 88, p. 387- 453). Elsevier. https://doi.org/10.1016/bs.abr.2018.09.003

Pubmed: Author and Title

Google Scholar: Author Only Title Only Author and Title

Sow, M. D., Segura, V., Chamaillard, S., Jorge, V., Delaunay, A, Lafon-Placette, C., Fichot, R., Faivre-Rampant, P., Villar, M., Brignolas, F., \& Maury, S. (2018). Narrow-sense heritability and PST estimates of DNA methylation in three Populus nigra L. populations under contrasting water availability. Tree Genetics \& Genomes, 14(5). https://doi.org/10.1007/s11295-018-1293-6

Pubmed: Author and Title

Google Scholar: Author Only Title Only Author and Title

Springer, N. M., \& Schmitz, R. J. (2017). Exploiting induced and natural epigenetic variation for crop improvement. Nature Reviews Genetics, 18(9), 563- 575. https://doi.org/10.1038/nrg.2017.45

Pubmed: Author and Title

Google Scholar: Author Only Title Only Author and Title

Stokes, T. L., Kunkel, B. N., \& Richards, E. J. (2002). Epigenetic variation in Arabidopsis disease resistance. Genes \& Development, 16(2), 171- 182. https://doi.org/10.1101/gad.952102

Pubmed: Author and Title

Google Scholar: Author Only Title Only Author and Title

Street, N. R., Skogström, O., Sjödin, A., Tucker, J., Rodríguez-Acosta, M., Nilsson, P., Jansson, S., \& Taylor, G. (2006a). The genetics and genomics of the drought response in Populus. The Plant Journal, 48(3), 321- 341. https://doi.org/10.1111/j.1365-313X.2006.02864.x

Street, N. R., Skogström, O., Sjödin, A, Tucker, J., Rodríguez-Acosta, M., Nilsson, P., Jansson, S., \& Taylor, G. (2006b). The genetics and genomics of the drought response in Populus. The Plant Journal, 48(3), 321- 341. https://doi.org/10.1111/j.1365-313X.2006.02864.X

Sun, Y., \& Yu, D. (2015). Activated expression of AtWRKY53 negatively regulates drought tolerance by mediating stomatal movement. 
Plant Cell Reports, 34(8), 1295- 1306. https://doi.org/10.1007/s00299-015-1787-8

Pubmed: Author and Title

Google Scholar: Author Only Title Only Author and Title

Tan, F., Zhou, C., Zhou, Q., Zhou, S., Yang, W., Zhao, Y., Li, G., \& Zhou, D.-X. (2016). Analysis of Chromatin Regulators Reveals Specific Features of Rice DNAMethylation Pathways. Plant Physiology, 171(3), 2041- 2054. https://doi.org/10.1104/pp.16.00393

Pubmed: Author and Title

Google Scholar: Author Only Title Only Author and Title

Trapet, P., Avoscan, L., Klinguer, A, Pateyron, S., Citerne, S., Chervin, C., Mazurier, S., Lemanceau, P., Wendehenne, D., \& BessonBard, A (2016). The Pseudomonas fluorescens Siderophore Pyoverdine Weakens Arabidopsis thaliana Defense in Favor of Growth in Iron-Deficient Conditions. Plant Physiology, 171(1), 675- 693. https://doi.org/10.1104/pp.15.01537

Pubmed: Author and Title

Google Scholar: Author Only Title Only Author and Title

Tsukahara, S., Kobayashi, A, Kawabe, A, Mathieu, O., Miura, A, \& Kakutani, T. (2009). Bursts of retrotransposition reproduced in Arabidopsis. Nature, 461(7262), 423- 426. https://doi.org/10.1038/nature08351

Pubmed: Author and Title

Google Scholar: Author Only Title Only Author and Title

Tuskan, G. A, DiFazio, S., Jansson, S., Bohlmann, J., Grigoriev, I., Hellsten, U., Putnam, N., Ralph, S., Rombauts, S., Salamov, A, Schein, J., Sterck, L., Aerts, A, Bhalerao, R. R., Bhalerao, R. P., Blaudez, D., Boerjan, W., Brun, A, Brunner, A, ... Rokhsar, D. (2006). The Genome of Black Cottonwood, Populus trichocarpa (Torr. \& Gray). Science, 313(5793), 1596- 1604.

https://doi.org/10.1126/science.1128691

Pubmed: Author and Title

Google Scholar: Author Only Title Only Author and Title

Vassileva, V., Hollwey, E., Todorov, D., \& Meyer, P. (s. d.). Leaf epidermal profiling as a phenotyping tool for DNA methylation mutants. 18.

Vining, K. J., Pomraning, K. R., Wilhelm, L. J., Priest, H. D., Pellegrini, M., Mockler, T. C., Freitag, M., \& Strauss, S. H. (2012). Dynamic DNA cytosine methylation in the Populus trichocarpa genome : Tissue-level variation and relationship to gene expression. Bmc

Genomics, 13(1), 27.

Pubmed: Author and Title

Google Scholar: Author Only Title Only Author and Title

Volaire, F., Lens, F., Cochard, H., Xu, H., Chacon-Doria, L., Bristiel, P., Balachowski, J., Rowe, N., Violle, C., \& Picon-Cochard, C. (2018). Embolism and mechanical resistances play a key role in dehydration tolerance of a perennial grass Dactylis glomerata $L$. Annals of

Botany, 122(2), 325- 336. https://doi.org/10.1093/aob/mcy073

Pubmed: Author and Title

Google Scholar: Author Only Title Only Author and Title

Vongs, A, Kakutani, T., Martienssen, R. A, \& Richards, E. J. (1993). Arabidopsis thaliana DNAmethylation mutants. Science (New York, N.Y.), 260(5116), 1926- 1928. https://doi.org/10.1126/science.8316832

Pubmed: Author and Title

Google Scholar: Author Only Title Only Author and Title

Wang, J., Tao, F., An, F., Zou, Y., Tian, W., Chen, X., Xu, X., \& Hu, X. (2017). Wheat transcription factor TaWRKY70 is positively involved in high-temperature seedling plant resistance to Puccinia striiformis f. Sp. Tritici. Molecular Plant Pathology, 18(5), 649- 661.

https://doi.org/10.1111/mpp.12425

Pubmed: Author and Title

Google Scholar: Author Only Title Only Author and Title

Wang, Yan, Wang, Q., Liu, M., Bo, C., Wang, X., Ma, Q., Cheng, B., \& Cai, R. (2017). Overexpression of a maize MYB48 gene confers drought tolerance in transgenic arabidopsis plants. Journal of Plant Biology, 60(6), 612- 621. https://doi.org/10.1007/s12374-017-0273-y

Pubmed: Author and Title

Google Scholar: Author Only Title Only Author and Title

Wang, Yushuai, Liang, W., \& Tang, T. (2018). Constant conflict between Gypsy LTR retrotransposons and CHH methylation within a stress-adapted mangrove genome. New Phytologist, 220(3), 922- 935. https://doi.org/10.1111/nph.15209

Pubmed: Author and Title

Google Scholar: Author Only Title Only Author and Title

Wang, Zhen, Wang, F., Hong, Y., Yao, J., Ren, Z, Shi, H., \& Zhu, J.-K. (2018). The Flowering Repressor SVP Confers Drought Resistance in Arabidopsis by Regulating Abscisic Acid Catabolism Molecular Plant, 11(9), 1184- 1197. https://doi.org/10.1016/j.molp.2018.06.009

Pubmed: Author and Title

Google Scholar: Author Only Title Only Author and Title

Wang, Zheng, Fang, H., Chen, Y., Chen, K., Li, G., Gu, S., \& Tan, X. (2014). Overexpression of BnWRKY33 in oilseed rape enhances resistance to Sclerotinia sclerotiorum Molecular Plant Pathology, 15(7), 677- 689. https://doi.org/10.1111/mpp.12123

Pubmed: Author and Title

Google Scholar: Author Only Title Only Author and Title

Wasternack, C., \& Hause, B. (2018). A Bypass in Jasmonate Biosynthesis - the OPR3-independent Formation. Trends in Plant Science, 
23(4), 276- 279. https://doi.org/10.1016/j.tplants.2018.02.011

Pubmed: Author and Title

Google Scholar: Author Only Title Only Author and Title

Wettstein-Knowles, P. von. (2016). Plant Waxes. In ELS (p. 1- 13). American Cancer Society. https://doi.org/10.1002/9780470015902.a0001919.pub3

Pubmed: Author and Title

Google Scholar: Author Only Title Only Author and Title

Wu, C., Bordeos, A, Madamba, Ma. R. S., Baraoidan, M., Ramos, M., Wang, G., Leach, J. E., \& Leung, H. (2008). Rice lesion mimic mutants with enhanced resistance to diseases. Molecular Genetics and Genomics, 279(6), 605- 619. https://doi.org/10.1007/s00438-0080337-2

Pubmed: Author and Title

Google Scholar: Author Only Title Only Author and Title

Xi, Y., \& Li, W. (2009). BSMAP : Whole genome bisulfite sequence MAPping program. BMC Bioinformatics, 10, 232.

https://doi.org/10.1186/1471-2105-10-232

Pubmed: Author and Title

Google Scholar: Author Only Title Only Author and Title

Xu, Z, \& Zhou, G. (2008). Responses of leaf stomatal density to water status and its relationship with photosynthesis in a grass. Journal of Experimental Botany, 59(12), 3317- 3325. https://doi.org/10.1093/jxb/ern185

Pubmed: Author and Title

Google Scholar: Author Only Title Only Author and Title

Yakovlev, I. A, Carneros, E., Lee, Y., Olsen, J. E., \& Fossdal, C. G. (2016). Transcriptional profiling of epigenetic regulators in somatic embryos during temperature induced formation of an epigenetic memory in Norway spruce. Planta, 243(5), 1237- 1249.

https://doi.org/10.1007/s00425-016-2484-8

Pubmed: Author and Title

Google Scholar: Author Only Title Only Author and Title

Yakovlev, I. A, \& Fossdal, C. G. (2017). In Silico Analysis of Small RNAs Suggest Roles for Novel and Conserved miRNAs in the Formation of Epigenetic Memory in Somatic Embryos of Norway Spruce. Frontiers in Physiology, 8.

https://doi.org/10.3389/fphys.2017.00674

Pubmed: Author and Title

Google Scholar: Author Only Title Only Author and Title

Yakovlev, I. A, Lee, Y., Rotter, B., Olsen, J. E., Skrøppa, T., Johnsen, Ø., \& Fossdal, C. G. (2014). Temperature-dependent differential transcriptomes during formation of an epigenetic memory in Norway spruce embryogenesis. Tree Genetics \& Genomes, 10(2), 355366. https://doi.org/10.1007/s11295-013-0691-z

Pubmed: Author and Title

Google Scholar: Author Only Title Only Author and Title

Yakovlev, l., Fossdal, C. G., Skrøppa, T., Olsen, J. E., Jahren, A H., \& Johnsen, Ø. (2012). An adaptive epigenetic memory in conifers with important implications for seed production. Seed Science Research, 22(02), 63- 76. https://doi.org/10.1017/S0960258511000535

Pubmed: Author and Title

Google Scholar: Author Only Title Only Author and Title

Yamamuro, C., Zhu, J.-K., \& Yang, Z (2016). Epigenetic modifications and plant hormone action. Molecular plant, 9(1), 57- 70.

https://doi.org/10.1016/j.molp.2015.10.008

Pubmed: Author and Title

Google Scholar: Author Only Title Only Author and Title

Yao, Y., Bilichak, A, Golubov, A, \& Kovalchuk, l. (2012). Ddm1 plants are sensitive to methyl methane sulfonate and $\mathrm{NaCl}$ stresses and are deficient in DNA repair. Plant Cell Reports, 31(9), 1549-1561. https://doi.org/10.1007/s00299-012-1269-1

Pubmed: Author and Title

Google Scholar: Author Only Title Only Author and Title

Yona, A H., Frumkin, l., \& Pilpel, Y. (2015). ARelay Race on the Evolutionary Adaptation Spectrum Cell, 163(3), 549- 559.

https://doi.org/10.1016/j.cell.2015.10.005

Pubmed: Author and Title

Google Scholar: Author Only Title Only Author and Title

Zemach, A, Kim, M. Y., Hsieh, P.-H., Coleman-Derr, D., Eshed-Williams, L., Thao, K., Harmer, S. L., \& Zlberman, D. (2013). The Arabidopsis Nucleosome Remodeler DDM1 Allows DNA Methyltransferases to Access H1-Containing Heterochromatin. Cell, 153(1), 193- 205. https://doi.org/10.1016/j.cell.2013.02.033

Pubmed: Author and Title

Google Scholar: Author Only Title Only Author and Title

Zemach, A, McDaniel, I. E., Silva, P., \& Zlberman, D. (2010). Genome-Wide Evolutionary Analysis of Eukaryotic DNAMethylation.

Science, 328(5980), 916- 919. https://doi.org/10.1126/science.1186366

Pubmed: Author and Title

Google Scholar: Author Only Title Only Author and Title 
Zhang, J., Jia, W., Yang, J., \& Ismail, A M. (2006). Role of ABA in integrating plant responses to drought and salt stresses. Field Crops Research, 97(1), 111- 119. https://doi.org/10.1016/j.fcr.2005.08.018

Pubmed: Author and Title

Google Scholar: Author Only Title Only Author and Title

Zhang, Q., Li, Y., Xu, T., Srivastava, A K., Wang, D., Zeng, L., Yang, L., He, L., Zhang, H., Zheng, Z, Yang, D.-L., Zhao, C., Dong, J., Gong, Z, Liu, R., \& Zhu, J.-K. (2016). The chromatin remodeler DDM1 promotes hybrid vigor by regulating salicylic acid metabolism Cell

Discovery, 2, 16027. https://doi.org/10.1038/celldisc.2016.27

Pubmed: Author and Title

Google Scholar: Author Only Title Only Author and Title

Zhang, Y.-Y., Fischer, M., Colot, V., \& Bossdorf, O. (2013). Epigenetic variation creates potential for evolution of plant phenotypic plasticity. New Phytologist, 197(1), 314- 322. https://doi.org/10.1111/nph.12010

Pubmed: Author and Title

Google Scholar: Author Only Title Only Author and Title

Zhang, Y.-Y., Latzel, V., Fischer, M., \& Bossdorf, O. (2018). Understanding the evolutionary potential of epigenetic variation : A comparison of heritable phenotypic variation in epiRILs, RILs, and natural ecotypes of Arabidopsis thaliana. Heredity, $121(3), 257-265$. https://doi.org/10.1038/s41437-018-0095-9

Pubmed: Author and Title

Google Scholar: Author Only Title Only Author and Title

Zhu, H., Wang, G., \& Qian, J. (2016). Transcription factors as readers and effectors of DNAmethylation. Nature Reviews Genetics, 17(9), 551- 565. https://doi.org/10.1038/nrg.2016.83

Pubmed: Author and Title

Google Scholar: Author Only Title Only Author and Title

Zhu, L.-Y., Zhu, Y.-R., Dai, D.-J., Wang, X., \& Jin, H.-C. (2018). Epigenetic regulation of alternative splicing. American Journal of Cancer Research, 8(12), 2346- 2358.

Pubmed: Author and Title

Google Scholar: Author Only Title Only Author and Title

Zhu, R., Shevchenko, O., Ma, C., Maury, S., Freitag, M., \& Strauss, S. H. (2013). Poplars with a PtDDM1-RNAi transgene have reduced DNAmethylation and show aberrant post-dormancy morphology. Planta, 237(6), 1483- 1493. https://doi.org/10.1007/s00425-013-1858-4

Pubmed: Author and Title

Google Scholar: Author Only Title Only Author and Title 